OCRWM Monitored Retrievable Storage Project

\title{
Systems Engineering Management Plan
} Volume 5 of the MRS Project Management Plan Revision 0 (A10000000-00811-4600-00002)

\section{January 1994}

U.S. Department of Energy Office of Civilian Radioactive Waste Management Washington, DC, 20585

\section{MASTER}




\section{FOREWORD}

The purpose of this Monitored Retrievable Storage (MRS) Project Systems Engineering Management Plan (SEMP) is to define and establish the MRS Project Systems Engineering process that implements the approved policy and requirements of the Office of Civilian Radioactive Waste Management (OCRWM) for the U.S. Department of Energy (DOE). This plan is Volume 5 of the MRS Project Management Plan (PMP). This plan provides the framework for implementation of systems engineering on the MRS Project consistent with DOE Order 4700.1, the OCRWM Program Management System Manual (PMSM), and the OCRWM Systems Engineering Management Plan (SEMP).

It must be noted that the use of the terms "MRS MSA" and "MRS Project" herein apply to the MRS Major System Acquisition, which includes the MRS, Transportation, and Waste Acceptance Elements of the Civilian Radioactive Waste Management System. The term "MRS Project Office" currently applies to the Office of Storage and Transportation (OST).

This plan will remain in full effect during execution of the Project and will be revised as required to ensure the success of the systems engineering process. The MRS Project Manager is responsible for approving this plan and any subsequent updates and directing its implementation.

\section{APPROVED BY:}

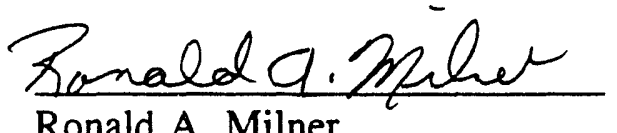

Ronald A. Milner

Chairperson, MRS Project Office

Baseline Change Control Board

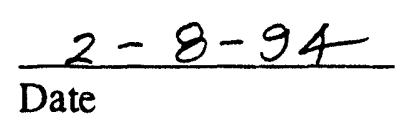

Date

\section{CONCURRED BY:}

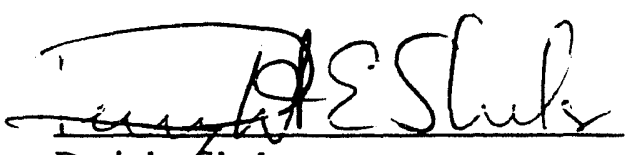

Dwight Shelor

Associate Director, Office of Systems and Compliance

$$
2-8-8 \not
$$

Date 
INTENTIONALLY LEFT BLANK 


\section{TABLE OF CONTENTS}

Page

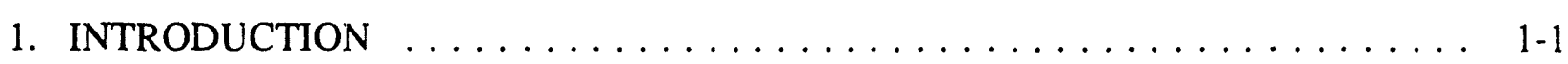

2. SCOPE, APPLICABחITY, AND CONTENTS $\ldots \ldots \ldots \ldots \ldots \ldots \ldots \ldots . \ldots \ldots$

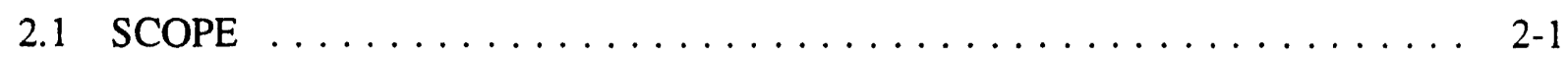

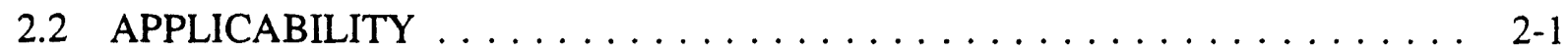

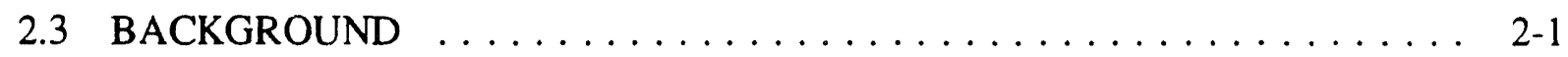

2.3.1 Systems Engineering $\ldots \ldots \ldots \ldots \ldots \ldots \ldots \ldots \ldots \ldots \ldots \ldots \ldots \ldots \ldots \ldots \ldots, 2-2$

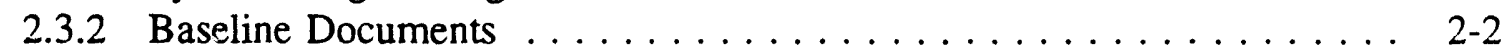

2.3.2.1 MRS Project Planning Document Architecture . . . . . . . 2-4

2.3.2.2 Baseline Develspment $\ldots \ldots \ldots \ldots \ldots \ldots \ldots \ldots .2-4$

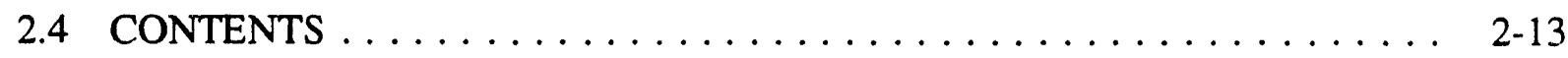

3. TECHNICAL PLANNING AND CONTROL $\ldots \ldots \ldots \ldots \ldots \ldots \ldots \ldots$ 3-1

3.1 ORGANIZATIONAL STRUCTURE \& CONTRACTUAL RESPONSIBILITY 3-1

3.1.1 DOE/OCRWM ......................... 3-1

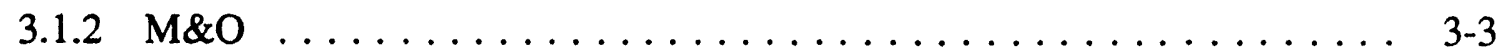

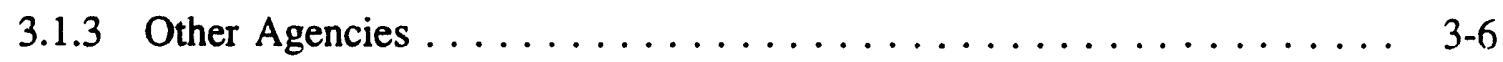

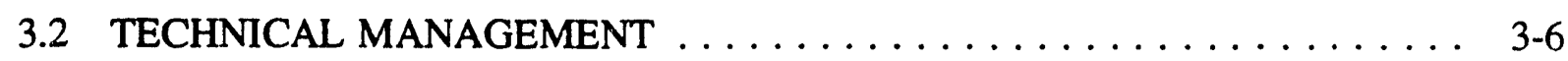

3.2.1 Technical Control . . . . . . . . . . . . . . . . . . . 3-7

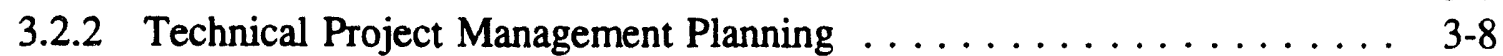

3.2.3 Document Control . ..................... 3-10

3.2.4 Configuration and Interface Management $\ldots \ldots \ldots \ldots \ldots \ldots \ldots . .10$

3.2.4.1 Configuration Management $\ldots \ldots \ldots \ldots \ldots \ldots \ldots \ldots$ 3-10

3.2.4.2 Interface Management $\ldots \ldots \ldots \ldots \ldots \ldots \ldots \ldots$ 3-11

3.2.5 Test and Evaluation $\ldots \ldots \ldots \ldots \ldots \ldots \ldots \ldots \ldots \ldots \ldots \ldots \ldots \ldots \ldots \ldots .13$

3.2.5.1 Technical Performance Measurement . . . . . . . . 3-14

3.2.5.2 Performance Assessment . . . . . . . . . . . . . . . 3-14

3.2.5.3 Site Characterization $\ldots \ldots \ldots \ldots \ldots \ldots \ldots \ldots$ 3-15

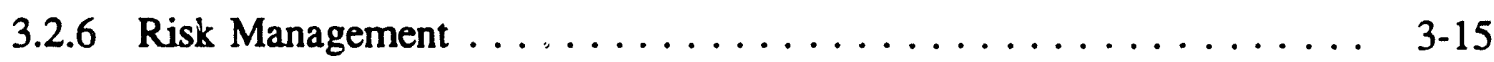




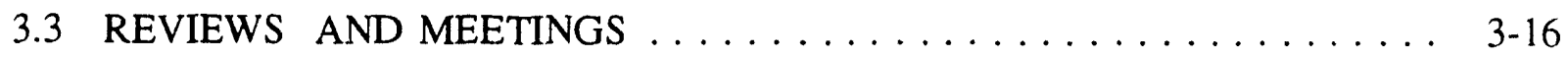

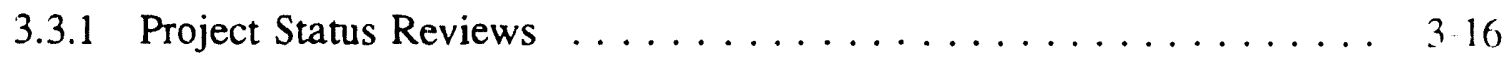

3.3.1.1 Headquarters Reviews . . . . . . . . . . . . 3-16

3.3.1.2 Project Reviews . . . . . . . . . . . . . . . 3-16

3.3.1.3 Field Reviews .................... 3-16

3.3.2 Technical and Design Review $\ldots \ldots \ldots \ldots \ldots \ldots$ 3-16

3.3.2.1 Program-Level Reviews .................. 3-18

3.3.2.2 Project-Level Reviews and Meetings . . . . . . . . . 3-18

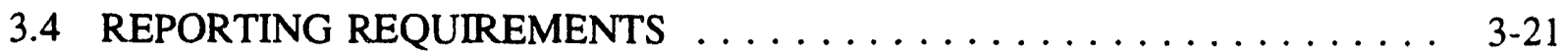

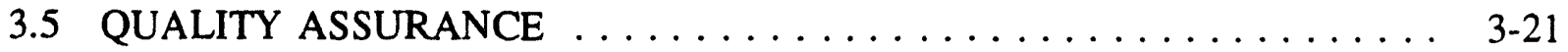

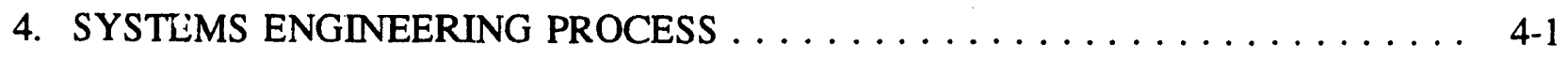

4.1 OVERVIEW OF THE PROJECT SYSTEMS ENGINEERING PROCESS . . . 4-1

4.2 FUNCTIONAL ANALYSIS $\ldots \ldots \ldots \ldots \ldots \ldots \ldots \ldots \ldots$

4.2.1 Function Identification $\ldots \ldots \ldots \ldots \ldots \ldots \ldots \ldots \ldots$ 4.4

4.2.2 Functional Sequencing and Scheduling ............... . 4-4

4.2.3 Specialty and Operational Considerations $\ldots \ldots \ldots \ldots \ldots$. . . . .

4.3 REQUIREMENTS IDENTIFICATION AND ALLOCATION . . . . . . . . 4-4

4.4 EVALUATION AND OPTIMIZATION $\ldots \ldots \ldots \ldots \ldots \ldots \ldots$

4.4 .1 Trade-off Studies . . . . . . . . . . . . . . . . . . . . 4-5

4.4.2 System Cost and Effectiveness Analysis and Modeling . . . . . . . . 4-6

4.5 DESIGN SYNTHESIS AND INTEGRATION $\ldots \ldots \ldots \ldots \ldots \ldots \ldots \ldots$

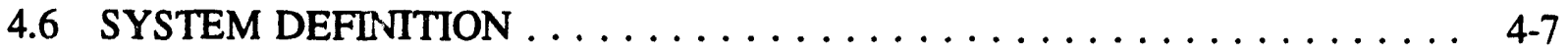

4.6.1 Design Traceability . . . . . . . . . . . . . . . . . . . . 4-7

4.6.2 System Specification Tree . . . . . . . . . . . . . . . . . 4 4-9

4.6.3 Requirements and Specification Generation . . . . . . . . . . . . 4-9

4.7 NRC LICENSING/SAR INTEGRATION $\ldots \ldots \ldots \ldots \ldots \ldots \ldots \ldots \ldots \ldots$

4.8 SYSTEM CONSTRUCTION AND TESTING $\ldots \ldots \ldots \ldots \ldots \ldots \ldots \ldots$ 
5. ELEMENT SYSTEMS ENGINEERING $\ldots \ldots \ldots \ldots \ldots \ldots \ldots \ldots \ldots \ldots$. 5 .

5.1 WASTE ACCEPTANCE ELEMENT $\ldots \ldots \ldots \ldots \ldots \ldots \ldots \ldots \ldots$.

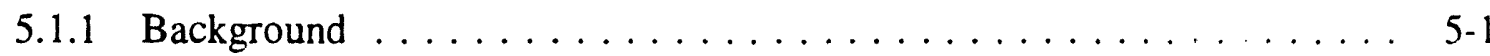

5.1.1.1 Waste Acceptance Function Tree ............. 5-1

5.1.1.2 Waste Acceptance System Architecture ........... 5-3

5.1.1.3 Waste Acceptance Principal Work Products ........ 5-6

5.1.2 The Waste Acceptance Acquisition Process . . . . . . . . . . . 5-7

5.1.3 Systems Engineering and the Waste Acceptance Element ...... 5-7

5.1.3.1 Program-Level Systems Engineering Affecting the Waste Acceptance Element ............. 5-7

5.1.3.2 Project-Level Waste Acceptance Systems Engineering ..... 5-7

5.1.3.3 Cls and the WA Element $\ldots \ldots \ldots \ldots \ldots \ldots \ldots \ldots$. $5-8$

5.2 TRANSPORTATION ELEMENT $\ldots \ldots \ldots \ldots \ldots \ldots \ldots \ldots \ldots \ldots \ldots$

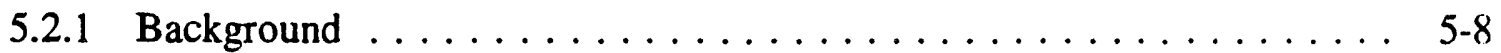

5.2.2 The Transportation Acquisition Process .............. 5-10

5.2.2.1 The Transportation Cask System Segment .......... 5- 5-10

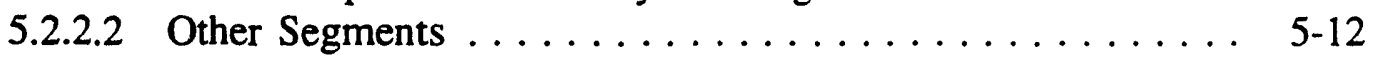

5.2.3 Systems Engineering and the Transportation Element $\ldots \ldots \ldots$ 5-12

5.2.3.1 Program Transportation Systems Engineering $\ldots \ldots \ldots \ldots$ 5-12

5.2.3.2 Project Transportation Systems Engineering ......... 5-13

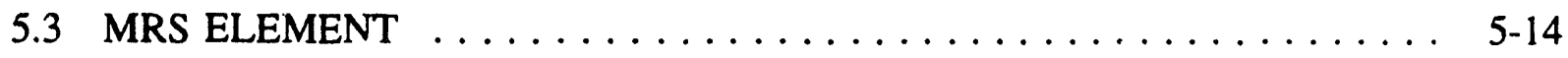

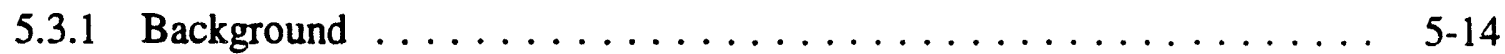

5.3.2 The MRS Element Acquisition Process $\ldots \ldots \ldots \ldots \ldots \ldots \ldots$ 5-16

5.3.3 Systems Engineering and the MRS Element $\ldots \ldots \ldots \ldots \ldots \ldots$ 5-16

5.3.3.1 Program MRS Systems Engineering $\ldots \ldots \ldots \ldots \ldots \ldots$ 5-16

5.3.3.2 Project MRS Systems Engineering $\ldots \ldots \ldots \ldots \ldots \ldots$ 5-17 
6. ENGINEERING INTEGRATION $\ldots \ldots \ldots \ldots \ldots \ldots \ldots \ldots \ldots \ldots \ldots \ldots \ldots \ldots$ 6-1

6.1 LIFE CYCLE COST . . . . . . . . . . . . . . . . . . 6-1

6.2 SPECIALTY ENGINEERING INTEGRATION $\ldots \ldots \ldots \ldots \ldots \ldots \ldots 6-2$

6.2 .1 Logistics Engineering $\ldots \ldots \ldots \ldots \ldots \ldots \ldots \ldots \ldots \ldots$

6.2.1.1 Computer-Aided Acquisition and Logistics . . . . . . . . . . 6-4

6.2 .1 .2 Provisioning and Supply Support .............. 6-5

6.2.1.3 Technical Documentation (Technical Manuals/Drawings) ... 6 6-5

6.2.2 Reliability, Availability, and Maintainability Engineering . . . . . . 6-5

6.2 .3 Human Factors Engineering . . . . . . . . . . . . . . . 6-6

6.2 .4 Safeguards and Security Engineering $\ldots \ldots \ldots \ldots \ldots \ldots \ldots \ldots \ldots \ldots$

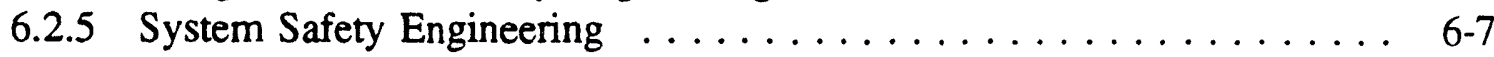

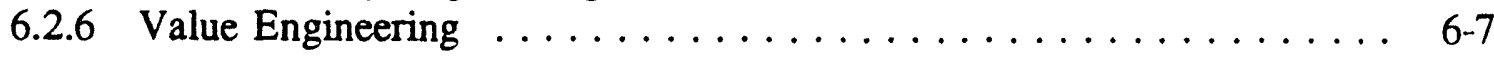

6.3 PROGRAMMATIC SPECIALTIES $\ldots \ldots \ldots \ldots \ldots \ldots \ldots \ldots \ldots . \ldots 6.7$

6.4 CONCURRENT ENGINEERING $\ldots \ldots \ldots \ldots \ldots \ldots \ldots \ldots \ldots \ldots .6 .6 \ldots$

APPENDIX A - ACRONYM LIST $\ldots \ldots \ldots \ldots \ldots \ldots \ldots \ldots \ldots \ldots \ldots \ldots \ldots \ldots \ldots \ldots$

APPENDIX B - DOCUMENT DEVELOPMENT $\ldots \ldots \ldots \ldots \ldots \ldots \ldots \ldots$ B-1

APPENDIX $\mathrm{C}$ - MODELS AND TRADE STUDIES $\ldots \ldots \ldots \ldots \ldots \ldots \ldots \ldots \ldots$

APPENDIX D - RISK MANAGEMENT PLAN $\ldots \ldots \ldots \ldots \ldots \ldots \ldots \ldots$ D-1

APPENDIX E - LIFE CYCLE COST PLAN $\ldots \ldots \ldots \ldots \ldots \ldots \ldots \ldots \ldots \ldots$ E-1

APPENDIX F - ENGINEERING SPECIALTY PLAN $\ldots \ldots \ldots \ldots \ldots \ldots \ldots \ldots$ F-1

APPENDIX G - REFERENCE AND RELEVANT DOCUMENTS $\ldots \ldots \ldots \ldots \ldots$ G-1 


\section{LIST OF FIGURES}

Page

2.3-1. CRWMS Program Document Hierarchy .................. 2-3

2.3-2. MRS Froject Management Plan Document Architecture . . . . . . . . . 2-5

2.3-3. Project Phases and Techrical Baselines . . . . . . . . . . . . 2-6

2.3-4. Application of the Systems Engineering Process $\ldots \ldots \ldots \ldots \ldots$. . . . . . .

2.3-5. MRS Project Baseline Hierarchy . . . . . . . . . . . . . . . 2-9

2.3-6. MRS Technical Baseline Development . . . . . . . . . . . . . . 2-10

2.3-7. MRS Facility Technical Baseline Development and the Licensing Process ... . 2-12

3.1-1. DOE/OCRWM MRS Project Organization $\ldots \ldots \ldots \ldots \ldots \ldots \ldots \ldots \ldots \ldots$

3.1-2. CRWMS M\&O Contractor's Storage \& Transportation Organization . . . . . . . 3-5

3.3-1. Generic Project Review Schedule . . . . . . . . . . . . . . 3-17

4.1-1. MRS MSA System Engineering Process . . . . . . . . . . . . . . 4-2

4.6-1. Requirements Document Development Process . . . . . . . . . . . . . 4-8

5.1-1. Waste Acceptance Functional Boundaries . . . . . . . . . . . . 5-2

5.1-2. Acceptance Waste Function Tree . . . . . . . . . . . . . . . 5-4

5.1-3. Waste Acceptance Element Configuration Architecture $\ldots \ldots \ldots \ldots \ldots$

5.2-1. Transportation Element Configuration Architecture . . . . . . . . . . 5-9

5.2-2. Transportation System Acquisition Process $\ldots \ldots \ldots \ldots \ldots \ldots \ldots \ldots$

5.3-1. MRS Element Configuration Architecture $\ldots \ldots \ldots \ldots \ldots \ldots \ldots \ldots$

B.3-1. Document Project Milestones $\ldots \ldots \ldots \ldots \ldots \ldots \ldots \ldots \ldots \ldots \ldots$ 


\section{LIST OF TABLES}

6.1-1. Project Life Cycle Cost Methodology $\ldots \ldots \ldots \ldots \ldots \ldots \ldots \ldots$ 6 3

B1. Assignment Matrix for Technical Baseline Documentation $\ldots \ldots \ldots \ldots$ B-1

B2. Assignment Matrix for Selected PMP-Related Documentation . . . . . . . . . B-2 


\section{INTRODUCTION}

This document is the Systems Engineering Management Plan (SEMP) for the Department of Energy (DOE) Monitored Retrievable Storage (MRS) Project. This MRS Project SEMP is Volume 5 of the MRS Project Management Plan (PMP). It fulfills the requirement for an MRS Project SEMP specified in the Program Management System Manual (PMSM), OCRWM's toplevel management directive, and is consistent with the guidelines provided in Chapter III of DOE Order 4700.1 .

The MRS Project is a part of a program to develop and operate a system, known as the Civilian Radioactive Waste Management System (CRWMS), to dispose of spent nuclear fuel and highlevel radioactive waste safely and permanently. The DOE Office of Civilian Radioactive Waste Management (OCRWM) is developing the system as mandated by the Nuclear Waste Policy Act of 1982 (NWPA) and subsequent amendments in 1987. Systems engineering is being used to establish and maintain the project technical baseline and therefore plays an integral role in managing the project.

In applying systems engineering to the OCRWM program, the program mission of safely and permanently disposing of spent nuclear fuel and high-level radioactive waste has been deconiposed into four functional areas: accept waste, transport waste, store waste, and dispose of waste. These functions have been allocated to four corresponding system elements: waste acceptance, transportation, monitored retrievable storage, and mined geologic disposal.

The four elements are currently being managed under two active major systems acquisitions (MSAs), one for the first three elements and another for the fourth element. The MRS MSA includes the waste acceptance, transportation, and MRS elements, while the Yucca Mountain Site Characterization MSA addresses current activities encompassed by the mined geologic disposal element. Additional MSAs will be added to replace or supplement the two currently active MSAs as the program develops.

The waste acceptance element includes those activities necessary to accept spent nuclear fuel and high-level waste $(\mathrm{HLW})$ from various generators/owners across the country. The second element, transportation, consists of those activities required to transport waste from nuclear power plants and other storage sites to a temporary or permanent DOE facility, and from temporary to permanent DOE facilities. The MRS element includes all activities required to site, design, and construct a temporary centralized storage (i.e., MRS) facility for spent nuclear fuel; although operating and decommissioning the facility are outside the scope of the MRS MSA, they also must be understood because of their potential impacts on design. The fourth and final element, mined geologic disposal, includes all activities, including extensive site characterization activities, required to permanently dispose of the waste in a deep underground repository. 
INTENTIONALLY LEFT BLANK 


\section{SCOPE, APPLICABRITY, AND CONTENTS}

\subsection{SCOPE}

In accordance with DOE Order 4700.1, this Systems Engineering Management Plan describes how systems engineering will be conducted and managed on the MRS Project. The Project SEMP identifies and describes the who, what, where, when, how, and why of project system engineering activities. More specifically, it identifies and describes the technical baseline documentation that will be developed to support the transformation of MRS Project objectives into an operational system (Section 2); the organizational responsibilities and the technical planning and control structures and methods that will be used to ensure that the project's technical development meets cost, schedule, and technical objectives (Section 3); the baseline systems engineering process itself (Section 4) and its application to, and tailoring for, each element (Section 5); and how other activities and specialty engineering areas that affect system design will be effectively integrated with the design activity (Section 6). This SEMP describes the systems engineering process as currently envisioned. It will be maintained through annual reviews and updated as required.

In order to facilitate document tracking, this SEMP contains a number of appendixes that are usually written as separate documents - the Risk Management Plan, the Life Cycle Cost Plan, and an Engineering Specialty Plan (a collection of specialty engineering plans.) As these plans are written, they will be included in the updates to the SEMP.

This MRS Project SEMP focuses on the Project and is consistent with the OCRWM SEMP (which describes how systems engineering will be conducted and managed at the program-level by OCRWM). Throughout this document, "program-level" refers to a CRWMS or program-wide activity (and is not within the scope of this SEMP), while "project-level" refers to an MRS Project-related activity (which is within the scope of this SEMP).

\subsection{APPLICABILITY}

The principles and procedures specified in this SEMP apply to the scientific and engineering activities related to the development and management of the MRS Project technical baseline. Responsibilities assigned to the M\&O and other contractors are subject to Project authorization and technical direction by the Project Office.

\subsection{BACKGROUND}

This SEMP will focus on describing three related processes: 1) the evolution of the technical baseline and its integration with the cost and schedule baselines; 2) the integration of both the customary and the project-specific specialty engineering efforts into the systems engineering process; and 3) system engineering support of technical and project management. The following sections provide an overview of the systems engineering process, the technical baseline that it will generate, and the cost and schedule baseline and project planning documents that will impact it. 


\subsubsection{Systems Engineering}

The systems engineering approach begins with a single, general mission statement, which becomes the system's top-level requirementis). Through an iterative process of analysis, definition, review, testing, and evaluation the systems approach decomposes this (these) requirement(s) into its components and synthesizes a system design that meets the stated need(s). Per DOE 4700.1, Attachment III-1, key steps in the process include the identification of system requirements from mission objectives, the allocation of these requirements first to system functions and then to configuration items, the integration of engineering specialties, the development of final design and procurement specifications based on these requirements, and the completion of the project based on satisfying final specifications.

These steps are documented in terms of a technical baseline. The technical baseline is a set of requirements and design documents that describe the system. These design documents are approved, and thereby, baselined, only after careful OCRWM review. The technical baseline is refined during the design, fabrication, and construction of the system using the systems engineering process. Changes to the technical baseline are controlled by the configuration management process, which ensures that changes to the technical baseline are made only after appropriate review and approval.

Cost and schedule baselines flow from and may impact the technical baseline. They represent the estimate of the cost to complete system development and the latest schedule of milestones in the development process. Like the technical baseline, cost and schedule baselines are rigidly controlled with changes being made only after careful review. Cost and schedule baselines are generally viewed as being outside the system engineering process but are obviously closely related to the technical baseline. Changes to the technical baseline are always reviewed in terms of cost and schedule impact, and budget changes are evaluated in terms of their possible impact on requirements and design. Therefore, while this SEMP is concerned mainly with the creation and evolution of the technical baseline, the project's role in maintaining the cost and schedule baseline is an integral part of this plan.

Although four engineering disciplines (mechanical, nuclear, civil, and electrical) are primarily responsible for ensuring an operable system is accomplished within their respective design, a major part of the systems engineering process is the integration of engineering specialties into the design effort. Engineering specialties are those disciplines that support the design process by applying knowledge from a specific area to ensure system operability in its operational environment. They include reliability, maintainability, availability, human factors engineering, environmental, safety, safeguards and security, logistic engineering, and other specialty areas involved in developing the system. Plans for the integration of specialty engineering activities with those of design engineering, testing, and production engineering, are either described in this SEMP or in the set of planning documents that make up the other volumes of the MRS PMP.

\subsubsection{Baseline Documents}

Figure 2.3-1 provides a summary of the OCRWM document hierarchy as established in the Program Management Systems Manual. It establishes the minimum documentation required for 


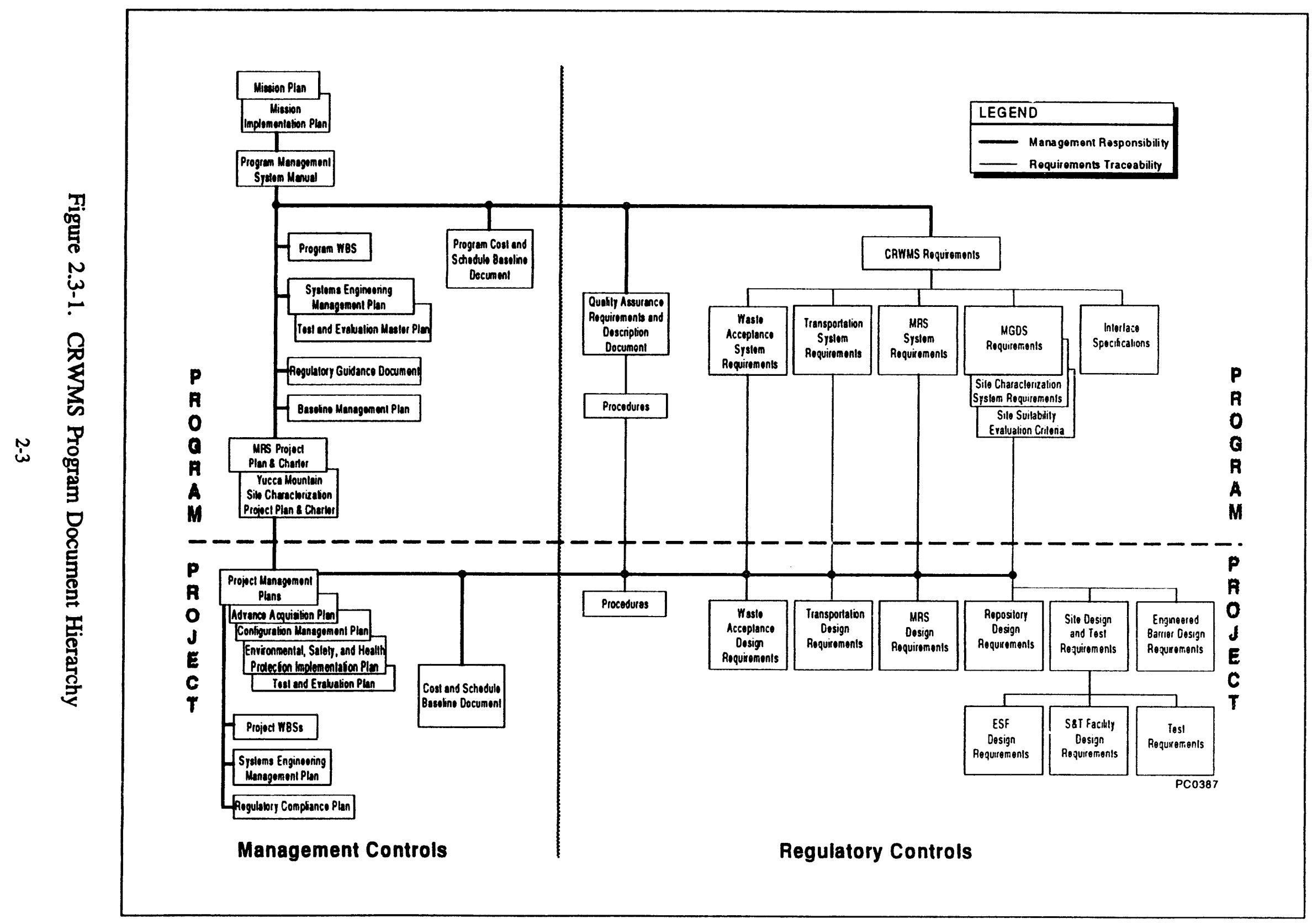


managing and developing the CRWMS. It includes management, technical, cost, schedule, and regulatory baseline documents.

This SEMP addresses the preparation of two types of MRS Project baseline documents - baseline technical documents and baseline management/planning documents. The requirements for these documents come from four major sources: the PMSM, the OCRWM SEMP, the MRS Project Management Plan, and this MRS Project SEMP. The MRS Project Office reviews and approves the need for the planning documents and reviews the baseline technical documentation. The Program Baseline Change Control Board (PBCCB) approves program technical baseline documents; the Project Office Baseline Change Control Board (POBCCB) approves project-level technical baseline documents. Section 2.3.2.1 addresses the planning document architecture, and Section 2.3.2.2 addresses the cost, schedule, and technical baselines.

\subsubsection{MRS Project Planning Document Architecture}

Figure 2.3-2 reproduces the PMP's MRS Project Planning Document Architecture. The PMP consists of 15 volumes that reflect this architecture. Each block directly under the PMP represents one of the PMP's volumes (with Volume 1 being the PMP's executive summary). The plans, charter, and procedure that appear under the SEMP, the MRS Project Configuration Management Plan (CMP), and the MRS Project Test and Evaluation Plan (T\&EP) will be provided as appendixes to these volumes. As indicated, the Project SEMP is one of these volumes. Although all of these planning documents are described in the PMP, a number of these heavily influence, and as $:$ heavily influenced by, the systems engineering process. The MRS Project WBS and the Project Cost and Schedule Baselines are two such documents that will be discussed in the next section and in Section 3.2. Systems engineering will be closely involved in the generation of the MRS Project CMP and the MRS Project T\&EP. This involvement is discussed in detail in Section 3.2.

\subsubsection{Baseline Development}

The technical baseline together with cost and schedule baselines, forms a basis for managing and imprementing the MRS Project. All three baselines will be maintained using the project control procedures described in Section 3.2.

Figure 2.3-3 provides a generic schedule that indicates major Program/Project phases, milestones, and technical documentation products. Figure 2.3-4 illustrates how the systems engineering process will be applied during each phase. The phases associated with each element are described in more detail in Section 5. The Key Decision (KD) milestones are points in the schedule where action is taken to get authorization for the project to proceed to its next phase. The principal technical baseline documents that will be developed by the program and project include: the CRWMS Requirements Document (CRD); the MRS, Transportation, and Waste Acceptance (WA) System Requirements Documents (SRDs); the Interface Specification (IFS); the Design Requirements Documents (DRDs); the Interface Control Documents (ICDs); the Safety Analysis Report (SAR); the Configuration Item (CI) Design Specifications (DSs); and the As Built (AB) CI DSs. The Physical System Requirements Documents (PSRs) provided the initial functional requirements basis for the CRD and SRDs. The development of this technical baseline is described in more detail below. 


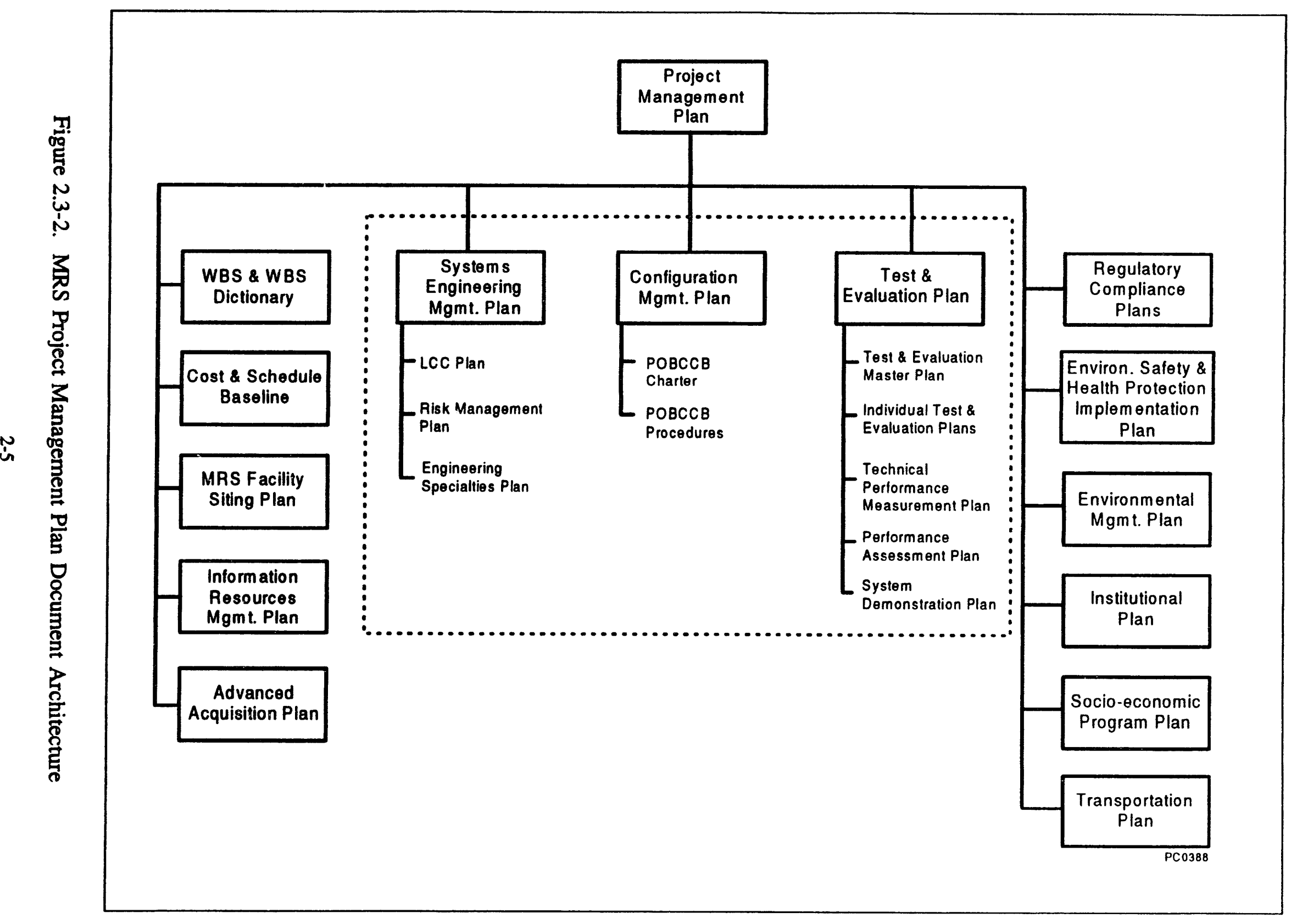



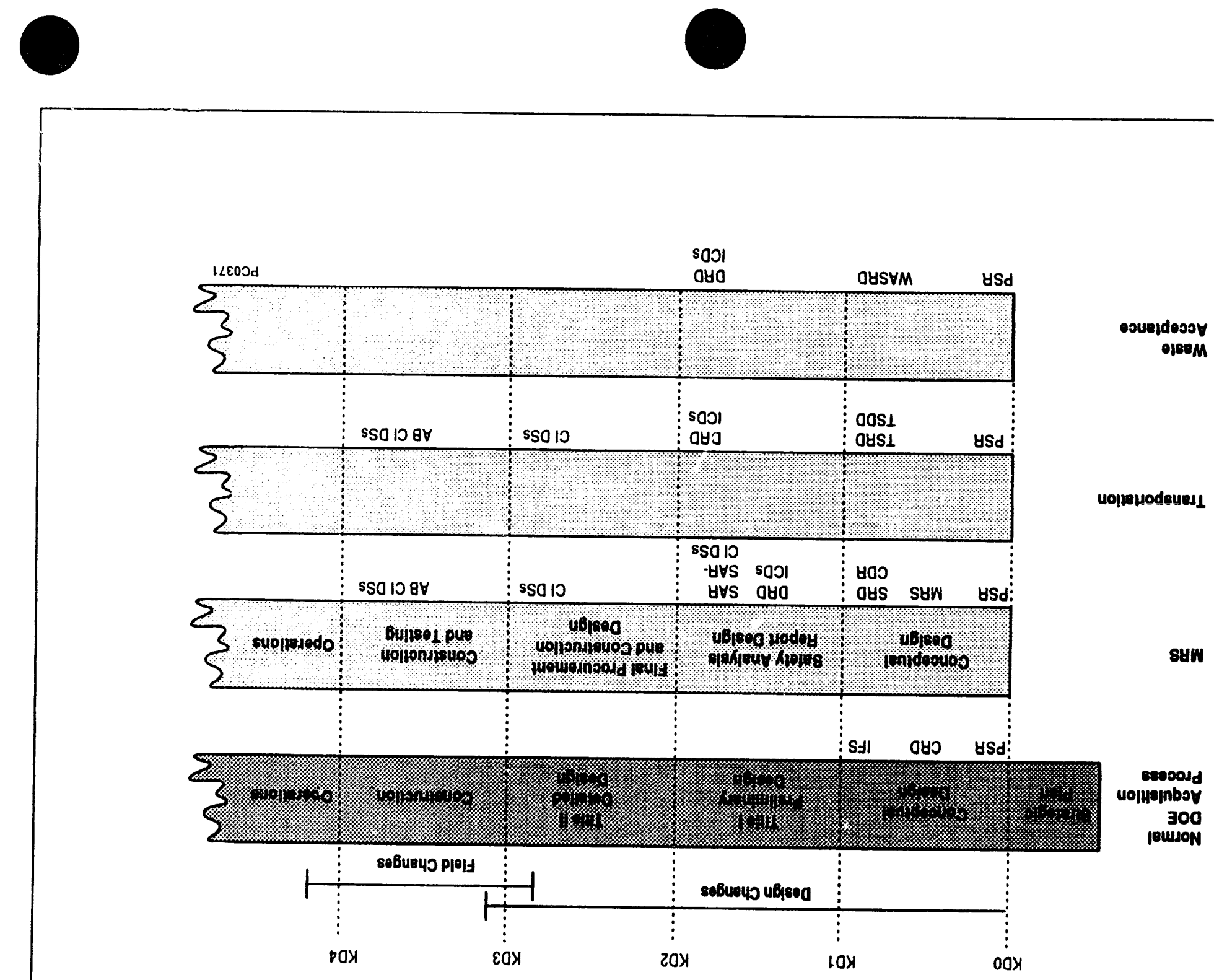

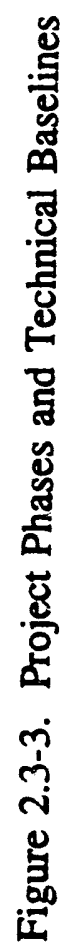



Although in general, the MRS Project follows the "normal DOE acquisition process," the details of each element's acquisition process will deviate from this model to some extent. These deviations are discussed in detail in Section 5. The most notable difference occurs in the development of the MRS Element which is divided into a SAR Design and a Final Procurement and Construction Design Phase to reflect the process associated with obtaining a Nuclear Regulatory Commission (NRC) License. This process is described in detail in Sections 4 and 5.

\subsection{Technical Baseline}

The CRWMS top-level requirements were initially developed under an interim technical baseline (based on the PSRs), which will be transitioned to a final technical baseline (based on the CRD, SRDs, and IFS). The interim baseline and the transition to the final baseline are described in Appendix A of the OCRWM SEMP.

The technical baseline begins with, and flows from, the CRD. The element-level SRDs, IFS, and Inter-Element ICDs in the technical baseline are produced at the program level along with the CRD. DRDs and Intra-Element ICDs are prepared by the Project.

The OCRWM document hierarchy stops short of identifying all project technical documentation requirements. Figure 2.3-5 shows two additional levels of required documentation to complete the technical baseline. The CI DSs document the results of detailed design and provide sufficient detail to construct/fabricate the system. The As-Built CI DSs contain the same level of detail as the design specifications but reflect design changes introduced during construction/fabrication.

The five steps in the evolution of the technical baseline and the names given to the baseline at each stage are shown in Figure 2.3-6. The first step, carried out at the program level, establishes the functional baseline and is a precursor to the CRD, SRDs, and IFS identified in the OCRWM document hierarchy. It describes top-level and functional system requirements as described in the OCRWM SEMP. PSRs are the output of this step.

The second step, also carried out at the program level, establishes the technical requirements baseline by generating the CRD, SRDs for each system element within the MRS Project, and associated IFS. The CRD provides requirements imposed on the CRWMS. These requirements are allocated to each system element affected by the requirement. Such requirements then flow into the element-level SRD and are expanded in detail to provide element-specific requirements of greater detail. Element SRDs and the IFS will be based, in part, on information developed in the MRS Project conceptual design phase. Conceptual designs will be developed in iterative fashion in response to functional requirements and will be reflected in SRDs that define system level requirements for each system element. Currently, an MRS Facility Conceptual Design Report (CDR) and a Transportation System Description Document have been completed. These documents provide the baseline conceptual design for the MRS and Transportation elements. A CDR for Waste Acceptance is not currently required (see Section 5.1). 


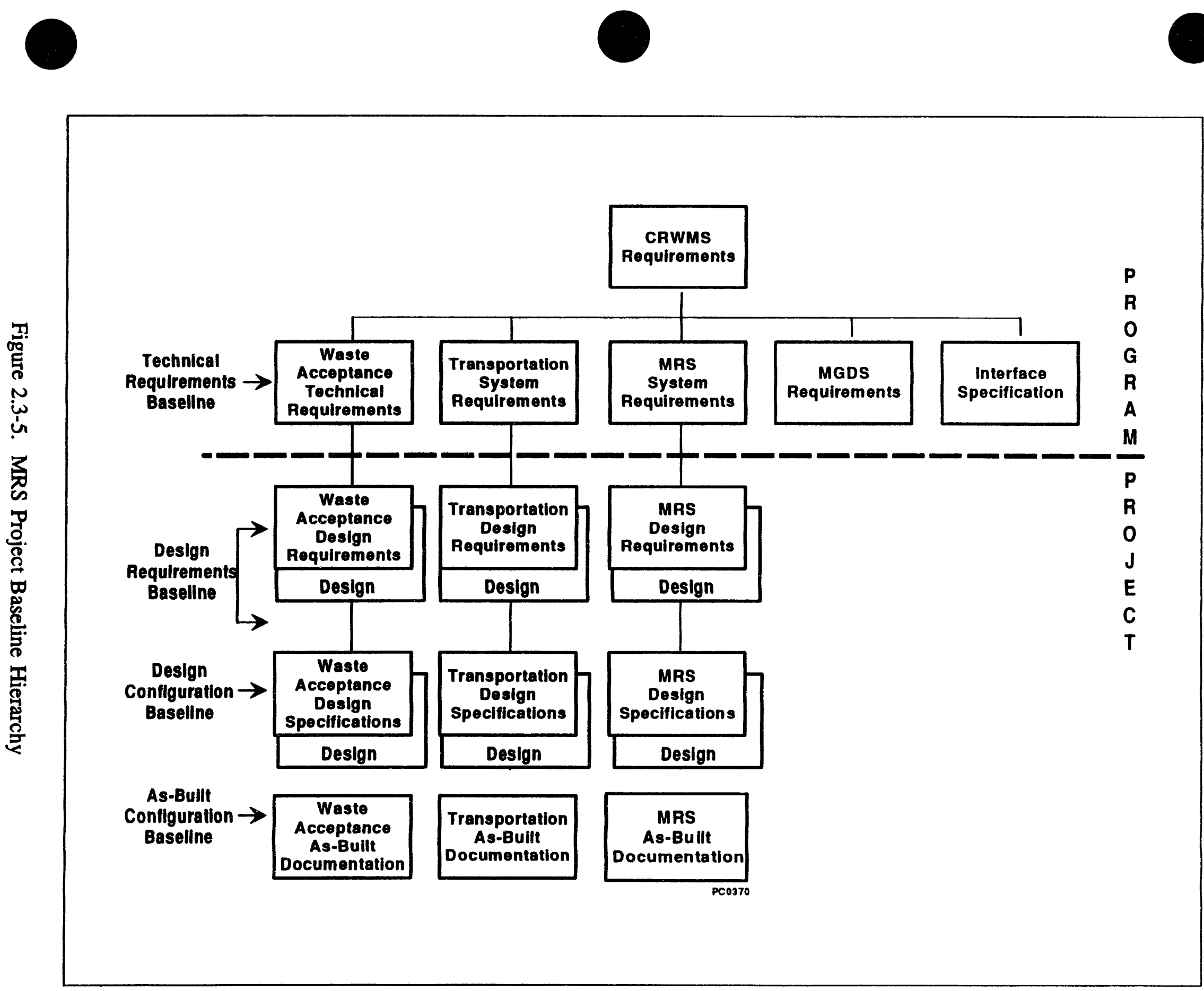




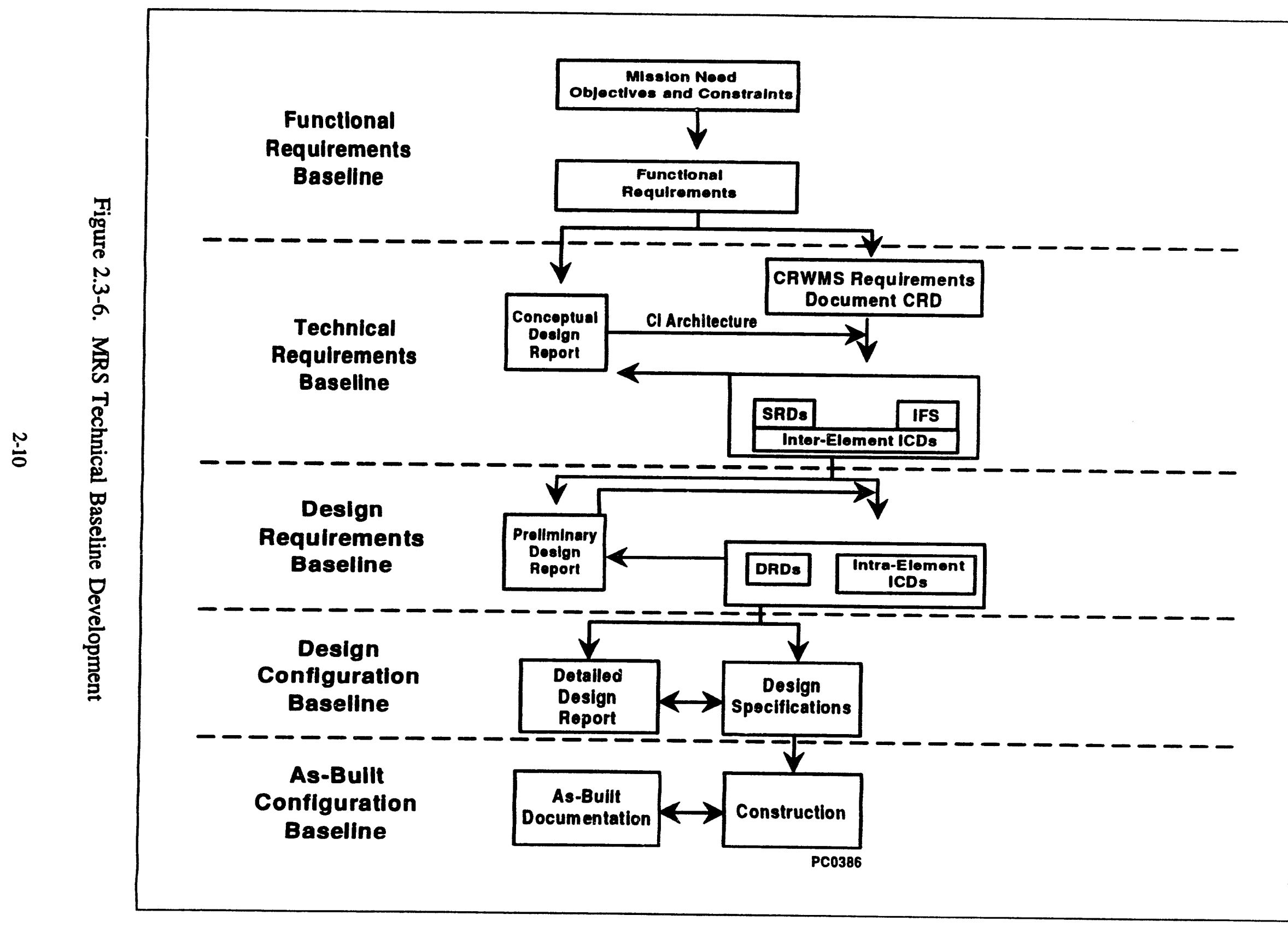


The primary purpose of the element-level SRDs is to identify the applicable system-level requirements and to allocate those requirements to element segments. The element-level SRDs will provide an overall description of the respective element and its segments, identify source documents, and define system-level functions, requirements, and interfaces. They identify mission requirements for the MRS Project elements, identify all applicable system source documents, identify top-level system functions, document element architecture by identifying segments and their interrelationships, allocate requirements to segments and interfaces within the Project, address requirements common to ail segments, identify interfaces with other CRWMS elements, and identify methods to verify achievement of requirements.

The third step, carried out principally at the project-level, establishes the design requirements baseline through the generation of DRDs and ICDs. The DRDs and Intra-Element ICDs are generated at the project level, while Inter-Element ICDs are generated at the program level. These documents complete the decomposition of functions and requirements, the identification of configuration items, and the allocation of requirements and functions to configuration items. This requirements analysis is usually considered complete when a requirement is allocated to no more than one function, and functions and tasks do not result in additional requirements for equipment, facilities, software, or personnel.

The fourth step in the development of the technical baseline is the development of the Design Configuration Baseline (in the CI DSs), which serve as the basis for procurement or construction. In the fifth and final step, any changes to this baseline that occur during fabrication and construction process are recorded in the As-Built Technical Baseline (in the As-Built CI DSs).

The assignment matrix in Appendix B, Table Bl identifies the organizations responsible for each technical baseline document discussed in this section. The organizations themselves are described in detail in Section 3.1.

The MRS facility will be licensed for construction and operation in one step by the NRC. Figure 2.3-7 shows the relationship of technical baseline evolution to license application (LA) development. The LA annotated outline will be produced by the Project, with periodic updates and the support of the Program, to establish and maintain a dialogue with NRC personnel. Technical material developed during conceptual and preliminary design will be used in these annotated outlines versions. For the MRS facility the Preliminary Design (Title I) Phase will be combined with detailed design (Title II) of structure, systems, and components important to safety, which are necessary to produce an SAR design. The SAR will be submitted to NRC to allow formal review of the LA to begin. The fully completed LA, including the MRS facility environmental impact statement (EIS), will be submitted subsequently during the Final Procurement and Construction Design phase (the remainder of Title II design).

\subsection{Cost and Schedule Baseline}

The cost and schedule baselines are maintained in documents at both the program and project levels. The project baselines that appear in the PMP provide a greater level of detail. The cost and schedule baselines reflect the technical baseline and evolve in unison with it. The Program Cost and Schedule Baseline Document contains Work Breakdown Structure (WBS) level 0 and 


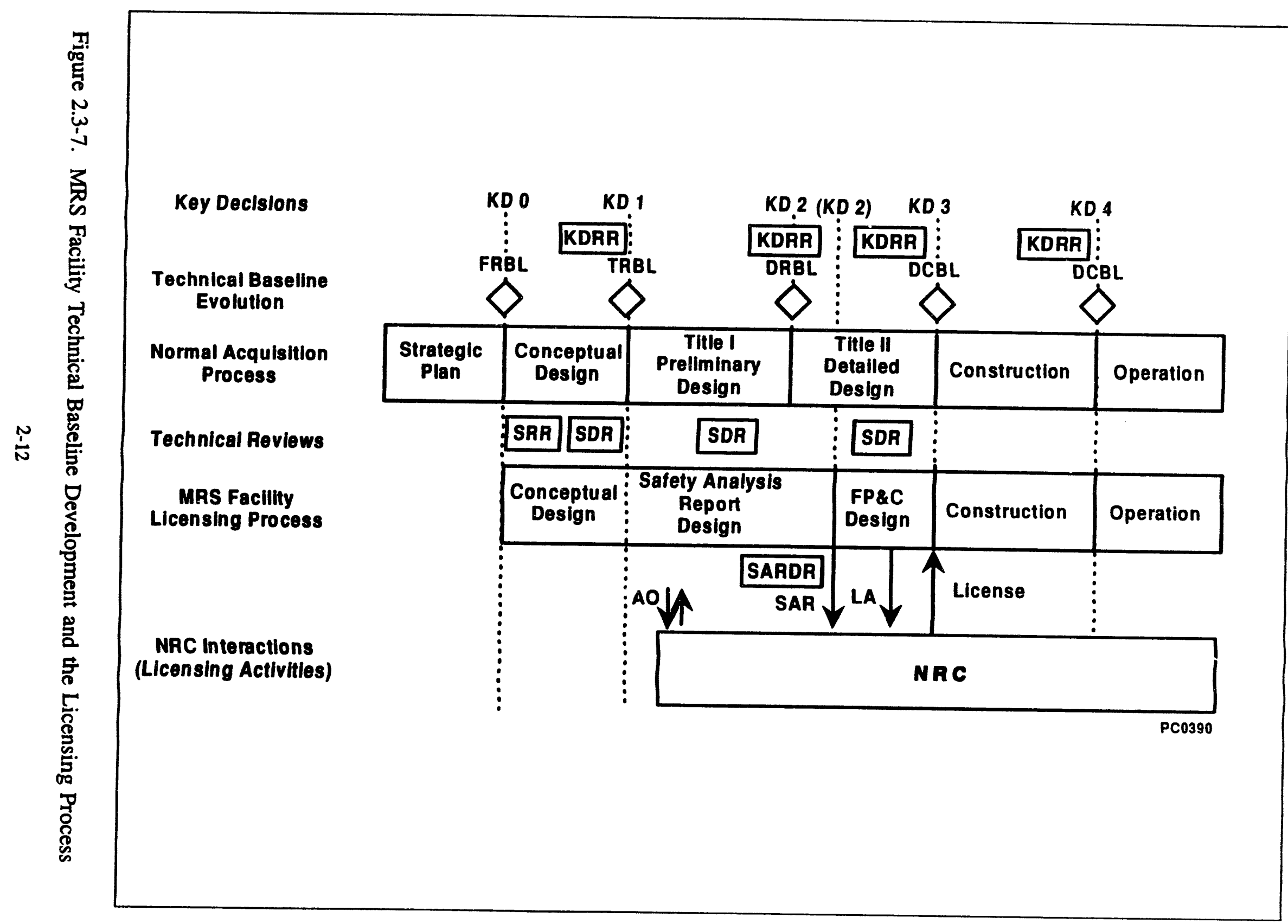


level 1 schedule milestones; the MRS Project Cost and Schedule Baseline Document provides milestones to level 3. The MRS Project Cost and Schedule Baseline Document is required by the PMSM, Appendix E, and its preparation responsibility is assigned in Appendix B, Table B2 of this SEMP.

There are five types of cost estimates defined in DOE Order 4700.1 that correspond to completion of the first four stages in the evolution of the technical baseline. They are the Planning/Feasibility Study Estimate, the Conceptual Design Estimate, the Title I Design Estimate, the Titlc II Design Estimate, and the Independent Cost Estimate.

\subsection{CONTENTS}

The contents of this SEMP are in accordance with DOE Order 4700.1, the Program Management Systems Manual, and the OCRWM SEMP. The following major sections are included:

- Section 1 provides a brief introduction to the CRWMS Program and this MRS Project SEMP.

- Section 2 describes the scope of the systems engineering process for the MRS Project, including descriptions of the technical baseline and planning documentation requirements.

- Section 3 describes the technical planning and control structure, including the organization and responsibilities of OCRWM and its Management and Operating (M\&O) contractor, cost and schedule frameworks, technical review and reporting requirements, and the Project's configuration management, test and evaluation, technical performance measurement, performance assessment, and quality assurance efforts.

- Section 4 defines and describes the baseline systems engineering approach that will be use by the MRS Project to transform its mission into an operational system.

- Section 5 describes how the process discussed in Section 4 is tailored to each element.

- Section 6 describes the engineering specialties (LCC, RAM, safety, security, human factors, etc.), programmatic specialties, and how these specialties will be integrated into the MRS Project systems engineering process through the use of Concurrent Engineering.

- Appendix A provides a list of acronyms used in this SEMP.

- Appendix B provides information on documentation, including responsitilities for technical baseline documentation and selected PMP-related documentation, a schedule for technical document preparation and revision as they relate to project milestones, and document summaries.

- Appendix C once completed, will discuss models and trade studies, and how they support the project. 
- Appendix D will incorporate the MRS Project Risk Management Plan once it is completed.

- Appendix E will incorporate the MRS Projecr Life Cycle Cost Plan once it is completed.

- Appendix F will incorporate the MRS Engineering Specialty Plan once it is completed.

- Appendix $\mathbf{G}$ provides a list of referenced and relevant documents. 


\section{TECHNICAL PLANNING AND CONTROL}

This section identifies technical project planning and control mechanisms important to the systems engineering process. These mechanisms are discussed in terms of the Project organizations and responsibilities of various groups within these organizations. Section 3.1 describes the organizational structure and responsibilities and the control of subcontractor engineering. It identifies organizational responsibilities, and authority for managing all aspects of the project (including technical management). Section 3.2 addresses the technical and project management planning activities. It includes a discussion of the control of subcontracted engineering; levels of control established for performance and design requirements, and the control method to be used; and control of documentation. Sections 3.3 and 3.4 describe the reviews and reporting methods. Section 3.5 describes the quality assurance methods used by the MRS Project. A generic schedule for the principal project design and technical reviews has been provided in Section 2.3.2

\subsection{ORGANIZATIONAL STRUCTURE \& CONTRACTUAL RESPONSIBILITY}

Organizations within DOE/OCRWM and the CRWMS M\&O Contractor will lead the implementation of technical planning and control. The structure and contractual responsibilities for each organization are summarized, along with those of other agencies and contractors. Details of each organization's role in the MRS Project are discussed in the PMP and PMSM.

\subsubsection{DOE/OCRWM}

DOE OCRWM is responsible for developing and managing the Civilian Radioactive Waste Management Program, which includes the MRS and the Yucca Mountain Site Characterization Projects or MSAs. The first repository MSA project encompassing the dispose of waste function is identified as a possibility on the Program WBS; it is inactive and will only be activated if a site is found to be suitable and a license is granted. OCRWM consists of eight major offices, each of which is managed by an Associate Director or Director. The responsibilities of each office within OCRWM are summarized in the OCRWM SEMP.

Within OCRWM, the Office of Storage and Transportation (OST) has primary responsibility for managing the MRS Project. The office is divided into two Divisions: Storage, and Transportation and Logistics as shown in Figure 3.1-1. The Branches in each Division have the following responsibilities:

- The Facilities Development Branch of the Storage Division (OST-SD) manages the implementation of the technical program for the MRS facility, including storage facility siting, design, construction, operation, and decommissioning activities. This branch has oversight responsibility for systems engineering activities including the MRS facility technical baseline and the planning documents that support it, configuration management and the MRS Project Configuration Management Plan, and this Project Systems Engineering Management Plan. 


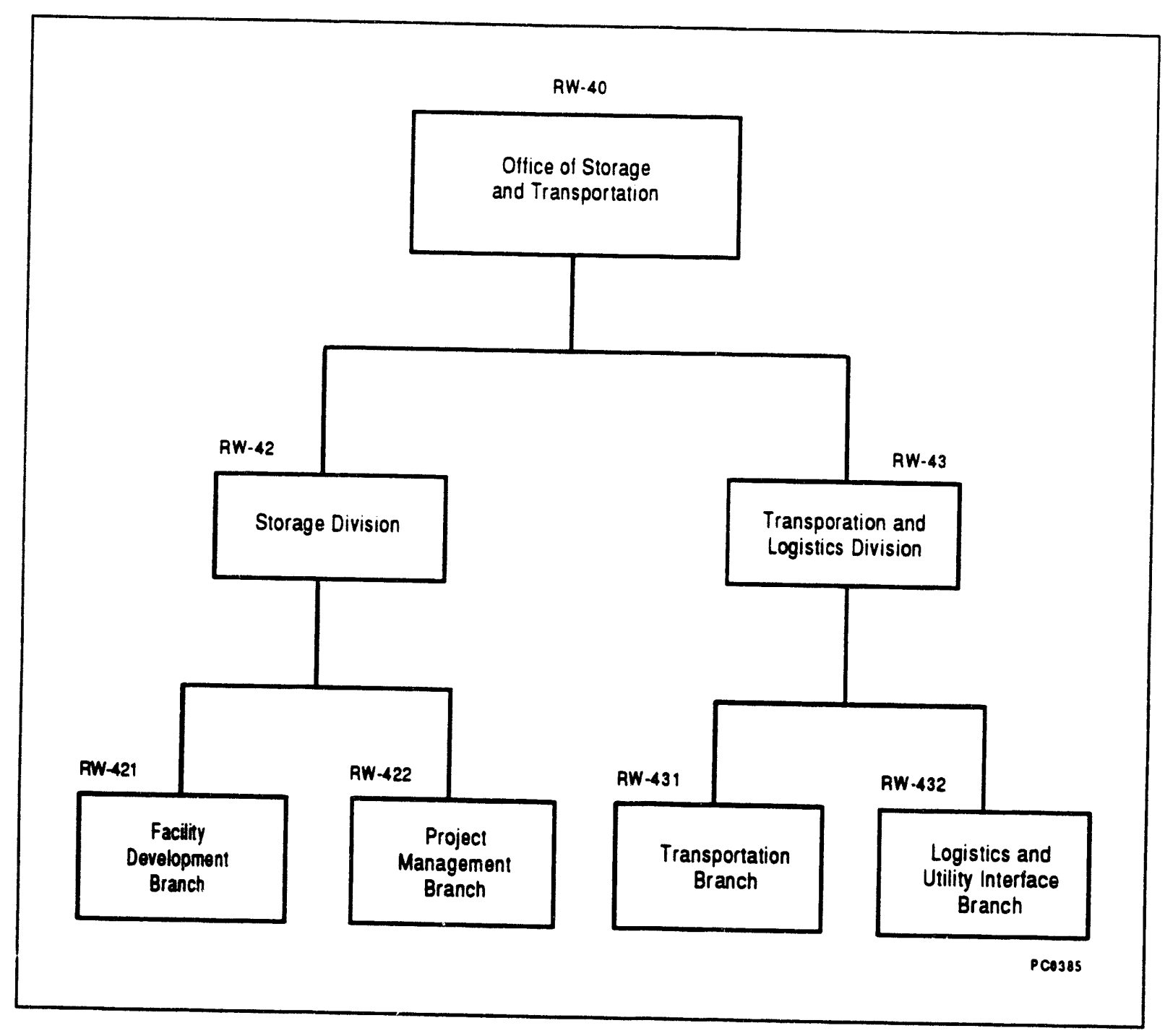

Figure 3.1-1. DOE/OCRWM MRS Project Organization

- The Project Management Branch of the Storage Division (OST-SD) manages the MRS facility with respect to cost and schedule requirements. This includes activities related to the National Environmental Policy Act (NEPA), licensing, and quality control. This branch has oversight responsibility for the MRS facility cost and schedule baselines, for configuration management, and for the project plan, project management pian, and configuration management pian.

- The Transportation Branch of the Transportation and Logistics Division (OST-TLD) manages the development of a transportation system for spent nuclear fuel and HLW, including cask system design, certification, testing, and acquisition as well as costs and schedules. This branch has oversight responsibility for the transportation technical, cost, and schedule baselines as well as the planning documents that support them. 
- The Logistics and Utility Interface Branch of the Transportation and Logistics Division (OST-TLD) manages the waste acceptance contracts with the utilities including the related tasks of contract policy and procedures, fee adequacy assessment, database management. and annual capacity and priority ranking reports. This branch has oversight responsibility for the waste acceptance technical, cost, and schedule baselines as well as the planning documents that support them.

T The OST interacts with other OCRWM offices and some DOE divisions outside OCRWM. T These include the Office of Systems and Compliance, the Office of Quality Assurance, the Office - of Program and Resources Management, the Office of Geologic Disposal, the Office of Contract B Business Management, the Office of Environment, Safety, and Health (EH-1), the Office of P Procurement (PR-1), the Office of Environmental Restoration and Waste Management (EM-1) a and the Office of the General Counsel (GC-1).

I) Issues that may develop concerning the development and change of the technical, cost, and s) schedule baselines will be resolved by the appropriate level baseline change control board. At tl the program level, the Program Baseline Change Control Board is responsible for approving tt technical documents, cost and schedule baseline documents, and selected program-level n management documents. At the project level, the MRS Project Office Change Control Board p performs these functions.

P Proposed changes to a Project-level baseline that do not affect a Program-level baseline and do impact greater than or equal to $\$ 25$ million and/or schedule impact greater than or equal to 3 months) will be adjudicated by the POBCCB. Proposed changes that impact a Program and/or exceed these thresholds will be forwarded to the PBCCB per the MRS Project CMP.

In addition to the individuals and offices at OCRWM and DOE headquarters in Washington, D.C., an MRS Project Office will be established at the site for the MRS facility. This will occur after a host site agreement has been approved by Congress. Host preferences will be considered when developing the organizational structure of the office.

In general, the MRS Project Office is responsible for preparing, reviewing, and approving project management, technical management, and technical baseline documentation. MRS Project baseline documentation and selected management documentation will be reviewed and approved by the POBCCB. The MRS Project Office accomplishes this through the use of planned design reviews attended by POBCCB members. These reviews are discussed in greater detail in Section 3.3.

\subsubsection{M\&O}

To assist in the development of the CRWMS, DOE has retained a Management and Operating contractor. The M\&O organization is led by TRW Environmental Safety Systems Inc., which in turn has major subcontracts with nine other teammate companies. The M\&O will establish additional subcontracts for short-term and/or specialty services on an as-needed basis.

The DOE/M\&O contract defines the contractual relationship between DOE and the M\&O. The work authorization structure described in the contract provides a mechanism for establishing the 
scope of work to be performed and delivered by the M\&O. Work Authorization Directives (WADs) are updated on an annual basis and non-contract deliverables are added to the scope of work as necessary.

The M\&O organization consists of three major organizations: Systems, Operations, and the Nevada Site. These organizations interact in a matrix format; the Systems organization develops system concepts and establishes system requirements, while the Operations and Nevada Site organizations develop system elements to satisfy those requirements and also provide management controls and information systems support.

Within the M\&O, the primary responsibility for the MRS Project falls under the Office of Storage and Transportation (OS\&T) in the Operations Organization. The organizational structure of the OS\&T is shown in Figure 3.1-2 and its responsibilities are summarized below:

- The MRS Site Investigations Department (formerly MRS Siting) prepares for the establishment of a site field office by managing (under the direction of OCRWM) on-site activities, providing planning support and policy guidance on siting issues, and managing (under the direction of OCRWM) site data collection and property acquisition efforts.

- The MRS Design Department is responsible for all design-related activities for the MRS facility including conceptual design, storage technology evaluation, the Safety Analysis Report design, and Final Procurement and Construction (FP\&C) design. MRS Design will prepare project-level technical baseline documents for the MRS facility.

- The Transportation Department is responsible for supporting all transportation-related activities including procurement, economic analysis, and support systems. This department will prepare project-level technical baseline documents for the transportation system.

- The Waste Acceptance \& Logistics Department is responsible for supporting all waste acceptance and related activities, including utility contract policy, economic analysis, delivery commitments, and data analysis. This department will prepare project-level technical baseline documents, as identified elsewhere in this SEMP, for the waste acceptance activity.

- The Systems Integration Department within the M\&O's OS\&T provides systems engineering leadership and is responsible for integrating all Project functions, providing key liaisons to $M \& O$ groups inside and outside the OS\&T, and managing technical, cost, and schedule performance. This department prepares MRS Project cost and schedule baseline documents and project management, configuration management, system engineering management, and other management plans. 


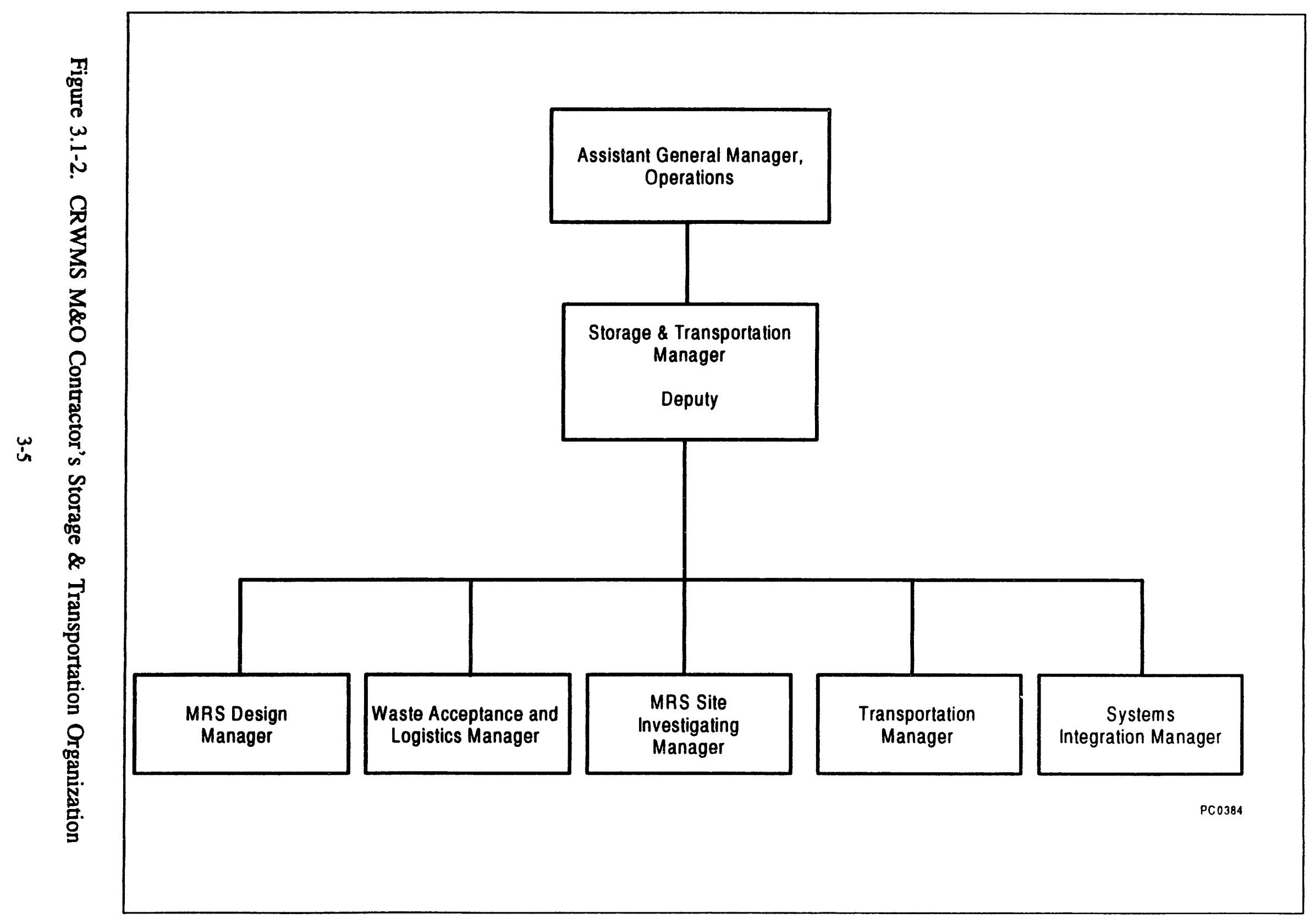


The M\&O's OS\&T uses resources in the rest of the M\&O organization to perform tasks such as performance assessment, modeling, licensing, regulatory, environment/safety/health, outreach/institutional, Program-level systems engineering, and quality assurance. The DOE/OCRWM/OST and the M\&O's OS\&T organization interface with other supporting agencies and contractors. These interfaces are discussed in Section 3.1.3.

\subsubsection{Other Agencies}

OCRWM will interact with numerous Government offices and agencies. These include the Office of the Nuclear Waste Negotiator (ONWN), the U.S. Environmental Protection Agency (EPA), and the NRC. The roles of and relationships between these agencies are summarized below; additional detail is provided in the PMP.

The ONWN is primarily responsible for identifying an MRS site location and negotiating a host agreement with the host State government and/or Indian tribe.

The EPA is responsible for publishing a Notice of Availability for the draft MRS facility EIS in the Federal Register. Once the EIS has been finalized by the DOE, the EPA will publish a Notice of Availability for this final EIS in the Federal Register. Refer to the Regulatory Guidance Document, Regulatory Compliance Plan, and Environmental Management Plan for details of the EPA's role in the MRS Project.

The NRC has been delegated licensing and related regulatory authority for an MRS facility pursuant to the Nuclear Waste Policy Act of 1982, as amended in 1987. As such, an NRC license to construct and operate an MRS facility must be obtained from the NRC by the MRS Project Office before construction of the MRS facility can begin. Similarly, NRC certification of transport casks must be obtained before they can be used in the CRWMS.

As part of the licensing procedure, OCRWM will develop an MRS Facility Environmental Report (ER) (which may be in the form of an Environmental Impact Statement and/or Environmental Assessment) and will submit it to the NRC in accordance with 10 CFR Parts 72 and 51. The NRC will then adopt the resulting ER to the extent practicable and /or write its own ER.

The role of State and local agencies in the project organization will be determined once an MRS host site agreement has been approved by Congress. As a minimum, however, State and local agencies will assist in the establishment of some Project environmental requirements.

\subsection{TECHNICAL MANAGEMENT}

Technical management is a systems engineering activity. It consists of those aspects of project management that guide the technical development of the system. As such it makes use of many of the same organizational structures, procedures, and tools used in project management. Although these structures, procedures, and tools are described in detail in the MRS Project PMP and its volumes, their application to the systems engineering process will be described briefly in this section. 
Principal objectives of MRS Project technical management are to: 1) ensure that the MRS Project meets its regulatory, performance, cost, and schedule objectives; 2) establish and maintain traceability of design and requirements; 3 ) establish and maintain control of the project portion of the technical baseline; and 4) ensure that QA procedures are followed. One of the principal products of systems engineering is the technical baseline documentation (e.g., Design Requirements Documents, Interface Control Documents, Configuration Item Design Specifications, As-Built CI DSs, and supporting documentation) through which the design is defined and which provides the required traceability of requirements and design. One of the principal aspects of both systems engineering and technical management is systems integration, which ensures that all sources of requirements (both technical and procedural) are identified early enough in the acquisition process to be incorporated into the system's preliminary design, and that the test and evaluation process is effectively integrated with design, construction, and operation. The sections that follow provide an overview of the scope of technical management and a summary of the principal tools used by technical management to maintain control of the technical development, construction, and preoperational activities.

Section 3.2.1 summarizes the Program's management control methods and identifies those that will be used in the technical management of the MRS Project. Section 3.2.2 summarizes how technical management relates to the plans that make up the appendixes of the PMP. Sections 3.2.3 and 3.2.4 address document control and configuration and interface management, while Sections 3.2.5 and 3.2.6 address test and evaluation planning, and risk management.

Although technical reviews and reports are also technical management tools, they will be described separately in Sections 3.3 and 3.4.

\subsubsection{Technical Control}

The MRS PMP provides a detailed description of the levels of program and project control and the tools that are used to establish and maintain management control. This section provides a summary of those levels of control and project management tools and identifies those that are applicable to the technical management of the project.

The Program may be characterized as having 4 levels of organization and technical control (DOE-level, program-level, project-level, and participant-level) and 10 general methods of control [plans, WBSs, budget authority, contractor/subcontractor Statements of Work (SOWs), WADs, a cost and schedule control system, reviews and reports, a configuration management system, a document control system, and quality assurance programs]. These are described in detail in the MRS Project Management Plan. This SEMP will focus on the methods of control that will be used by technical management at the project level.

The project will exert technical (and cost and schedule) control through the use of: SOWs; the POBCCB; Project Office Interface Control Working Groups (POICWGs); the PMP and its associated appendixes; the approval of participant-level plans, the MRS Project WBS, cost and schedule baselines (C\&SBs), and WADs; and technical reviews. 


\subsubsection{Technical Project Management Planning}

The MRS Project Management Plan, Volume 1, is the principal project management planning document required by the OCRWM PMSM and is described in Chapter II of DOE Order 4700.1. It sets forth the plans, organization, and systems that will be used by those responsible for managing the project. The PMP and its associated volumes and appendixes provide detailed descriptions of the project management structures, procedures, and tools that will be used to manage the project. Since systems engineering will make use of many of these same structures, procedures, and tools to provide the technical management, it is appropriate to review them here. The principal volumes of the PMP are identified in Figure 2.3-2 and summarized below.

The MRS Project Work Breakdown Structure (PMP Volume 2) provides the framework for the detailed planning and control of the work (including technical activities) to be performed under the direction and control of the MRS Project Office. The WBS Dictionary provides a brief description of the activities associated with each element of the WBS. Whereas the Program WBS establishes the Project's structure to level three, the Project WBS decomposes the Project's structure to level four, or more, as needed to support budget development. Since the WBS provides the framework for the planning and control of work that includes systems engineering and technical activities, it is a key technical management tool. The PMP provides the WBS for the MRS down to the third level. The technical management aspect of systems engineering will work in concert with project management to ensure that work performed under other WBS elements is effectively integrated into the development of the Project's design requirements and specifications. As such, systems engineering will play an integral role in the development of the Project WBS.

Project-level systems engineering activities will be performed principally under the following elements of the WBS: 3.1.1 Systems Engineering (MRS); 3.1.4 MRS Facility; 3.2.1 Systems Engineering (Transportation); 3.2.2 Cask Systems; 3.2.4 Support Systems; and 3.3 Waste Acceptance (as required).

The MRS Project C\&SBs (PMP Volume 3) provide cost estimates and schedule goals for project activities and the MRS Project Cost and Schedule Control System (C\&SCS) will be used to generate the C\&SBs and to track and monitor progress. The MRS Project C\&SB will differ from the Program C\&SB in that it will provide more detailed tracking and reporting based on project activities. Technical management will provide input to the cost and schedule baselines and will make use of the associated databases to manage the technical activities. It is also likely that cost and schedule changes will impact technical activities.

Although not a part of the PMP, the WADs provide a critical project/technical management tool for managing project contractors. It is closely connected to the WBS, the C\&SBs, and the Summary Task Planning Sheets (STPSs). The WADs (signed by OCRWM's Associate Director for the Office of Storage and Transportation) direct Project Participant work by identifying specific tasks that will be performed and deliverables that will be developed in a given year under given budgetary constraints and programmatic direction. Technical management will be exercised by reviewing the WBS, the C\&SB, and the STPSs to develop recommendations for technical activities and deliverables to be included in the WADs. The resulting WADs will be used as a technical management tool to direct technical activities and will serve as the basis 
against which MRS Project Performance Measurement will be performed. Technical management will also make use of STPSs to plan and definitize participant and subcontractor tasks.

Configuration management is an essential aspect of technical management. The MRS Project Configuration Management Plan (CMP) (PMP Volume 6) and its associated Project Office Baseline Change Control Board Charter and Project Office Baseline Change Control Procedure describe in detail how configuration management $(\mathrm{CM})$ will be performed by the Project Office. Section 3.2.4 of this SEMP describes configuration management in more detail.

Test planning, testing, and analysis of test results are integral parts of the systems engineering process. Technical management will be closely involved in the development of a comprehensive test and evaluation program, in identifying the associated cost, and in establishing the schedule for the test program. The MRS Project Test and Evaluation Plan (T\&EP) (PMP Volume 7) will provide a detailed plan for the MRS Project test program. The MRS Project test and evaluation program is described in more detail in Section 3.2.5 of this SEMP.

The MRS Project Information Resource Management Plan, PMP Volume 8, will describe information management systems in terms of office automation, management support, and engineering support for the MRS Project. The plan will be compatible with the information resource management procedures established in the CRWMS Information Resource Management Program Plan required under the PMSM, Rev. 5.

The MRS Project Advanced Acquisition Plan, PMP Volume 9, describes the objectives and functions of acquisition or assistance. The contents of the plan will be in accordance with DOE Order 4700.1, Attachment II-7. A Construction Management Plan will be included as an appendix to the Advanced Acquisition Plan. Construction management concerns itself with the construction of facilities only (and not such things as the fabrication of special equipment, such as casks). Technical management will be involved in determining the need for such a plan and in the writing of the plan. DOE Order 4700.1 sets guidelines for Construction Management. During design phase(s), a study will be performed to identify and evaluate alternative approaches to construction management. If, on the basis this study, the Program Secretarial Officer (in this case the Director of OCRWM) determines that such a plan is needed, a detailed construction Management Plan will be prepared before construction starts.

The remaining plans identified in Figure 2.3-2 may have a significant impact on the development of the technical baseline. As such, technical management is responsible for alerting the Project Office of any need to integrate the activities governed by these other plans with the technical development activities (e.g., the potential design impact of the activities governed by these other plans should be established early in the Preliminary/SAR Design Phase), and providing this "Programmatic Integration" where required. Specific programmatic plans that are likely to have a significant impact on design include the MRS Facility Siting Plan; the Regulatory Compliance Plan(s); the Environmental, Safety, and Health Protection Implementation Plan; the Environmental Management Plan; and the Transportation Plan. The Institutional Plan and the Socioeconomic Plan may also have design implications. See Section 5.3 for additional details. 


\subsubsection{Document Control}

Document control will be performed on quality affecting documents by the appropriate configuration management document control organizations at OCRWM, and by the Project and Project participants in compliance with the Quality Assurance Requirements Document (QARD) using appropriate QA and CM procedures. Distribution and update control of other documents will be accomplished by their authors, consistent with the MRS Project Configuration Management Plan.

\subsubsection{Configuration and Interface Management}

\subsubsection{Configuration Management}

Baseline management, as defined in OCRWM's Baseline Management Plan (BMP) and its associated charter and procedures, consists of the management of the technical, cost, and schedule baselines for the Program, which are known collectively as the "Program Baseline." The MRS Project baseline management process is described in the MRS Project Configuration Management Plan, PMP Volume 6, and its related Charter and Procedures. The MRS Project CMP follows the guidelines set in the OCRWM BMP and describes how the project baseline documentation is identified, controlled, accounted, and verified. Although it describes the four levels of change control responsibility [Energy System Acquisition Advisory Board (ESAAB), Program, Project Office, and Contractor/Project Participant] and the associated Baseline Change Control Boards (BCCBs), its principal focus is on those activities governed by the POBCCB].

In the case of the MRS Project, $\mathrm{CM}$ is responsible for identifying and establishing the technical baseline and those aspects of it that are to be brought under configuration control. (It is also responsible for establishing the cost and schedule baselines.) It is also responsible for establishing and implementing configuration identification, configuration control, configuration status accounting, and configuration verification procedures.

The MRS Project CMP describes how the technical baseline (including interface documents), the cost and schedule baselines, and selected project/technical management documents are subject to configuration management by the MRS Project Office. CM, an essential aspect of technical management, identifies documents that will be brought into the Configuration Information System (CIS) and describes the processes by which these documents will be approved and entered into the CIS; changes to the technical baseline will be controlled; and the status of these documents will be tracked and the configuration will be verified. It also identifies and describes the levels of baseline and interface control and the baseline change control boards that exercise this control (with particular emphasis on the POBCCB). The Project Office Baseline Change Control Board Charter, an appendix to the CMP, provides a detailed outline of the POBCCB structure, membership, and member responsibilities. The Project Office Baseline Change Control Procedure, another appendix to the CMP, provides a detailed outline of the baseline establishment and change control procedures. 


\subsubsection{Interface Management}

Interface management ensures that design interfaces are identified, controlled, and coordinated among participating organizations [as required by 10 CFR $72.146(\mathrm{~b})]$. The procedures for the review, approval, release, distribution, and revision of documents involving project-level design interfaces are described in the MRS Project CMP. The procedures associated with program-level interfaces are described in the OCRWM BMP.

The MRS Project interface management process consists of the following:

- Interface Identification consists of determining the existence of an interface, a need for its control, its documentation in an ICD, and its approval by the POBCCB. This general process is described below. The specific POBCCB review and approval process and procedures are described in the MRS Project CMP and its associated Project Office Baseline Change Control Procedure.

- Interface Control consists of controlling proposed and approved changes to the interface technical baseline. This process is described in Section 3.2.4.2.1. The specific POBCCB review and approval process and procedures are also described in the MRS Project CMP and its associated Baseline Change Control Procedure.

- Interface Status Accounting documents the status of the interface baselines, once they have been established. It will be performed as a part of "configuration status accounting" as described in the MRS Project CMP.

- Interface Verification consists of verifying that the interface meets its requirements and conforms to the approved technical baseline. It will be performed as a part of "configuration verification" as described in the MRS Project CMP.

MRS Project Participants will support the Project Office in all aspects of MRS Project interface management.

\subsection{Interface Control Levels}

In accordance with the OCRWM SEMP, CRWMS interfaces are classified as either program interfaces or element interfaces. Program interfaces are defined as any interface whose functions and/or influence extend outside a single CRWMS program element and are the responsibility of the Program. For example, program interfaces are those interfaces that exist among two or more CRWMS elements (i.e., Waste Acceptance, Transportation, MRS, and MGDS) or between a program element and an external entity. Element interfaces are defined as any interface whose functions and/or influence are contained solely within a single CRWMS program element. If an element interface involves more than one project participant, it is governed by the Project Office and is approved by the POBCCB. If the interfaces are internal to a single project participant, they are governed by that participant.

The Program IM process will be managed and controlled through the Program BCCB (PBCCB) and Program Interface Control Working Groups (ICWGs). Program ICWGs are program 
organizations charged with the responsibility to define, develop, and review program interfaces and their related documentation (e.g., the IFSs and inter-element ICDs). They also provide technical evaluations of proposed changes to those interfaces in support of the PBCCB. The Project will provide qualified representatives to support Program ICWGs. The Interface Specification and Inter-element ICDs must be approved by the PBCCB to become part of the technical baseline. Once the interface baseline has been so established, changes to the baseline will be proposed by the ICWG and controlled by the PBCCB.

\subsection{Project Office Interface Control Working Groups}

The Project $\mathrm{MM}$ process will be managed and controlled by the POBCCB, Project Office ICWGs (POICWGs), and the project participants. POICWGs will be established, at the discretion of the Project Manager, to control and direct the generation of intra-element interfaces between MRS Project Participants and subcontractors (and its related documentation), to propose changes to the intra-element interface baseline, and to provide support to the POBCCB in its evaluation of the baseline and proposed changes to it.

The resulting intra-element ICDs must be approved by the POBCCB to become part of the technical baseline. Once the interface baseline has been established, changes to the baseline will be proposed by the POICWG or project participant and controlled by the POBCCB. The POICWGs will resolve interface problems, establish interface agreements, and provide the official communications link between MRS Project Participants and subcontractors and the POBCCB regarding intra-element interfaces. A POICWG may represent MRS Project interests to the PBCCB when the Project is involved in Program interface disputes, as requested by the PBCCB. The individual appointed as the POICWG Chairperson is responsible for administrating interface management for the MRS Project Office and ensuring that MRS Project Participants comply with the requirements of this section and related MRS Project procedures.

The project participants are responsible for developing internal interfaces.

\subsection{Interface Documentation, Generation, and Control}

Program and element interfaces are documented in four types of technical baseline documents: System Requirements Documents, the Interface Specification, inter-element Interface Control Documents, and intra-element ICDs.

Program interfaces (and their functional, physical, and administrative requirements) are identified and documented in the IFS and defined in the SRDs. An ICD completes the requirements and design definition of the interface to the level necessary to ensure that the IFS requirements will be met. It identifies, quantifies, and controls the design characteristics of the interface. The OCRWM SEMP and the OCRWM BMP describe how program interfaces are identified, developed, and managed. The project will assist the program in its development of detailed designs for program interfaces and the detailed design will be documented in related CI DSs, drawings, etc., that will be developed by the project.

Quality affecting MRS Project element interfaces (and their requirements) will be identified, defined, and documented in Intra-Element ICDs. The MRS Project SEMP and MRS Project 
CMP describe how project interfaces are identified, developed, and managed. These ICDs are prepared in accordance with applicable M\&O Quality Administrative Procedures (QAPs). Nonquality affecting interfaces and interface documentation will be identified, developed, and managed using procedures that will be developed on an as-needed basis. ICDs will be developed for interfaces between configuration items that are developed by different contractors. These intra-element ICDs will be included as appendixes to the appropriate element DRD. They will be reviewed and approved by the appropriate POBCCB.

These documents will be prepared, approved, submitted, and distributed in accordance with applicable M\&O QAPs or, for non-quality affecting interfaces, a similar procedure as determined by the appropriate office manager. Quality affecting interface documentation generated as part of the interface control process will be collected and maintained in accordance with the requirements specified in applicable $M \& O$ QAPs and non-quality affecting interface documentation will be controlled by similar procedures that will be approved by the Project Office.

In order to establish tracking control of the interfaces, interface control numbers will be assigned to each interface and its related documentation. Interface control numbers will be assigned by the POICWG Secretary in accordance with applicable M\&O QAPs.

\subsubsection{Test and Evaluation}

Test and Evaluation (T\&E) of a system throughout the acquisition process reduces acquisition risk and provides early and continuing estimates of the system's operational effectiveness and suitability. There are two general categories of T\&E: development and operational. Development T\&E provides data for engineering design and development, verifies performance objectives and specifications, demonstrates that design risks have been minimized, evaluates the compatibility of elements, and ensures that the system/equipment is ready for operational testing. Operational T\&E establishes the system's operational effectiveness and suitability, identifies needed modifications or improvements, provides information on organizational and training requirements, and provides data to verify the adequacy of manuals, handbooks, support plans, and documentation.

The MRS Project T\&E program will verify technical parameters that are considered verifiable by test, inspection, or demonstration. The MRS Project T\&E program, required by DOE Order 4700.1, Attachment I-4, will be documented in the MRS Project Test and Evaluation Plan (T\&EP). This plan will be incorporated as Volume 7 of the PMP. The MRS Project Test and Evaluation Master Plan (TEMP) will be developed early in the preliminary design phase to serve initially as an annotated outline for the T\&EP, and later as its executive summary. The T\&EMP will identify the overall T\&E strategy for each project element (i.e., MRS, WA, and Transportation) and for the project as a whole. At a minimum, it will identify the programs and methods that will be used to meet and verify $\mathrm{CI}$ and system compliance with technical baseline requirements. It will be consistent with the program-level OCRWM Test and Evaluation Master Plan (TEMP). Individual T\&E plans and procedures covering a specific series of T\&Es will be prepared and added to the T\&EMP as they are developed. The MRS Project T\&EP will consist of the T\&EMP as the executive summary and the collection of all the individual T\&E plans. 
The T\&EMP will be prepared under the direction of the MRS Project Office and will be subject to POBCCB approval. Individual T\&E Plans will be prepared in accordance with DOE 4700.1, and subject to approval of the POBCCB.

A specific operational plan that would be included in the operational portion of the Project T\&EP would be the MRS System Operational Test and Evaluation Plan. This plan will describe the process for verifying the operability of the MRS facility after construction is complete. It will ensure that pre-operational testing satisfies all applicable NRC requirements, including 10 CFR Part 72.24 and Regulatory Guide 3.48. This plan will be developed under the direction and control of the MRS Project Office.

There are three other systems engineering activities that are so closely related to T\&E that they may be considered a part of it and will be included as appendixes to the MRS Project T\&EP. These are Technical Performance Measurement, Performance Assessment, and Site Characterization, which are addressed in the following sections.

\subsubsection{Technical Performance Measurement}

The technical performance measurement (TPM) program is an integral portion of the T\&E program. TPM is defined as product design assessment and forms an important portion of the development testing program. It estimates, through engineering analyses and tests, the values of essential performance parameters of the current design and serves as a major input in the overall evaluation of the system's operational effectiveness and suitability.

The MRS Project Technical Performance Measurement Plan will describe how TPM will be performed at the project-level. The plan will be written under the direction and control of the MRS Project Office.

Technical performance parameters related to requirements critical to the Project mission objectives and radiological safety will be identified during the design requirements development process. These parameters will then be decomposed into components during the design process at the project level and analyzed to determine the parameters to be verified and how they will be accomplished.

"Achievement to date" of all identified parameters will be tracked, as part of TPM implementation, in order to measure parameter variances against the planned value profile. For technical performance deficiencies, alternate recovery plans with cost, schedule, and technical performance implications fully exposed will be prepared. Where performance exceeds project requirements, reallocation of resources will be assessed. All proposed changes to the technical baseline brought about by TPM will be subject to the change control process. TPM planning, the first step in implementation, will be started when requirements allocation to configuration items is substantially complete and draft DRDs are available.

\subsubsection{Performance Assessment}

$F_{i}$ hough the Nuclear Waste Policy Amendments Act (NRC regulations specified in 10 CFR Part 72.104 and 10 CFR Part 72.106 do not require a long-term performance assessment for the MRS 
facility, an independent evaluation of the ability of the MRS facility designs to satisfy radiological safety requirements for individuals outside the protected area of the MRS facility will be conducted under the direction and control of OSC.

An MRS Project Performance Assessment Plan has been prepared for the MRS Project that defines this performance assessment process. The plan will be reviewed and approved by the MRS Project Office and subject to approval by the POBCCB Chairperson. It will be included as a chapter or appendix to the MRS Project T\&EP.

\subsubsection{Site Characterization}

Although the NWPAA does not require an "MRS Site Characterization Plan" or extensive underground testing for the MRS facility (as for the geologic repository), a site investigation and testing program will be developed. The requirements for a site investigation and testing program originate from 10 CFR Part 72, Subpart E. Subpart E implies that site characterization must be incorporated into the MRS facility design and safety analysis. Data and analysis from site investigations will be used to support the facility design and safety analyses and is also required for the MRS License Application. The site investigation and testing program for the MRS facility will be described in the MRS Site Investigation Plan, which will be considered a part of the overall test and evaluation program and included as a chapter or appendix to the MRS Project T\&EP.

\subsubsection{Risk Management}

Risk Management is the systematic process of identifying potential risks and opportunities, assessing the associated probabilities of occurrence, assessing the consequence or benefit of the occurrence (forecast of the expected outcome), and deciding on contingent management actions to mitigate the risk or enhance the opportunity. Risk management will begin early in the engineering design and continue through program development, test and evaluation, licensing, operation, closure, and decommissioning.

A MRS Project Risk Management Plan (RMP) will be developed as an appendix to this SEMP that will be consistent with the guidance found in the CRWMS Program Risk Management Plan and in DOE Order 4700.1. The MRS Project RMP will describe how risk identification, risk assessment, risk prioritization, risk reduction, and the risk management function will be performed on the MRS Project.

MRS Project definition and redefinition will include a continuing analysis of the risks associated with the related cost, schedule, and technical parameters. This analysis will identify critical systems and will investigate methods for system proofing, prototyping, testing, and backup development. The project risk analysis will also aid in the identification of test requirements, technicai performance measurements, and critical milestones.

Risk templates will be used, where applicable, to evaluate risk associated with system and equipment trade-off studies. These templates will address sources of risk during the transition from system design development to system construction. Each template contains a description of the area of risk, an outline for reducing risk, and a time line that shows the risk area's relation 
to the system acquisition cycle. All identified risk management actions will receive DOE concurrence through the MRS Project Office prior to implementation.

\subsection{REVIEWS AND MEETINGS}

This section describes the project reviews through which technical management control is exercised on and by the project. Figure 3.3-1 shows a generic schedule of project reviews.

\subsubsection{Project Status Reviews}

The objective of Project Status Reviews is to inform senior management of project status and all relevant issues and changes, such as mission need, budget/financial re-direction, scope, costs, timing, management structure, or changes having significant environmental, quality assurance, and safety impacts. Project status reviews will be held at two levels for the MRS Project: Headquarters Reviews and Project Reviews.

\subsubsection{Headquarters Reviews}

Headquarters reviews (HRs) are reviews presented by the MRS Project Manager to the Director, OCRWM, with subject matter in accordance with DOE Order 4700.1. Headquarters reviews of the MRS Project will be held at least once every 90 days at DOE headquarters in Washington, D.C. In accordance with DOE Order 4700.1, copies of presentations and Action Memoranda or Memoranda for the Record will be maintained by the MRS Project Office.

\subsubsection{Project Reviews}

Project reviews (PRs) are reviews of project status, with more focus and detail than headquarters reviews, presented by the M\&O to the MRS Project Office with subject $m$ ter in accordance with DOE Order 4700.1. Project Reviews of the MRS Project will be held at least once every 90 days at DOE headquarters in Washington, D.C., at the MRS Project Office, or at the M\&O Contractor facilities, whichever is more appropriate for the particular review.

\subsubsection{Field Reviews}

Field reviews (FRs) are reviews presented by the MRS Project Office to the Director, OCRWM, with subject matter in accordance with DOE Order 4700.1. Field review will be scheduled in coordination with OCRWM to precede Key Decision points and will include discussion of the scope, cost, schedule, and funding baselines.

\subsubsection{Technical and Design Review}

In accordance with the guidance of DOE Order 4700.1 , a series of technical reviews will be conducted at the program and project levels to assess the development of the technical baseline. The program reviews (described in Section 3.3.2.1) will be used to verify the system requirements and the conformance of the project-level technical baseline to these requirements. The project reviews and meetings (described in Section 3.3.2.2) will be used to verify the design 


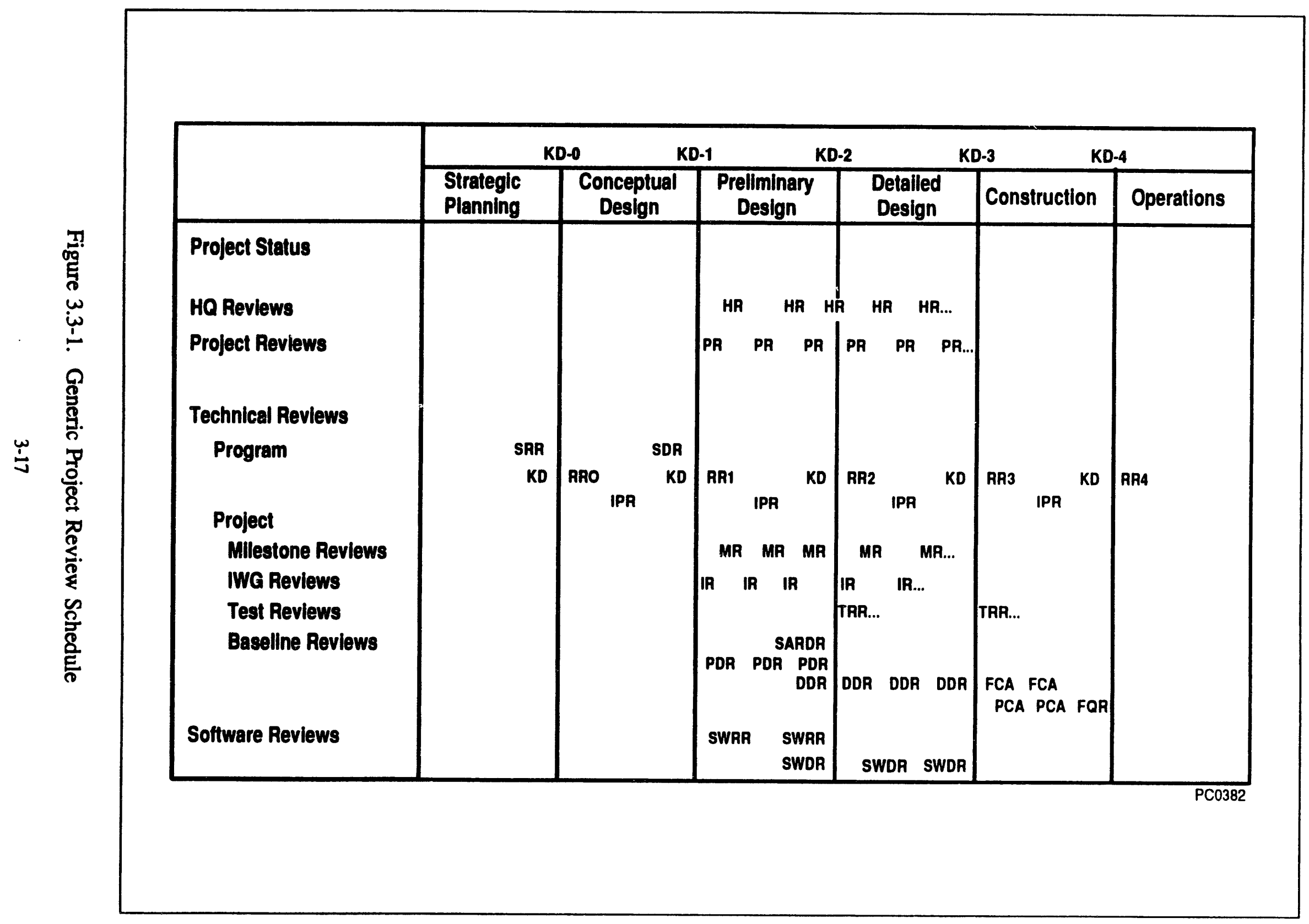


requirements and specifications. Figure 3.3-1 provides a generic schedule that indicates roughly the frequency and relevant periods for these reviews.

\subsubsection{Program-Level Reviews}

The reviews described in this section are the principal means by which the OSC manages the systems engineering process at the program level. As such, they are described in the OCRWM SEMP. They provide the verification needed to establish program integrity for the Director, OCRWM. These reviews include a System Requirements Review (SRR), a System Design Review (SDR), Key Decision Readiness Reviews (KDRRs), and In-Process Reviews (IPRs). A brief description of each is provided below.

A. The SRR is conducted to ascertain progress in defining system requirements and to evaluate the technical adequacy of those requirements. It also assesses the adequacy of mutual understanding of these requirements across the program. Management agreement on the set of system-level functions is required prior to the initiation of the functional analysis and allocation process. This review is held prior to KD-0.

B. The SDR (Conceptual) is conducted to evaluate the system requirements for adequacy and risk; ensure a mutual understanding among program participants of the system requirements and corresponding conceptual design; assess the engineering process that produced the system requirements; and provide a forum to adjudicate comments. It serves as the required technical review prior to PBCCB approval of the Conceptual Design Report (CDR), validates the CDR and System Requirements Document, and verifies that the conceptual design conforms the system requirements. This review is held prior to the KD-1 KDRR.

C. KDRRs are conducted to ensure that the Director, OCRWM has the information and assurance necessary to satisfy ESAAB and Independent Cost Estimate (ICE) program readiness prerequisites. Each KDRR will verify that these prerequisites and the programmatic requirements for the start of the next phase of the acquisition activity have been completed; the current design conforms to specified requirements; applicable QA controls and procedures related to the next phase have been developed and reviewed; and facilities and other resources will be available on schedule. The KDRRs are held prior to Key Decisions (KDs) and after the applicable SDR or project design review (discussed in the next section).

D. IPRs, or Energy Acquisition Reviews, are conducted in the event that there are no $\mathrm{KDs}$ or expanded decision points for a project in any given year. These reviews provide the Director, OCRWM with the current project status and evaluation of project costs, schedule, and technical performance against current baselines.

\subsubsection{Project-Level Reviews and Meetings}

The MRS Project will conduct the project-level reviews described briefly below. Except as noted, all reviews are applicable to all three elements (MRS Facility, Transportation, and Waste Acceptance). 
A. Milestone Reviews are conducted to ascertain the status of the technical progress, cost, schedule, and/or other project objectives. These reviews will be conducted periodically at the project manager's discretion and are usually scheduled at the completion of some predetermined project or design milestone.

B. Preliminary Design (Title I) Reviews are conducted to: (a) provide a formal review of the DRD volume for segment-level configuration items to verify their conformance with the system requirements identified in the appropriate SRD and in the IFS; (b) document the design requirements and the preliminary design; (c) evaluate the technical adequacy and risk resolution of the preliminary design; (d) provide a formal review of the physical and functional interfaces (among facilities, hardware, software, personnel and procedures) established in element and program ICDs to verify their compatibility and their conformance with the SRDs and the IFS; and (e) assess progress to determine project readiness to successfully complete the (KD-2) ESAAB Review. PDRs occur during the SAR Design Phase for the MRS element and during the Preliminary (Title I) Design Phase for the Transportation (and possibly the Waste Acceptance) element. The Director, OCRWM and the Project Manager will determine whether the PDRs will occur prior to, or to be concurrent with, the MRS element's SARDR and the Transportation (and Waste Acceptance) element's KD-2 KDRR. Completion of the PDRs and POBCCB approval of the DRDs and ICDs establish the design requirements baseline.

C. The Safety Analysis Report Design Review (SARDR) only applies to the MRS facility (within the MRS Project). The SARDR serves three functions. First, it provides a formal review of the MRS Facility's design to verify that it satisfies the applicable quality assurance, licensing, and technical requirements associated with the release of the MRS Facility License Application (LA) and associated Safety Analysis Report. More specifically, it verifies that the SAR Design (which documents those aspects of the MRS Facility design pertinent to its LA and associated SAR) conforms to the appropriate design requirements. The MRS Facility's SAR Design is documented in the structures, systems, and components important to safety. The appropriate design requirements are documented in the SAR and baselined in the MRD, DRD, and ICDs.

The second purpose of the SARDR is to verify the adequacy of the detailed design of those structures, systems, and components important to safety (as documented in the MRS Facility's SAR and baselined in the MRS CI DSs). Finally, the SARDR will occur at the end of the SAR Design Phase and prior to KD-2. The Director, OCRWM and the Project manager will determine whether the SARDR will occur prior to, or concurrent with, the KD-2 KDRR.

D. Detailed Design (Title II) Reviews (DDRs) and Final Procurement and Construction (FP\&C) Design Reviews are conducted to: (a) provide a formal review of the final design engineering documentation (CI DSs) to verify that it conforms with approved design requirements baselined in the DRD; (b) evaluate the adequacy of the detailed 
design; (c) assess design producibility and risk areas; and (d) assess progress to determine project readiness to successfully pass (KD-3) ESAAB Review.

DDRs are conducted for the MRS element during the SAR Design Phase for CI DSs for structures, systems, and components important to safety and during the FP\&C Design Phase for the remaining CI DSs. DDRs are conducted for the Transportation (and Waste Acceptance) elements during the Detailed (Title II) Design Phase. The Director, OCRWM and the Project manager will determine whether the DDRs will occur prior to, or be concurrent with, the KD-3 KDRR. Completion of the DDRs and POBCCB approval of the CI DSs establish the design configuration baseline.

E. Software Requirements Reviews are conducted to ensure that computer software requirements are complete, verifiable, and consistent and to ensure there is sufficient detail available to complete the computer software design. These reviews will be conducted, as needed, at the appropriate WBS level for that software. These reviews, if applicable to software subject to the KDRR process, will be held prior to the KD-2 KDRR.

F. Software Design Reviews (SWDRs) are conducted to ensure tha: software design documentation is independently reviewed and that the final document is approved. Test plans and procedures are reviewed to assess their adequacy. The review ensures that all requirements are correctly addressed in the software design and that the software design provides an adequate basis for the implementation activities. SWDRs will be conducted as required by the Project Manager, at the appropriate WBS level for that software, and in accordance with the OCRWM QARD and approved procedures. These reviews, if applicable to software subject to the KDRR process, will be conducted prior to the KD-3 KDRR.

G. Subcontractor/Vendor Reviews are conducted to ensure that technical efforts performed by subcontractors/vendors (under contract to provide any part of the CRWMS) are checked for adequacy and completeness. These reviews will be held by the Project and/or project participants, as needed, through all project phases.

H. Integration Working Group Reviews are conducted to serve two purposes. First, they provide an informal forum for reviewing progress on project tasks. Second, they provide a forum for engineering integration and the investigation and resolving of technical issues (a technical interchange meeting). These reviews will be scheduled at no more than 90-day intervals by the Project and/or project participants through all project phases.

I. Test Readiness Reviews (TRRs) are conducted to determine whether a participant or subcontractor is ready to begin the testing of specific CI. A TRR will be held for each CI that is to be tested. These reviews will be held for the MRS Project Manager by participant personnel, during the detailed design and construction phases of the project. 
J. Functional Configuration Audits (FCAs) will be performed to verify that development or construction has been satisfactorily completed and that the configuration items have achieved the performance and functional characteristics specified in their technical documentation. During the FCA, performance test data will be compared with the applicable design performance requirement(s). The results will be checked for completeness and accuracy. Failure of the configuration item to perform in accordance with functional requirements will be resolved by redesign and fabrication/construction or approval of a baseline change proposal to change the requirement. FCAs are to be conducted as part of the construction phase and performed using applicable quality assurance or engineering procedures.

K. Physical Configuration Audits (PCAs) are conducted to establish the final product baseline by examining the as-built CIs against physical requirements contained in the design specifications. A separate Physical Configuration Audit will be performed for each CI. These audits will be held for the MRS Project Manager by participant personnel during the construction phase. Without physical Cls, the Waste Acceptance Element will not have any physical configuration audits associated with it.

L. Formal Qualification Reviews (FQRs) are conducted to verify that the performance of the Cls, when integrated into the system, meets all system functional requirements and properly function together as a system. This review will be held for the MRS Project Manager in preparation for KD-4 KDRR.

M. Peer Reviews are conducted to evaluate work when the adequacy of information or the suitability of procedures and methods cannot otherwise be established through testing, calculations, or reference using previously accepted standards and practices. For example, a Peer Review may be called when novel or unprecedented testing, procedures, or analyses will be used. These reviews will be conducted, in accordance with applicable M\&O QAPs by technically qualified personnel who are independent of those who performed the work but who have technical expertise at least equivalent to those who performed the original work.

\subsection{REPORTING REQUIREMENTS}

It is DOE policy to have a single reporting system that provides the status of projects relative to established baselines. The MRS Project Manager will submit quarterly, supplemental, and annual reports on changes to and performance as measured against the technical, cost, and schedule baselines. Refer to the Project Management Plan for detailed reporting requirements.

\subsection{QUALITY ASSURANCE}

The quality assurance program prescribes, in part, measures to ensure that quality is achieved for items important to safety. This will be verified through audits, surveillance, and reviews using a graded QA approach. At the project level, quality affecting items are being identified and incorporated into the program. Audits include an objective evaluation of work areas, quality 
observations of activities, or reviews of documentation to evaluate compliance with approved procedures.

Throughout this SEMP references are provided to applicable M\&O QAPs that are appropriate to each topic and procedures are described. It should be noted that the QAP references provided in this plan are meant to provide guidance and are not to be considered exhaustive. Per agreement between the OCRWM Office of Quality Assurance and the M\&O, the MRS Project will follow all applicable M\&O QAPs. Nothing described in this SEMP should be construed as modifying, replacing, or limiting any applicable QA program requirements. 


\section{SYSTEMS ENGINEERING PROCESS}

This section provides a detailed description of the systems engineering process that will be implemented by the MRS Project. The systems engineering process describes the basic steps that comprise the process: functional analysis (i.e., requirements identification and allocation, and functional identification) synthesis, evaluation and decision, and the description of system elements. The system engineering process also supports the project management process by developing and controlling the technical baseline, using techniques such as configuration management. Generally, systems engineering develops a technical baseline through an iterative process of defining and redefining functional requirements into hardware, software, and construction specifications during the design process. The system engineering process set forth in DOE Order 4700.1 includes the following key steps: definition of mission need and project objectives; functional analysis; functional allocation; design synthesis (including conceptual design development); system definition; evaluation/optimization (including evaluation of alternative system configurations); and the building, testing, and demonstration of the system. This section will identify a systems engineering process specifically tailored to the MRS Project that incorporates these key steps. This section begins with an overview of the systems engineering process and its application during each of the project's phases, followed by a summary of some key program-level systems engineering results that will provide the framework for the MRS Project.

\subsection{OVERVIEW OF THE PROJECT SYSTEMS ENGINEERING PROCESS}

The systems engineering process that will be implemented by the MRS Project is consistent with that described in the OCRWM SEMP and is described in Section 2 and illustrated in Figure 4.11. As indicated in Figure 4.1-1, the systems engineering process begins with the input of requirements, which become progressively more detailed at each phase. This methodology of identifying input requirements, developing more detailed requirements, and producing technical baseline documentation incorporating the results is repeated iteratively for the Preliminary and Detailed Design Phases. This methodology incorporates the following key steps:

- Functional Analysis in which functional decompositions will be performed on the input requirements (or mission need)

- Requirements Identification and Allocation in which lower performance and regulatory requirements will be identified and allocated to the derived functions

- Design Synthesis and Integration in which design options will be identified that accommodate the derived requirements

- Evaluation and Optimization in which design options (and/or requirements allocations) will be traded off to identify the optimum design (and/or requirements allocation)

- System Definition in which the system design will be documented in text, diagrams, and models 


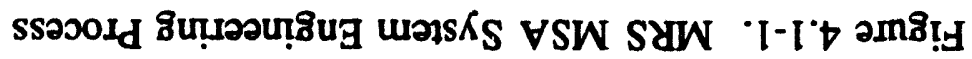
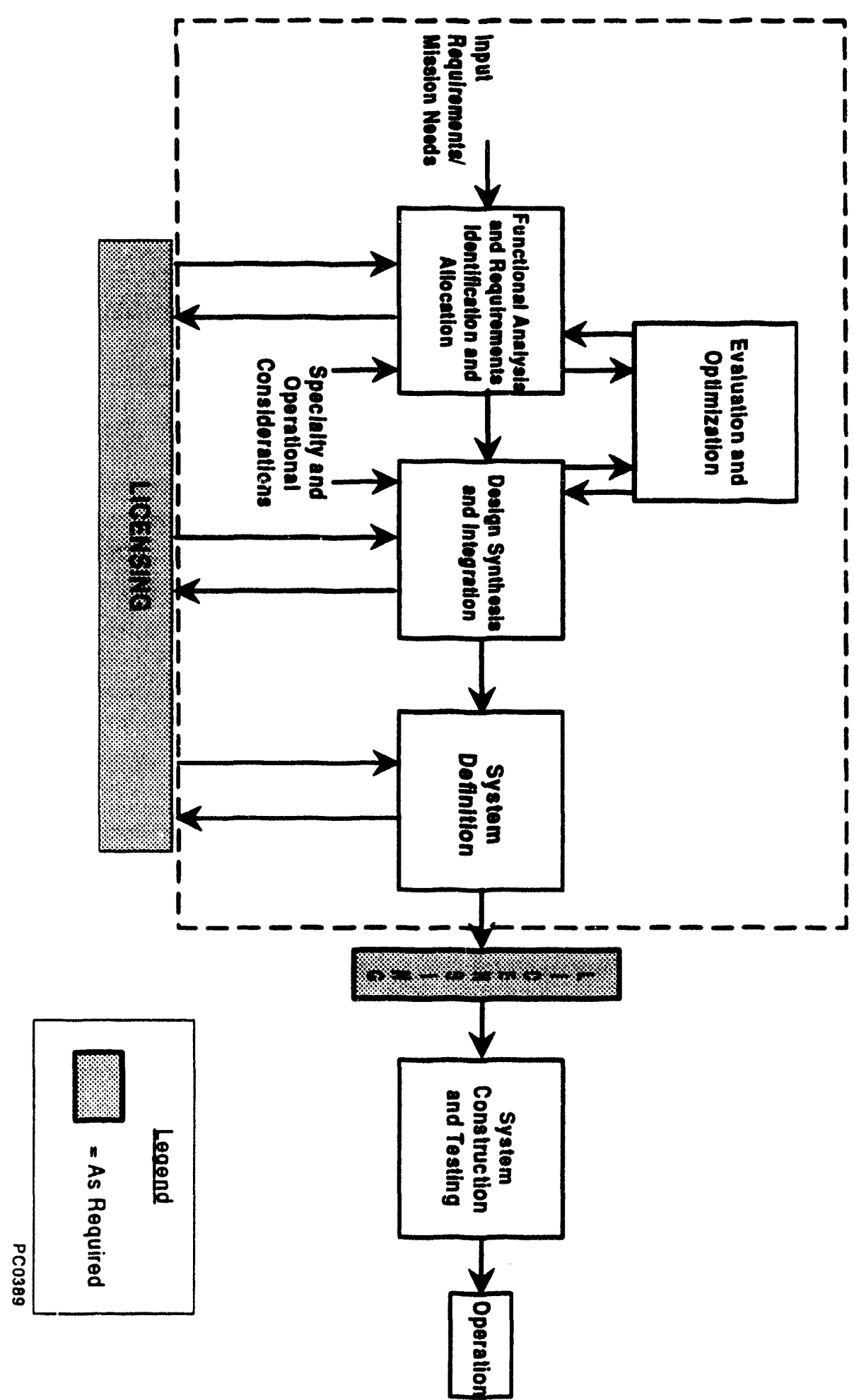
- Licensing in which integration of licensing requirements early on in the system definition process will enable preparation of an NRC-conforming MRS Facility License Application

- System Construction and Testing in which satisfaction of MRS Project requirements is ensured.

Figure 4.1-1 also shows how Specialty and Operational considerations (e.g., regulatory requirements, the results of specialty engineering studies, etc.) are integrated into the systems engineering process during the functional analysis, the requirements identification and allocation, and the design synthesis and integration steps. Once the detailed design phase is completed, the systems engineering process will include a System Construction and Testing phase, during which satisfaction of all MRS Project requirements is ensured. Since the MRS facility will require obtaining an NRC license, the systems engineering process will incorporate licensing considerations as well. This is accomplished by expanding the Requirements Identification and Allocation process (indicated in Figure 4.1-1), which is conducted for the Preliminary and Detailed Design Phases to include appropriate licensing and environmental requirements, and tailoring verification activities to ensure SAR design requirements are satisfactorily accomplished.

\subsection{FUNCTIONAL ANALYSIS}

A function is a characteristic action to be accomplished by one of the system elements. Functional analysis and requirements allocation are key components in the systems engineering process. The identification of system requirements from mission objectives and their allocation to functions, and then to facilities, hardware, or software configuration items, is one of the primary functions of systems engineering. System functions and support functions are defined in an iterative process based on the results of the mission analysis, the derived system performance requirements, and feedback from the synthesis of lower-level system elements.

Functional analysis will be performed during the Conceptual Design Phase by the Program and during the Preliminary Design and SAR Design Phases by both the Project and the Program. This functional analysis will be documented in the CRWMS Requirements Document (CRD) and the System Requirements Documents (SRDs), Interface Specification (IFS), Design Requirements Documents (DRDs), and Interface Control Documents (ICDs) that are a part of the OCRWM Document Hierarchy (see Figure 2.3-1) and MRS Project Technical Baseline Hierarchy (Figure 2.3-5). The Program functional analysis process is described in detail in the OCRWM SEMP.

The Project's functional analysis will begin in the Preliminary/SAR Design Phase and continue through the Construction Phase.

Each design phase involves functional analysis to progressively more detail. Specifically, the system-level functions identified in the CRD and element-level SRDs are those required to meet the mission objective(s). Functions identified in DRDs are those necessary to meet the systemlevel requirements of the SRDs and to establish a design specification for each Configuration Item (CI). The MRS Project CI Design Specifications (DSs) for the Transportation (and possibly the Waste Acceptance) Element will be developed during the Detailed Design phase. For the MRS Element, the SAR-related portions of the CI DS will be developed during the SAR Phase and the remaining CI DSs will be developed during the Final Procurement and Construction 
Design phase. These project-level documents complete the requirements allocation process and, thus, establish the technical baseline for construction/fabrication and testing of system equipment and facilities.

\subsubsection{Function Identification}

The MRS Project will analyze and decompose functions as contained in the SRDs to determine the specific functions that must be performed to satisfy the mission needs and objectives.

Identification of functions and subfunctions will be accomplished, in an iterative process, through the use of functional flow block diagrams (that depict function sequencing and primary relationships) and the use of $\mathrm{N}^{2}$ diagrams to identify input and output interfaces between functions. Since the functional flow block diagrams will make use of the decimal numbering system, these tools will provide traceability between higher- and lower-level functions and their associated requirements.

Program-level function identification will be accomplished in element-level SRDs prepared under the direction and control of OSC. Function identification involves further decomposing the toplevel system functions established to meet mission needs and objectives. For example, the Store Waste function has been further decomposed in the MRS SRD into three subfunctions: 1) handle SNF; 2) store SNF; and 3) support SNF Storage Operations.

Project-level functions necessary to support element design activities will be identified in DRDs by respective Project Division Directors, subject to approval by the MRS Project Office, as further levels of functions are identified via further decomposition. This process will be continued until the lowest level of detail is reached where discrete configuration item tasks can be defined, restated in hardware and engineering specification terms, readily managed, and accomplished.

\subsubsection{Functional Sequencing and Scheduling}

The functions and subfunctions identified above must be arranged in a logical sequence so that any specified operational usage of the system can be traced in an end-to-end path. Analysis will be performed to determine appropriate functional "time lines" for time-critical functional sequences crucial to mission success, safety, and utilization. The results of these analyses will be documented in time line sheets and traceability will be maintained through the use of the decimal numbering system.

\subsubsection{Specialty and Operational Considerations}

Regulatory requirements and requirements that arise from various specialty engineering disciplines will also be incorporated into the functional analysis.

\subsection{REQUIREMENTS IDENTIFICATION AND ALLOCATION}

Each of the functions and subfunctions identified in the sections above must be allocated a set of technical performance and design requirements. These requirements, derived concurrently with 
the development of the functions, performance of the system design synthesis, and evaluation of trade-off analyses, will be defined in element-level SRDs prepared under the direction of OSC. Along with the functional decomposition described in Section 4.2, every requirement and function noted in SRDs that affects the system design will be decomposed, stated in terms applicable to an engineering specification in DRDs, and eventually allocated to specific facility, hardware, or software configuration items. Allocated requirements will be traceable, via the analysis by which they were derived, to the system requirement they are designed to fulfill.

As the requirement allocation process continues, each requirement is defined within program technical documentation with more and more detail. When the requirement is to a level of detail that permits it to be stated in hardware, software routine, equipment, or construction specification terms that satisfy the needed functional/performance requirements of the CRWMS, then it is included in design configuration specifications for each $\mathrm{CI}$. The requirements analysis is usually considered complete when a further decomposition of functions or tasks does not result in additional requirements for equipment, facilities, software, or personnel.

Regulatory requirements and requirements that arise from various specialty engineering disciplines will also be incorporated into the requirements identification and allocation process.

Systems engineering tools and techniques will be used at each level to document performance requirements for each function identified at the project level and to provide traceability. Performance requirements will be stated in terms of:

- The purpose of the function

- Performance parameters

- Design constraints

- Requirements for reliability, human performance, safety, operability, maintainability, and transportability.

\subsection{EVALUATION AND OPTIMIZATION}

In accordance with the OCRWM SEMP, design evaluation and optimization activities will be performed throughout the requirements analysis and design synthesis process. Design evaluation and optimization activities include test and evaluation, and performance assessment (Section 3.2.5), life cycle cost analysis and specialty engineering (Sections 6.1 and 6.2), trade-off studies (Section 4.4.1), effectiveness analyses (Section 4.4.2), and risk evaluation and mitigation (Section 3.2.6).

\subsubsection{Trade-off Studies}

Trade-off studies will be conducted to formulate and evaluate systems alternatives and evaluation criteria. Evaluation of trade-off studies ensures that the selected alternative satisfies the allocated functional performance requirements and that documentation provides a systems engineering basis for selecting the optimum design alternative. As a formal analysis method, trade studies evolve 
with the systems acquisition process and solve complex problems involving more than one probable selection criterion, and provide for documented decision rationale. As the system matures, trade analysis will be used, where appropriate, in support of make-or-buy decisions as well as proposed design changes. In addition, trade studies will be used to aid the establishment of system configurations and to establish detailed design of individual system components. Additionally, trade studies and analyses will be used in the source selection process, test planning, logistics development, reliability, supportability, project control, LCC, and project budgeting.

Trade studies must consider all the factors that bear significantly on operational and logistical support functions of the system. Sensitivity analysis will be performed, as appropriate, in order to define the value of study results. Particular attention will be given to mathematical and/or simulation models used as measurements of system effectiveness and/or systems costs.

\subsubsection{System Cost and Effectiveness Analysis and Modeling}

System cost effectiveness analysis will be conducted on a continuous basis to ensure evolving engineering decisions, resulting from the review and analysis of system/equipment alternatives, are implemented only after determination of their impact on system effectiveness and acquisition, operation and ownership cost. System cost and effectiveness models will be employed as directed by the Project's OS\&T, subject to MRS Project Office approval, when they contribute to the decision making process. All models will be validated before their use by the Project.

\subsection{DESIGN SYNTHESIS AND INTEGRATION}

Design synthesis is the point in the systems engineering process when an optimum or preferred design concept is created to satisfy stated requirements. Under DOE Order 4700.1 , all system elements should be considered in arriving at a design concept by integrating resulting component level details into a consolidated overall design. Also, specialty engineering considerations must be identified and integrated into the design synthesis.

Synthesis is the activity that ensures all system influences are considered during the development of a design concept. During design synthesis the results of various technical studies and the requirements delineated in the functional analysis effort, including inputs from all the engineering specialty areas, are evaluated so that engineering creativity and technology are brought to hear in the creation of the system design concept.

As part of the design synthesis effort, the performance, configuration, and arrangement of the selected system, its elements, and the technique for their test support and operation, will be portrayed as a set of design criteria, schematic diagrams, models, computer simulations, layouts, detailed drawings, and operating plans. These portrayals illustrate system and item interfaces, permit traceability between the elements at various levels of system detail, and provide means for complete and comprehensive change control. For the MRS element, the results of the initial design synthesis have been described in the MRS Facility Conceptual Design Report (CDR) prepared by the MRS Project Office. Similar CDRs will be prepared for other elements of the MRS Project, as required. 


\subsection{SYSTEM DEFINITION}

The Project's architecture and design will be developed, defined, and documented in an iterative fashion that will maintain design and requirements traceability. As indicated in Figure 2.3-6, the system design and operational concept will be developed and documented in a series of Conceptual Design Reports, Preliminary Design Reports, Detailed Design Reports, and As Built Documentation. These design documents will be developed in parallel with the technical baseline (i.e., System Requirements Documents (SRDs), Design Requirements Documents (DRDs), Configuration Item Design Specifications (CI DSs), and As-Built CI DSs), and will support its development.

The Program's top-level system architecture and conceptual design is developed during the conceptual design phase and baselined in the CRD and SRDs.

During the preliminary design phase, the Project completes the identification of its element architecture and preliminary design. The element architecture is baselined in each element's DRD and each element's preliminary design (and operational concept) is documented in a Preliminary Design Report. The DRDs complete the identification of CIs and provide the design requirements for each CI's DS.

The development of the Project's baseline design is completed during the detailed design phase (or Final P.ocurement and Construction Design phase for the MRS element). This design is documented in the Detailed Design Reports and baselined in the CI DSs.

Finally, modifications to the baseline design that occur during the construction and operations phases will be documented in the As Built Documentation and become a part of the As Built Baseline through the As Built CI DSs.

\subsubsection{Design Traceability}

A documented systems engineering process must provide traceability, i.e., the ability to track a requirement to progressively higher or lower levels of documentation. Traceability includes tracking allocated design requirements (as documented in the DRDs and Interface Control Documents (ICDs) and design specifications (as documented in the CI DSs) and tracing, through the WBS, the design specifications for the lowest level of assembly to the appropriate design requirement(s), and a design requirement to the appropriate system requirement(s) (specified in the SRDs, Interface Specification (IFS), and CRD), and vice versa. In addition, traceability of systems engineering documentation ensures that the impact of changes to requirements at any level of the systems engineering documentation or program specifications can be reviewed for impact on the total system.

The technical baseline documentation (CRD, SRDs and IFS, DRDs and ICDs, and CI DSs) will identify requirements (functional, technical, design, and product) and allocate them to progressively indentured levels and to each item of the configuration hierarchy. As such, requirements traceability will be established progressively through the levels of the Project technical baseline documentation to respective configuration items. The primary tool for establishing, maintaining, and reporting requirements traceability will be the Autonated 
Requirements Management System (ARMS), an on-line computer data base management program containing the text of all technical baseline documents and cross correlation matrixes that link higher-level requirements (in higher-level documents) to lower-level requirements and configuration items (in the lower-level documents) and vice versa.

Traceability will be established and maintained by the MRS Project by allocating, prior to synthesis, ail requirements and other analytical data to MRS Project functions and identifying the requirements and data by the function number to which they pertain. Function numbers will be established as part of the functional analysis process described above. During synthesis, requirements will be allocated to MRS Project elements, subsystems, and components, which will be identified by the appropriate configuration item number(s).

Documentation of constraints and requirements allocation are essential elements of the traceability process. Design constraints and allocation of functional performance requirements to configuration items will be documented. Analyses that support these requirement allocations will also be documented. The DRDs will be developed through the systems engineering process described in the OCRWM SEMP and this document, and illustrated in Figure 4.6-1. described in the OCRWM SEMP and this document, and illustrated in Figure 4.6-1.

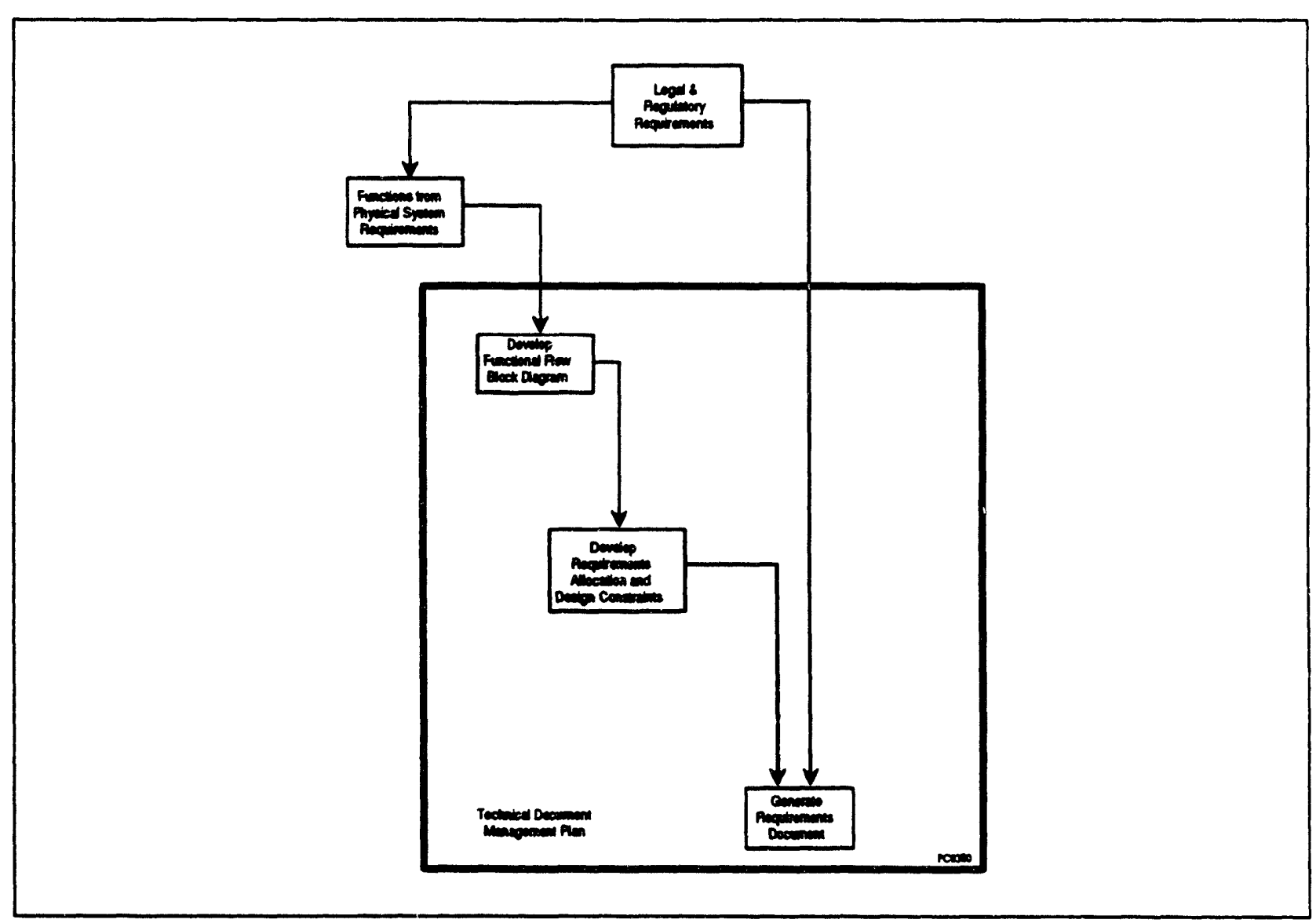

Figure 4.6-1. Requirements Document Development Process 


\subsubsection{System Specification Tree}

The systems engineering process will develop a system specification tree that relates to the technical elements of the WBS in accordance with requirements established. The specification tree will have an indentured structure, with each technical element tied to those above and below it in the architecture. It will be used to provide traceability from lower levels to upper levels, and to determine the impact of upper-level changes on lower level elements.

\subsubsection{Requirements and Specification Generation}

Many DRDs, ICDs, and CI DSs influence the achievement or verification of program configuration quality requirements and objectives. The preparation of much of the project-level technical baseline is likely to be Quality Affecting Work (QAW), which is defined in QAP-2-1 and governed by QAP-3-5. QAP-3-5 requires the preparation and approval of a Technical Document Preparation Plan (TDPP) prior to the commencement of work on a QA document. A TDPP describes the format and content of technical baseline documents. TDPPs will be prepared for all DRDs and for those ICDs, CI DSs, and AB CI DSs that are judged to be QAW under QAP-3-5. The format and content of ICDs, CI DSs, and AB CI DSs that are not covered by QAP-3-5 will follow those outlined in a generic set of non-QA TDPPs that will be prepared by the Project and will be tailored to the project's needs. Procurement and construction specifications will follow the Construction Specification Institute format.

\subsection{NRC LICENSING/SAR INTEGRATION}

Since the CRWMS Program has the additional task of obtaining NRC licenses for its major projects, the traditional systems engineering prucess must be augmented to incorporate licensing considerations by establishing a responsive interface between the licensing process and the facility design/engineering process. Establishing this interface will be accomplished by expanding the requirements process to include appropriate licensing, environmental, and institutional requirements and constraints, and tailoring the verification activity to ensure licensing and environmental activities are included. The NRC licensing requirements identified in 10 CFR Part 72, for example, must be satisfactorily accomplished. Specialty plans will be prepared, where required, to address these concerns. For example, a CRWMS Program Regulatory Guidance Document sponsoied by OCRWM's Office of System \& Compliance (OSC) and an MRS Project Regulatory Compliance Plan sponsored by OCRWM's Office of Storage and Transportation will be prepared to ensure licensing and regulatory activities are included in the verification process. 


\subsection{SYSTEM CONSTRUCTION AND TESTING}

The system construction and testing element of the system engineering process will focus on the test and evaluation management effort and the configuration management effort of the system acquisition process. Test Readiness Reviews will be conducted, and Functional Configuration Audits and Physical Configuration Audits will be performed, to ensure that the as-built configuration items meet their performance requirements and are documented in accordance with traceability requirements. A Formal Qualification Review will also be conducted to verify that the performance of the configuration items, when integrated into the system, meets all system functional requirements and properly function together as a system.

Additional information will be added to this section in future revisions of this SEMP as this information becomes available. 


\section{ELEMENT SYSTEMS ENGINEERING}

The three elements that make up the MRS Project are Waste Acceptance, Transportation, and Monitored Retrievable Storage. This section discusses how the Project systems engineering process is applied to each element: Section 5.1 addresses Waste Acceptance, Section 5.2 addresses Transportation, and Section 5.3 addresses MRS.

\subsection{WASTE ACCEPTANCE ELEMENT}

\subsubsection{Background}

Typically, the elements that define a system consist of hardware, software, facilities, personnel, and procedural data. The WA element's mission encompasses all aspects of the waste acceptance process, including SNF data collection, acceptance priority ranking, allocation of acceptance capacity, fee collection, assessment of fee adequacy, acceptance planning and scheduling, development and implementation of waste acceptance criteria and protocols, title transfer, and material control and accountability. As such, the WA element is primarily composed of personnel and procedural data attributes, and does not currently include facilities, hardware, and/or software items.

The WA element currently consists of Government-furnished items and specification items not requiring lower-level configuration management. Government-furnished items are those items that are supplied by the Government and may be existing products that are maintained under identified CRWMS functions. Specification items are acquisition items that, although they must be acquired by the Government, are standard industry items not requiring configuration management to procure. For example, standard office space can be acquired by lease or purchase without configuration management control. Since the WA element does not currently have any configuration items below the segment level, but rather only has Government-furnished items and specification items, the WA segments are by default configuration items in accordance with program-level systems engineering direction. The sections below, which discuss the typical components of a systems engineering approach tailored to the WA element, therefore treat the WA segments as configuration items.

\subsubsection{Waste Acceptance Function Tree}

An MRS Project functional analysis has been performed by each element. The WA analysis has identified the essential functions the WA element must perform. All of the WA functions, as depicted in Figure 5.1-1, are performed while interfacing with other Program entities. Thus, although the responsibilities assigned to the WA element are extensive, they all involve interface management, and the WA configuration architecture has been established accordingly. As indicated in the figure, the WA functions result in interfacing with purchasers/producers, the Transportation element, the nuclear waste fund management effort, and the Material Control and Accountability (MC\&A) data interfaces. Thus, in accomplishing the functions assigned to it, the WA element manages certain interfaces. As such, it has unique systems engineering characteristics compared to the other CRWMS elements. 


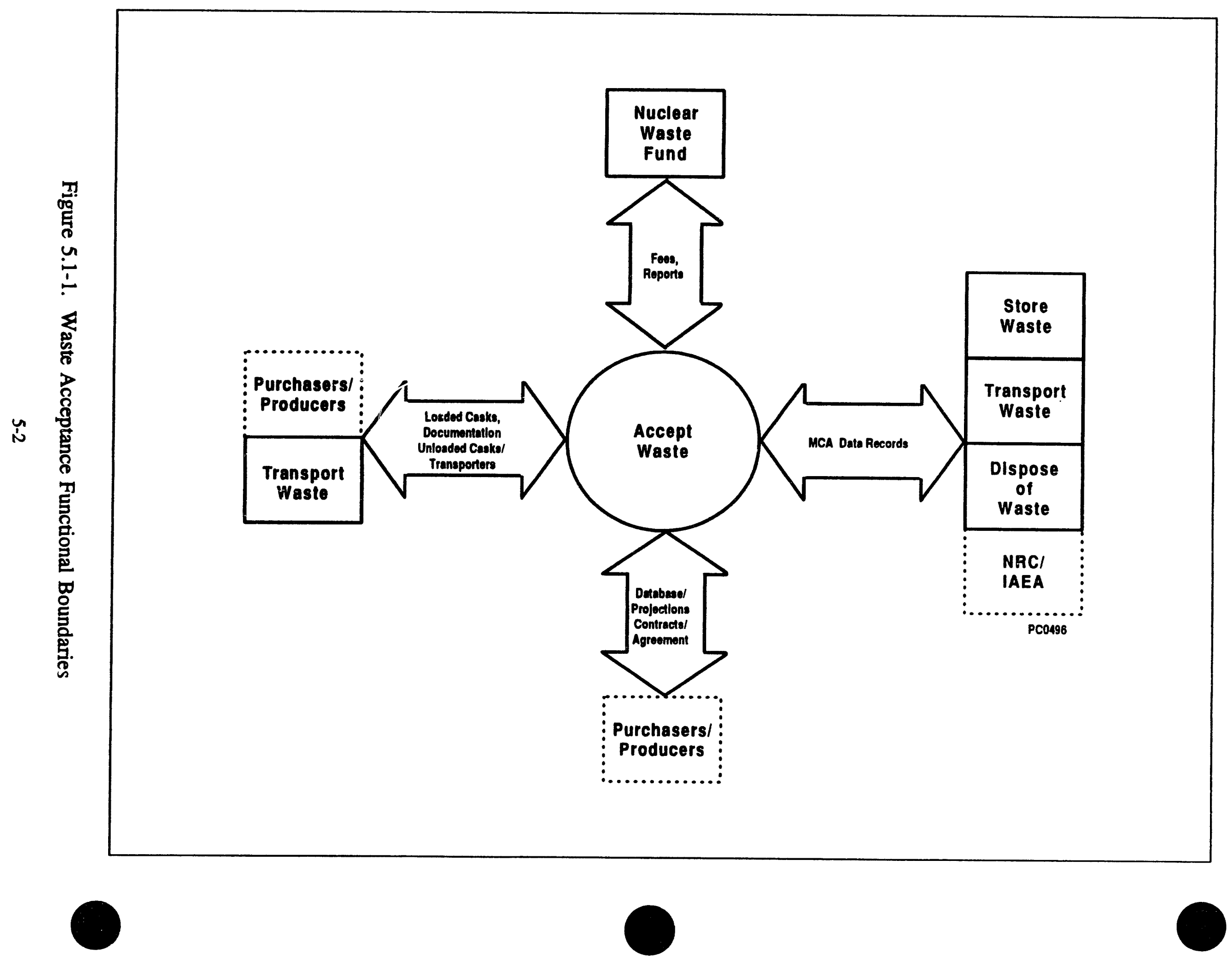


As a result of the functional analysis, the WA element must perform the following top-level functions:
1.1.1 Define Waste Acceptance Criteria
1.1.2 Establish Contracts/Agreements
1.1.3 Plan for Waste Acceptance
1.1.4 Accept Waste Custody
1.1.5 Resolve Improperly Described Waste
1.1.6 Provide Fee Collection
1.1.7 Inventory Accounting.

Figure 5.1-2 is an Accept Waste Function Tree and indicates how the identified top-level functions are further decomposed and the relationship of the functions. Having been identified, the WA functions can now be assigned technical and programmatic/regulatory requirements as the requirements are identified. With respect to the WA element, which involves managing interfaces, this requirements allocation activity is particularly important for functions that interface with functions performed by other elements of the program. For example, as depicted in the CRWMS Interface Specification (IFS), the Allocate Waste System Capacity and the Identify Waste Locations/Characteristics functions interface with all of the other CRWMS elements, namely, the MGDS, MRS, and Transportation elements. Also, the Resolve Improperly Described Waste function interfaces with the MGDS and MRS elements, while the Define Site Interface Capabilities, Observe Waste Preparations, and Accept Title/Documentation functions interface with the Transportation element. Since the responsibility of the WA element is the management of these interfacing functions, description of these functions is provided below.

The Allocate Waste System Capacity function involves allocating projected acceptance capacity to Purchasers. The Identify Waste Location/Characteristics function documents the purchasers'/producers' waste locations and characteristics. The Resolve Improperly Described Waste function involves making arrangements with the purchasers/producers to correct the waste description when a discrepancy is found in the waste during transfer operations or after OCRWM has taken title to it. The Define Site Interface Capabilities function involves determining the interface capabilities at each purchaser's/producer's site to ensure that they can be accommodated by the CRWMS equipment and facilities. The Observe Waste Preparations function involves verifying that the waste to be delivered as described in the Final Delivery Schedule is that which is loaded into the transport cask. Finally, the Accept Title/Documentation function involves transferring ownership of the waste from the purchaser/producer to the DOE.

\subsubsection{Waste Acceptance System Architecture}

To accomplish the functions described above, the systems configuration architecture indicated in Figure 5.1-3 has been developed for the WA element. The WA element consists of the following four segments depicted in Figure 5.1-3:
A. Contract/Agreement Management Segment
B. Waste Fund Management Segment 


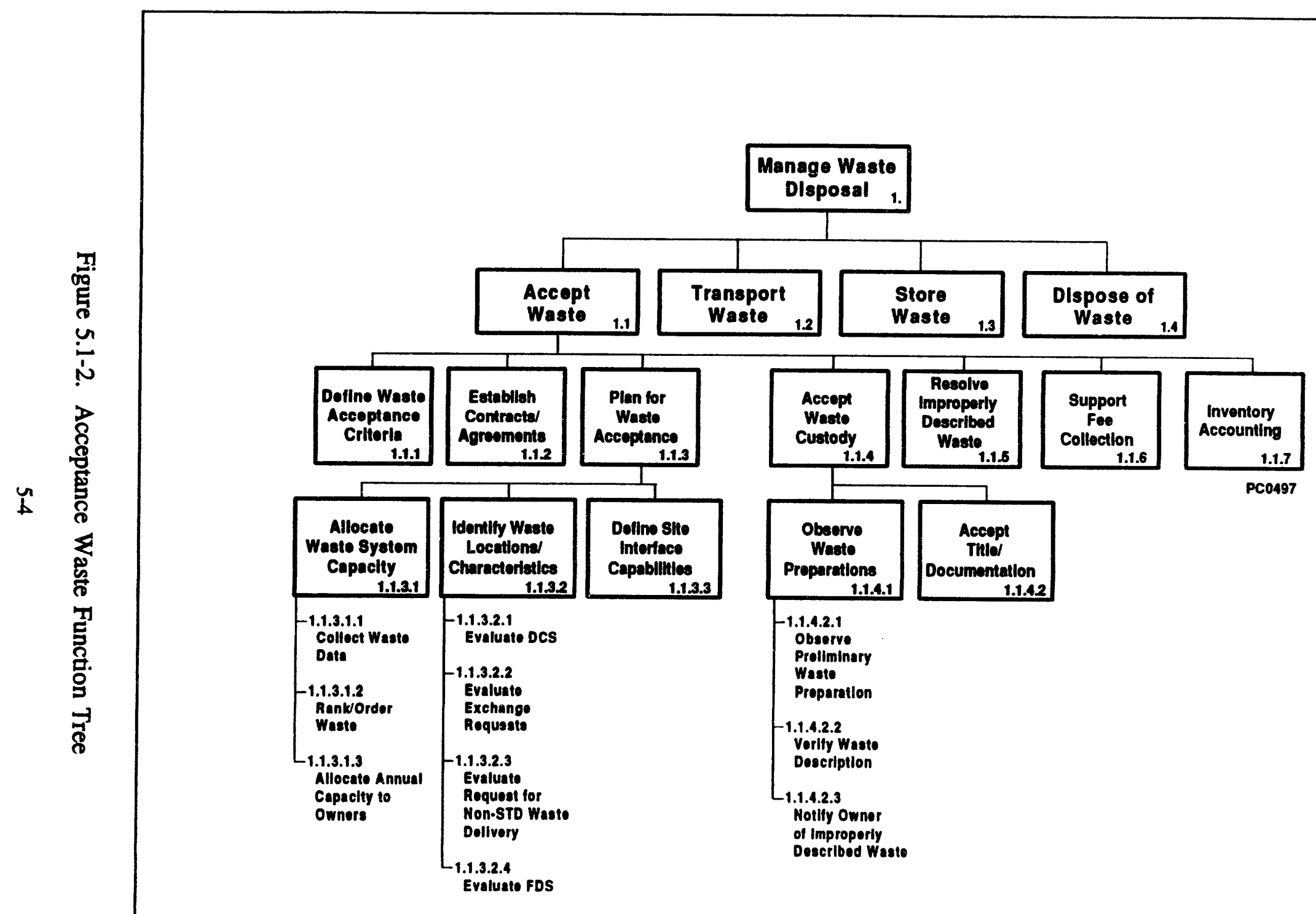



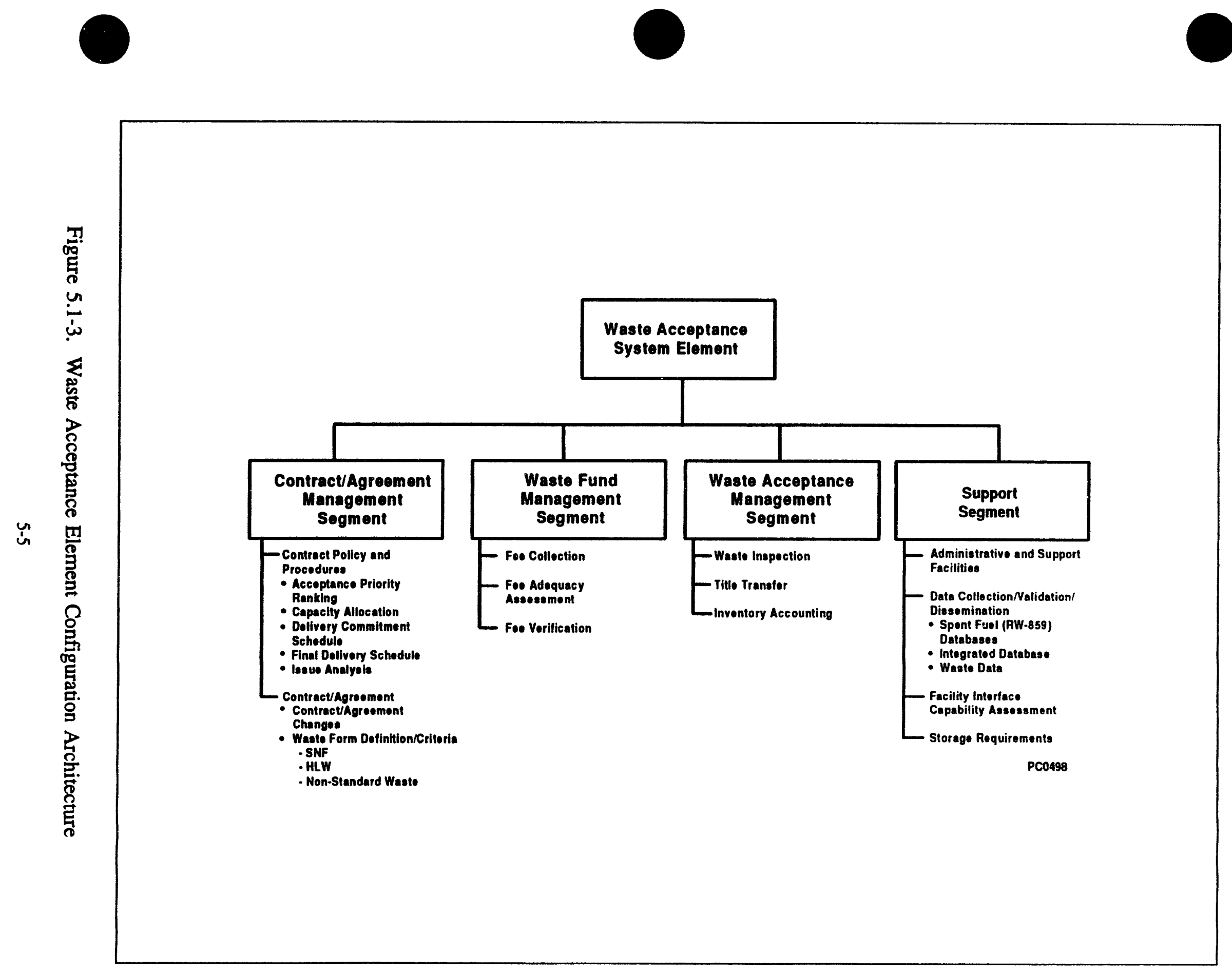
C. Waste Acceptance Management Segment

D. Support Segment.

The Contract/Agreement Management Segment primarily involves the establishment and maintenance of contracts/agreements between DOE and Purchasers/Producers. Waste acceptance criteria are developed and implemented; Delivery Commitment Schedules and Final Delivery Schedules are reviewed and approved/disapproved. Databases are managed and used to plan and schedule the acceptance of waste by DOE.

The Waste Fund Management Segment is responsible for managing the Nuclear Waste Fund, which includes managing databases for tracking fee collections, determining the adequacy of the fee paid by purchasers/producers, and conducting financial risk assessments as necessary.

The Waste Acceptance Management Segment is responsible for material control and accountability, verifying the description of SNF and HLW to be accepted, and ultimately accepting title to the SNF. MC\&A activities involve controlling and accounting for material in the CRWMS during transport, storage, and disposal operations. These activities include controliing waste inventory, surveillance of waste inventory, periodic inventory reconciliation, tracking containers, seal monitoring/controlling, and records management.

The Support Segment provides industry standard facilities, equipment, and personnel necessary to support WA planning and operation. This includes administrative and support facilities, support equipment and automated data processing equipment and management support, and records management support.

The application of the Project systems engineering process for the WA element, therefore, is tailored to manage WA interfaces and establish a framework for the requirements allocation process that is compatible with other CRWMS elements and allows for future WA expansion. Compatibility, in the Project systems engineering context, refers to a common scheme of requirements traceability via configuration identification. Should WA functional responsibilities expand in scope due to unforeseen circumstances, however, lower-level WA configuration items could easily be identified and accommodated with the approach taken.

\subsubsection{Waste Acceptance Principal Work Products}

The principal products and support activities of the WA element include maintaining Spent Nuclear Fuel Databases, the Acceptance Priority Ranking, the Annual Capacity Report, the Review and Approval of Delivery Commitment Schedules and Final Delivery Scheduies, Management of the DCS Exchange Process, the ACR Issue Resolution Process, Resolution of Contract-Related Issues through Rulemaking, the Storage Requirements Report, EIA publications funded by OCRWM (including the World Nuclear Capacity and Fuel Cycle Requirements Reports and the Spent Nuclear Fuel Discharges from U.S. Reactors Reports), Facility Interface Capability Assessment (FICA) Database Maintenance and Supporting Records, Rulemaking to Resolve Issues Related to Waste Acceptance, Procedures for Waste Verification, and Fee Adequacy Assessment. 


\subsubsection{The Waste Acceptance Acquisition Process}

The work activities conducted under the WA element primarily consist of managing already developed Government-furnished items and/or specification items, and do not consist of developing or acquiring new configuration items. Many of the activities assigned to the WA element, therefore, are managed at a level of effort type of project control, working toward the ultimate milestone of spent nuclear fuel acceptance. The status of the WA element will be reviewed as part of the Key Decision Readiness Review (KDRR) process. As such, while the WA element will not be required to develop physical designs according to the acquisition process followed by the other elements (i.e., the MRS facility conceptual, preliminary, and detailed design phases), the timing of the reviews of the WA level of effort activities will correlate with the MRS Project acquisition process phases. A WA Design Requirements Document (DRD), however, must be prepared prior to $\mathrm{KD}-2$ to enable: 1) presentation of the WA systems engineering application from a project office perspective; 2) allocation of identified requirements to WA functions; 3) allocation of WA functions and the corresponding requirements to WA segments (i.e., the WA configuration items); and, more importantly, 4) successful accomplishment of KD-2 by the MRS Project. Except for the requirement to prepare a WA DRD, accomplishing KD-2 for the WA element only signifies that level of work activities are proceeding as planned.

\subsubsection{Systems Engineering and the Waste Acceptance Element}

\subsubsection{Program-Level Systems Engineering Affecting the Waste Acceptance Element}

The CRWMS Requirements Document (CRD) identifies the top levels of the CRWMS system architecture, and functional hierarchy and begins to allocate top-level requirements to the CRWMS elements, such as the WA element. The CRD also allocates top-level system functions to the WA element.

The Waste Acceptance System Requirements Document (WA SRD) will carry the definition of the WA system architecture and function tree to the Design Requirements Baselines level by: 1) further identifying system requirements associated with the WA element; 2) decomposing the Accept Waste function, probably as depicted in Figure 5.1-2 (i.e., to level 5 in sorne cases); 3) further defining the WA element architecture to the subsystem level, if required at all; 4) allocating the functions and requirements to WA segments; 5) identifying functional interfaces; and 6) identifying which requirements, if any, need verification and the method by which they will be verified.

\subsubsection{Project-Level Waste Acceptance Systems Engineering}

The systems engineering approach outlined in Sections 2 and 4 of this MRS Project SEMP will be tailored to reflect the uniqueness of the WA element. Specifically, since the WA element is not expected to develop or acquire new hardware, facilities, or software items in the future, the WA element will prepare a DRD but will not develop Design Specifications or As-Built Design Specifications. The WA DRD will: 1) complete the definition of the WA element's systems architecture, if required due to an unexpected change in WA's work scope; 2) identify all WA configuration items, which currently are expected to be the four WA segments by default; 3 ) complete the requirements/function decomposition, identification, and allocation process; 4) 
complete the identification of intra-element interfaces, if required; and 5) identify all items of the WA element that require verification, if any.

Although not currently planned, in the event that any configuration items below the segment level are identified, the appropriate design specifications and as-built design specifications would be developed per the MRS Project systems engineering process.

\subsubsection{CIs and the WA Element}

A configuration item is an aggregation of facilities, hardware, or software (or a facility or piece of hardware or software) that performs some end function(s) and is determined by management to warrant direct configuration management and control. At this point, the WA Element itself is considered a configuration item of level 1 and each segment is considered a configuration item of level 2. Due to the non-physical nature of the WA Element, configuration items may not exist below level 2. If they do, it is unlikely that they will be identified below the subsystem level (i.e., level 3).

\subsection{TRANSPORTATION ELEMENT}

\subsubsection{Background}

The Transportation Element performs the following top-level functions:

\subsubsection{Accept Loaded Cask for Transportation}

2.1.2 Ship Waste

2.1.3 Support Waste Transport Operations.

This element, shown in the element-level specification tree in Figure 5.2-1, consists of four segments: 1) Transportation Cask System 2) Service and Maintenance Support 3) Field Operations, and 4) Planning and Control.

The Transportation Cask System Segment is further subdivided into six main areas of interest. The first item in Casks, of which there are four initiatives, namely: 1) From-Reactor, 2) FromMRS, 3) Specialty, and 4) HLW. The next three items identify equipment needed to move the casks, such as railiroad cars, special-purpose trailers, and tractor/trailer combinations in addition to other support and ancillary equipment. The last two items treat special tools and fixtures, parts, and spares that are unique to this segment.

Initial emphasis is on the development and acquisition of Initiative 1 (From-Reactor) cask systems (FRCSs). There are two "phases" associated with the development and procurement of FRCSs: Phase 1 and Phase 2. Phase 1 cask systems would be designed using proven technology (i.e., technology previously certified by the NRC) to ensure the availability of a fleet of cask systems in 1998. Phase 2 casks use innovative technology to improve cask capacity and other cask performance characteristics. In addition to the two phases described above, the use of existing or modified sxisting casks is also being investigated. 


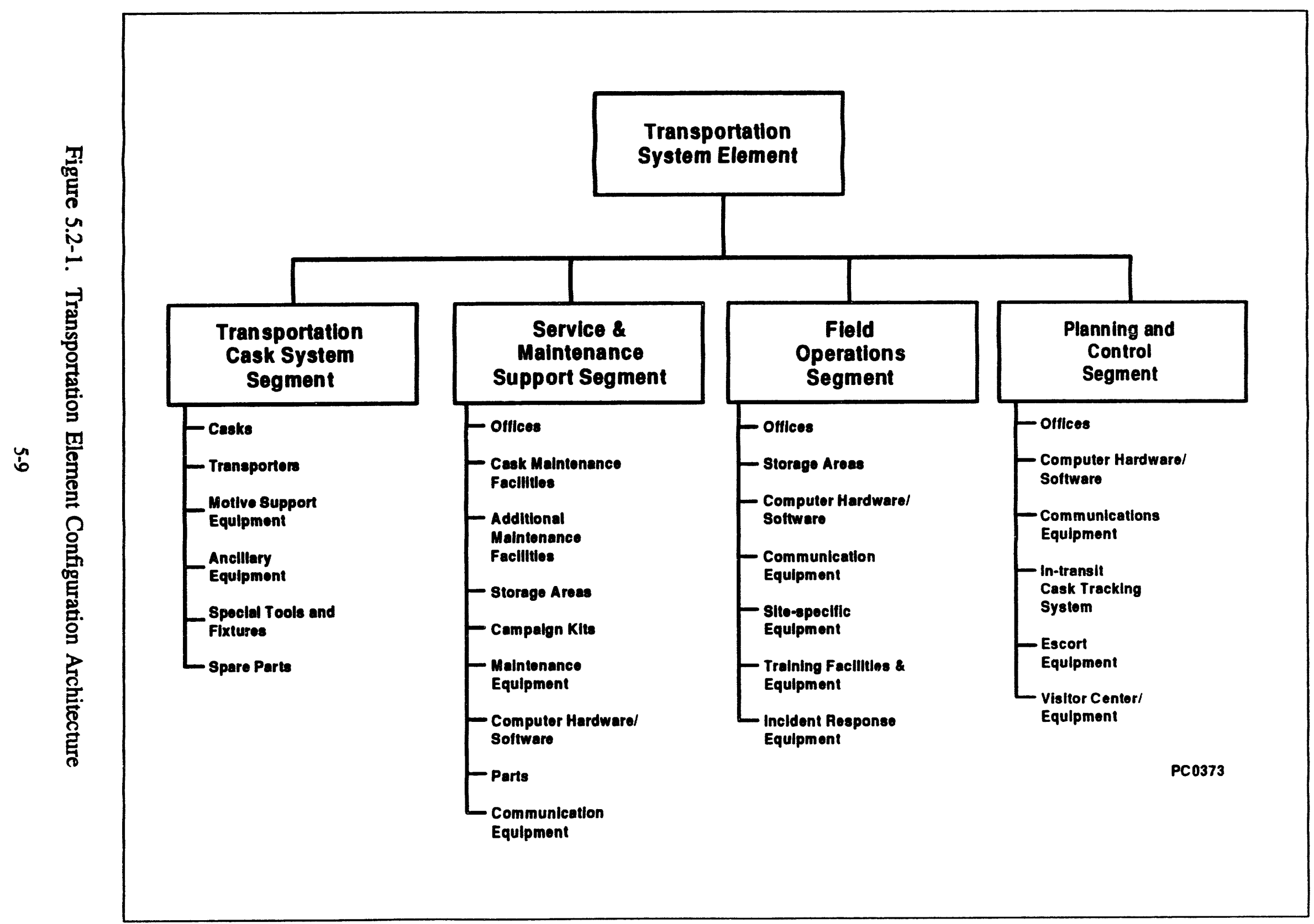


The Service and Maintenance Support Segment represents the area of interest that includes inspecting, testing, and maintaining casks and rolling stock in maintenance facilities within a given physical MRS site.

The Field Operations Segment provides support at the Purchasers' facilities where SNF is accepted. This segment will provide both training and support to the Purchasers, other CRWMS elements, OCRWM, and emergency response authorities, as necessary.

The Planning and Control Segment represents the area of interest that provides facilities (e.g., Operational Control Center), systems, equipment, and services for managing transportation operations, training waste owner and transportation personnel, procuring equipment and services, and inspecting, testing, and maintaining equipment in compliance with CRWMS requirements.

Some of the facilities and services may be developed by the project and some may be contracted out. This determination will be made during the preliminary design phase and is discussed in Section 5.2.3.

\subsubsection{The Transportation Acquisition Process}

The MRS Project is divided into six phases by virtue of its five Key Decision (KD) milestones. The "standard DOE acquisition process," represented in Figure 5.2-2, terms these six phases the Strategic Plan, Conceptual Design, Title I Preliminary Design, Title Il Detailed Design, Construction (and Testing), and Operation Phases. Although these particular activities may occur out of phase for different parts of the element (e.g., the initial four casks), it is still useful to think of the Element as generally progressing in this fashion between $\mathrm{KD}$ milestones. The important aspect of each of the design phases is the progress that is required in the requirements/design documentation. Specifically, the Conceptual Design Report, System KD1, the Design Requirements Document (DRD), and Interface Control Documents must be baselined prior to KD2, and the Configuration Item Design Specifications (CI DSs) must be baselined prior to KD3.

\subsubsection{The Transportation Cask System Segment}

The development of the Cask Systems Segment does not fall neatly into the MRS Project's "standard acquisition process." Some cask systems currently being considered are already operational, some are well on their way to detailed design, while still others are unlikely to begin even preliminary design until the MRS Project is well into detailed design (or even possibly in operation). Furthermore, the acquisition process associated with each cask system might best be divided into the following phases: conceptual design, preliminary design, detailed/SAR design, vendor fabrication and certification, and operations.

As indicated, an RFP will be issued for Phase 1 FRCSs late in the Project's conceptual design phase. The conceptual/preliminary/ detailed designs and the licensing and verification plans that are provided in the resulting proposals will be evaluated and a vendor selected. Upon selection, the vendor will obtain certification for the cask and carry out fabrication and preoperational testing in time for the FRCSs to be available to begin operation with the rest of the Project. The 


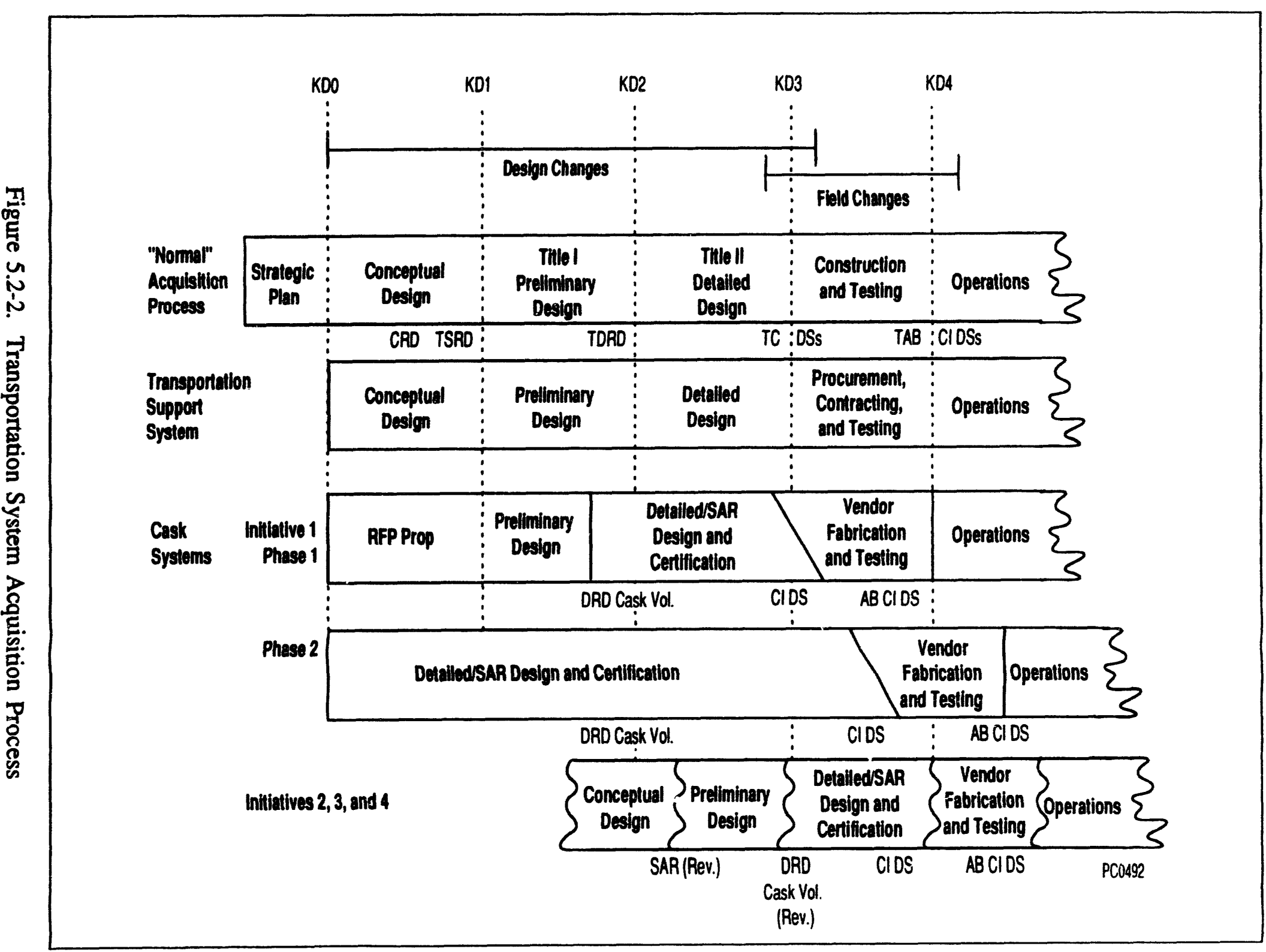


Phase 2 FRCSs are currently in the detailed/SAR design phase. Once the detailed designs are complete, certification will be obtained, the FRCSs will be fabricated and preoperationally tested, and operation will begin.

Finally, the Initiative 2, 3, and 4 cask systems will follow the standard acquisition process, but their phases will lag those associated with the Transportation Support System. At this point it is unclear what this lag will be.

\subsubsection{Other Segments}

The other transportation segments will follow the standard acquisition process through its development of DRD volumes. During DRD development, preliminary decisions will be made regarding which facilities and services will be procured and which will be developed by the project. During the Detailed Design Phase, CI DSs will be developed or obtained from vendors as needed.

\subsubsection{Systems Engineering and the Transportation Element}

The Project's application of systems engineering to the development of the Transportation Element, completes the systems engineering process outlined in the OCRWM SEMP and initiated by the Program. As such, it is appropriate to provide a brief summary of the Program transportation systems engineering activities that provide the basis for the Project Transportation systems engineering activities.

\subsubsection{Program Transportation Systems Engineering}

The CRD identifies the top-level system requirements, functions, and system architecture. It identifies Transportation as a system element and allocates top-level system requirements and functions to the Transportation Element. The Transportation System Requirements Document (SRD) carries the system definition to the conceptual design level by: further identifying system requirements associated with the Transportation Element; decomposing the Transport Waste function (to level 5 in some cases); further defining the Transportation Element architecture to the subsystem level; allocating the functions and requirements to Transportation segments; identifying functional interfaces; and identifying which requirements needed verification and the method by which they would be verified. This document will be developed late in the MRS Project Conceptual Design Phase.

\subsubsection{Project Transportation Systems Engineering}

\subsection{The Transportation Cask System Segment}

\subsection{Initiative 1 From-Reactor Cask Systems}

During the MRS Project Conceptual Design Phase, the Transportation Division developed an RFP and a Traceability Document for Phase 1 FRCSs. The RFP identifies the design requirements for the Phase 1 FRCSs and the Traceability Document traces these requirements to the Transport Waste PSR. Together these documents served as an interim SRD and DRD for Phase 1 FRCSs 
to support the release of the RFP and to guide the development of the appropriate portions of the Transportation SRD.

Early in the Project's Preliminary Design Phase, the Transportation Cask Systems Segment Volume of the Transportation DRD will be written that will complete the preliminary definition of the Phase I FRCSs. It will complete the definition of the preliminary design; identify all lower-level configuration items (if any exist); complete the requirements/function decomposition, identification, and allocation process; complete the identification intra-element interfaces; and identify all items of the Phase I FRCS that require verification. It will also include requirements associated with the engineering specialties.

The requirements identified in the RFP and the traceability established by the Traceability Document will be incorporated into the Transportation DRD as appropriate (since the Transportation DRD traces its functional and performance requirements to the TSRD rather than the PSR).

Also during the Preliminary Design Phase, the CI DSs associated with procurement of the Phase I FRCSs will be obtained from the vendors and evaluated for consistency with the Transportation DRD.

Phase 2 FRCSs will follow the same general systems engineering process as outlined for the Phase 1 FRCSs. In the late conceptual design and early, preliminary design phases, the TSRD and the Transportation DRD (respectively) will be developed to reflect the requirements that are driving the design of the Phase 2 FRCSs. Upon completion of SAR design, the CI DSs associated with the procurement of the Phase 2 FRCSs will be obtained from the vendors and evaluated for consistency with the Transportation DRD.

The Project will oversee the vendors' development of the FRCSs' preliminary design, detailed design, certification, testing, and manufacturing using the systems engineering approach described in the OCRWM SEMP and in Section 4 of this MRS Project SEMP.

\subsection{Other Cask Systems}

The Initiative 2, 3, and 4 cask systems will follow the systems engineering approach outlined in the OCRWM SEMP and in Sections 2 and 4 of this MRS Project SEMP, and described in detail for the Transportation Support System below. Since the development of the Initiative 2, 3, and 4 cask systems will lag the development of the rest of the Transportation Element, the transportation technical baseline (Transportation SRD, Transportation DRD, Transportation CI DSs, etc.) will undergo revisions as each phase of each Initiative's development is completed.

\subsection{Other Segments}

In general, the other transportation segments will follow the systems engineering approach outlined in the OCRWM SEMP and this MRS Project SEMP. This section provides a brief summary how the systems engineering methodology described in these documents will be applied to these segments (and the Transportation Element). 
During the preliminary design phase, a Transportation DRD will be written for the Transportation Element, by the project, that will complete the preliminary definition of the appropriate subsystems of the Transportation Element (i.e., the preliminary definitions of the Initiative 2-4 cask systems are not expected to be completed). The Transportation DRD will complete the definition of the preliminary element architecture; identify all appropriate Transportation Element configuration items (CIs); complete the requirements/function decomposition, identification, and allocation process; complete the identification intra-element interfaces; and identify all items of the Transportation Element that require verification. It will also include requirements associated with the engineering specialties.

During the preliminary design phase, the CIs that are identified will be brought under configuration control in accordance with the OCRWM BMP and MRS Project CMP and proposed changes to the program baseline will be managed in accordance with these plans and their related procedures. Documentation requiring program and project control will also be identified and brought under document control in accordance with the OCRWM procedures for configuration items and document identifiers. During this phase, any development, pre-operational (e.g., verification), and operational test and evaluations associated with the appropriate Transportation Element Segments will be identified and included in the MRS Project Test and Evaluation Plan. During this phase it is also likely that design tests and evaluations will be performed.

During the detail design, construction, and operational phases, control of the Transportation element's baseline configuration will continue to be established and maintained by the configuration management and document control systems and the Transportation Element will be verified.

During the detailed design phase, CI DSs will be developed for the configuration items identified in the Transportation DRD and subcontractor DSs will be examined to determine if they meet DRD requirements. During this phase it is likely that design and verification tests and evaluations will be performed.

During the construction and testing phase, the facilities and services required to begin and maintain operation will be constructed, established, and/or procured. These items will also be verification tested.

\subsection{MRS ELEMENT}

\subsubsection{Background}

The MRS Element supports the following top-level functions:

\subsubsection{Handle SNF \\ 3.1.2 Store SNF \\ 3.1.3 Support SNF Storage Operations.}

This element, shown in the element-level specification tree in Figure 5.3-1, consists of eight physical segments, which are mostly associated with facilities and hardware. The Site Development segment deals with the various issues of the development of a given site once it 


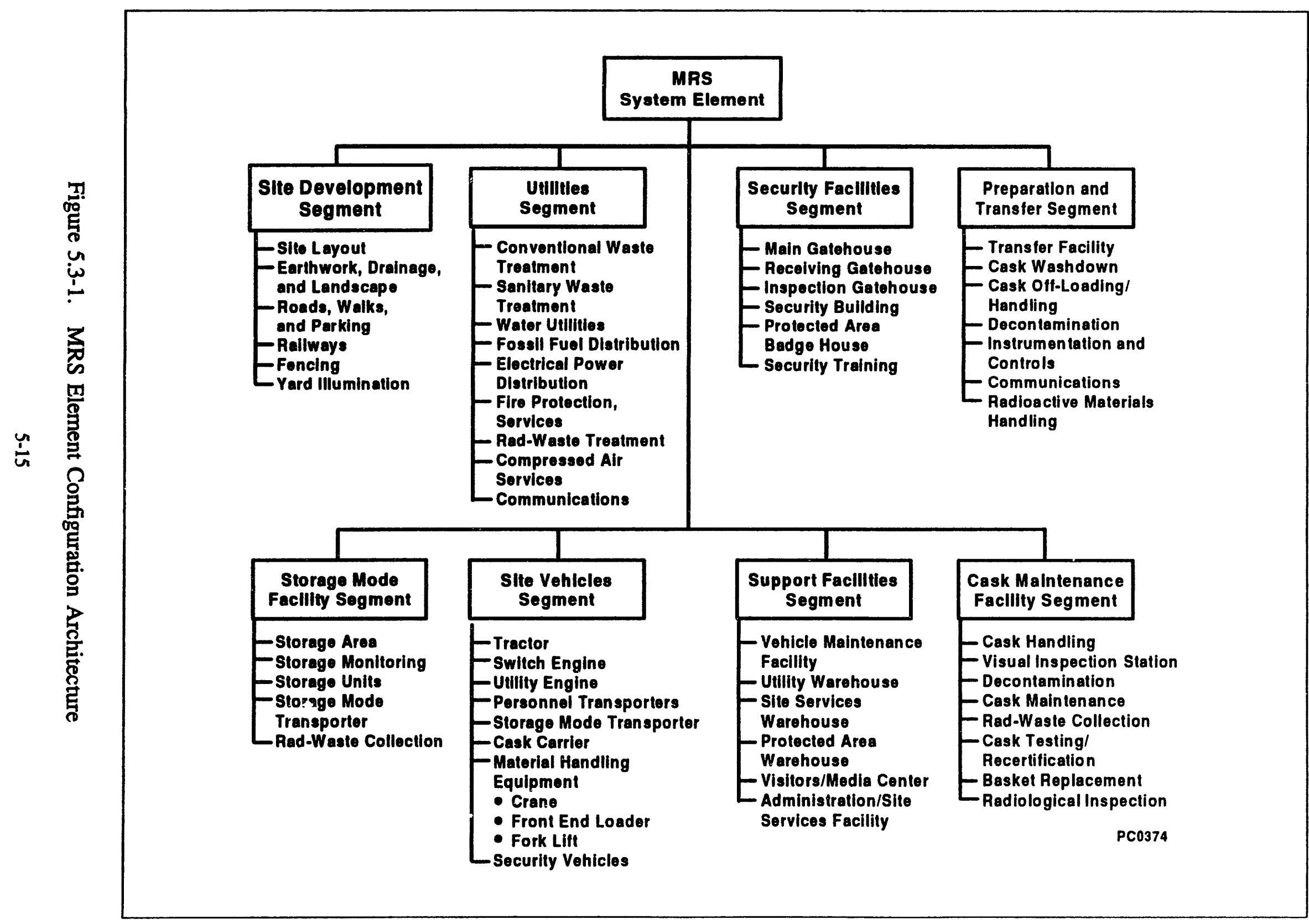


has been selected. The Utilities segment responsibilities treat conventional fuel, electrical power, sanitary waste, and other services normally encountered in the running of a factory or plant. The Security Facilities segment provides the physical protection and inspection of a secure area or set of buildings. The Processing and Transfer segment provides services unique to transit SNF and other cask types in terms of cask handling, washing and/or washdown. The segment is also responsible for special purpose instrumentation and controls, communication, and handling of other radioactive materials pertinent to the project. The Storage Mode Facility segment is responsible for areas that are suitable for spent nuclear fuel storage, its monitoring, and special purpose transporters, and other site-generated radiation waste collection. The Site Vehicles segment handles all forms of "vehicles" used for motive power, tractors, railroad engines, transportation, as well as security vehicles. The Support Facilities segment is responsible for buildings, such as warehouses, maintenance facilities, visitor/media centers, and administrative/ site facilities. The Cask Maintenance Facility segment provides maintenance services for casks, including special handling, inspection, decontamination, testing/recertification, and other specific tasks unique to radiological waste. In summary, the MRS System Element is assigned the mission to provide all specific and related services relative to the temporary storage of SNF awaiting disposal in a geologic repository. The primary activities associated with this segment include: receiving and placing into storage SNF from civilian nuclear reactors; allowing for monitoring and managing of SNF while in storage; providing for ready retrieval of stored SNF; and preparing SNF for shipment to the geologic repository.

\subsubsection{The MRS Element Acquisition Process}

The MRS Element's acquisition process differs from the "normal DOE process" as indicated in Figure 2.3-6. It consists of the following five phases: Conceptual Design, SAR Design, Final Procurement and Construction Design, Construction, and Operation. These five phases are separated by the four Project Key Decision Milestones: KD1, KD2, KD3, and KD4. The MRS System Requirements Document (SRD) and a Conceptual Design Report (CDR) must be completed prior to KD1. The MRS Design Requirements Document (DRD), Safety Analysis Report (SAR), required Configuration Item Design Specifications (CI DSs), SAR Design, and configuration item Preliminary Design Reports (PDRs) must be completed prior to KD2. The remaining CI DSs must be completed prior to $\mathrm{KD} 3$ and the As-Built CI DSs must be completed and verified prior to Operation. Figure 2.3-6 also indicates the licensing activities that will run parallel to the design activities.

\subsubsection{Systems Engineering and the MRS Element}

The Project's application of systems engineering to the development of the MRS Element, completes the systems engineering process outlined in the OCRWM SEMP and initiated by the Program. As such, it is appropriate to provide a brief summary of the Program MRS systems engineering activities that provides the basis for the MRS Element systems engineering activities.

\subsubsection{Program MRS Systems Engineering}

The CRD identifies the top-level system requirements, functions, and system architecture. It identifies MRS as a system element and allocates top-level system requirements and functions to the MRS Element. The MRS SRD carries the system definition to the conceptual design level 
by: further identifying system requirements associated with the MRS Element; decomposing the Store Waste function (to level 5 in some cases); further defining the MRS Element architecture to the subsystem level; allocating the functions and requirements to MRS segments; identifying functional interfaces; and identifying which requirements needed verification and method by which they would be verified.

\subsubsection{Project MRS Systems Engineering}

In general, the MRS Element will follow the systems engineering approach outlined in the OCRWM SEMP and in Sections 2 and 4 of this MRS Project SEMP. This section provides a brief summary how the systems engineering methodology described in these documents will be applied to the MRS Element.

Systems Engineering will play a key role in the development of the three principal products of the MRS Element's SAR Design Phase: the MRS DRD, the SAR-related CI DSs, and the MRS NRC License Application (including the SAR Design).

The License Application Annotated Outline identifies the information required by the NRC to grant a license for the construction and operation of the MRS Facility. The licensing requirements identified by this document will guide the development of the DRD and the selection of Cls, and in the identification of those CI DSs that must be completed during the SAR Design phase as a part of the SAR.

The MRS DRD will complete the preliminary definition of the MRS Element. Specifically, it will complete the definition of the preliminary element architecture; identification of MRS Element configuration items; requirements/function decomposition, identification, and allocation process; identification intra-element interfaces; and identification of MRS Element items that require verification. The DRD completes the preliminary definition of the MRS Element that was started in the MRS SRD, and it will trace its architecture and functional and performance requirements to this SRD.

The MRS Element's SAR design phase contains elements of both the preliminary and final design. In accordance with 10 CFR Part 72.146(a) (1988), during this phase specifications will be developed for those structures, systems, and components important to safety. These specifications will be developed to meet the requirements of and reflect the design basis identified in the DRDs and required by the LA. This will be accomplished by taking information from the DRD and DSs developed during this phase and incorporate it as appropriate for the LA. Because the DRDs and DSs will be developed concurrently with the LA, DOE and contractor organizations responsible for licensing will work closely with the design organizations to ensure that all necessary information will be available at the end of the phase.

The CIs identified during the SAR design phase will be brought under configuration control in accordance with the OCRWM BMP and MRS Project CMP, and proposed changes to the program baseline will be managed in accordance with these plans and their related procedures. Documentation requiring program and project control will also be identified and brought under document control in accordance with the OCRWM Baseline Management Procedure for Configuration Items (CI) and CI Identifiers and the OCRWM Baseline Management Procedure 
for Document Identifiers. Also during this phase, any development, pre-operational (e.g., verification), and operational test and evaluations associated with the MRS Element will be identified and included in the MRS Project Test and Evaluation Plan.

If a site is not identified by KD1, work on the MRS DRD and SAR Design will be focused on those aspects of the MRS Element that are independent of site.

During the Final Procurement and Construction (FP\&C) Design Phase, the remaining, non-SARrelated CI DSs will be developed, reviewed, and approved. During the FP\&C Design and operational phases, control of the MRS Element's baseline configuration will continue to be established and maintained by the CM and document control systems and the MRS Element will be verified. 


\section{ENGINEERING INTEGRATION}

The development of a complete MRS Project technical baseline requires the integration of more than the traditional engineering disciplines (e.g., civil, mechanical, electrical, etc.). It also requires the integration of both Engineering Specialties (e.g., Logistics, Reliability/Availability/ Maintainability, Life Cycle Cost, Human Factors, Security, Safety, etc.) and Programmatic Specialties (represented by Regulatory Compliance, Environmental, Socioeconomic, and Institutional Programs). This section describes all of these specialties, their impact on the technical baseline, the plans for the development of the associated documentation, and how these specialties will be integrated into the technical baseline. To this end, engineering specialties are discussed in Sections 6.1 and 6.2, programmatic specialties are discussed in Section 6.3, and concurrent engineering is discussed in Section 6.4 .

\subsection{LIFE CYCLE COST}

Although Life Cycle Cost (LCC) analysis is often treated as a specialty engineering discipline, it is of such importance to the program and project that it will be treated separately in this SEMP.

The Program's Total System Life Cycle Cost (TSLCC) is an estimate of the cost of the system over its entire life cycle, through decommissioning of the facilities. Since the LCC of major program acquisitions are essentially "fixed" by the end of preliminary design, it is important to establish these cost estimates early in preliminary design. The MRS Project will provide input to the Program's TSLCC efforts and develop an MRS Project Life Cycle Cost (PLCC) estimate that includes the MRS, Transportation, and Waste Acceptance elements.

LCC analysis will not end with this baseline MRS PLCC. LCC management continues through all phases of a system's life. During the design phases, the PLCC will be continually updated to reflect approved changes in the technical, cost, or schedule baselines or the impact of additional design details. LCC studies will also be conducted to support design trade-offs, to reduce cost risks, and to estimate the impact of proposed changes to the baseline. In the construction and operations phases, LCC studies will be performed to determine if proposed design changes will reduce or contain cost.

In order to guide the project in these efforts, the project will prepare and implement an MRS Project LCC Plan early in the preliminary design phase. Once completed, this plan will be appended to this MRS Project SEMP and updated as needed.

The MRS Project LCC Plan will identify and describe the LCC program. Specifically it will identify and describe the program's tasks, milestones, deliverables, and responsibilities; policies, procedures, and structures for maintaining LCC visibility and control; recommended goals and allocation procedures; methods for determining and identifying LCC cost drivers and issues subject to trade-off analyses; planned LCC models, analyses methods, and modeling techniques to be employed; data sources and output descriptions; the management approach for integrating LCC efforts into project and technical management activities, including description of WBS or cost element structure; relationship of LCC to RAM and logistics support analysis; planned 
feedback mechanism for tracking and supporting cost-related design goals and status; and subcontractor relationships. An annotated outline of the MRS PLCC Plan will be developed and maintained to provide LCC Estimate documentation.

Table 6.1-1 shows the general system methodology that will be employed by the MRS Project in its LCC analysis process. Using the MRS element as an example, the baseline for the MRS facility will be established during the conceptual design phase. During the phase in which a final procurement configuration (FPC) is established, the LCC effort will be directed toward updating and maintaining a corresponding LCC baseline from which all project decisions can be measured. Equally important to the LCC analysis process is the identification of those system requirements and design features that are identified as cost drivers. Logistics planning will be established to support cost reduction efforts. LCC modeling of alternative designs and systems concepts will be conducted to guide the MRS Project Office in the decision making process. Due to the critical nature of operations and maintenance activities, as well as the extended life cycle of the project, LCC impacts of design decisions will be accessed to ensure that the engineering alternatives being considered to reduce acquisition costs do not have support costs that would more than offset their initial savings.

\subsection{SPECIALTY ENGINEERING INTEGRATION}

This section identifies and describes the engineering specialty efforts that will be integrated into the systems engineering process for the MRS Project. These efforts include: integrated logistics support (ILS); reliability, availability, and maintainability (RAM); human factors engineering; system safety engineering; system safeguards and security engineering; personnel and training; value engineering; and constructability/producibility analysis.

In general, a concurrent engineering approach will be used to ensure coordination of the engineering specialties and their integration in the system engineering process. This approach requires participation by specialty engineers throughout the preliminary design, detailed design, construction and testing, and operational phases of the acquisition process. To ensure that the impact of these specialties is properly considered, an MRS Project Engineering Specialty Plan (ESP) will be developed under the direction of the Project Office early in the preliminary design phase. This Project ESP will describe how the guidance provided by the Program ESP will be implemented by the MRS Project. Early consideration of the design impact of these specialties will also support the MRS Project LCC efforts. Once completed, this plan will be appended to this MRS Project SEMP and updated as needed.

The Project ESP will contain one chapter devoted to each of the eight engineering specialties. Each chapter will describe how that specialty will be integrated into the design effort. In the sections that follow, each of these specialty engineering disciplines will be described in more detail. 


\begin{tabular}{|c|c|c|c|c|c|c|}
\hline \multicolumn{7}{|c|}{ Project Life Cycle Cost Methodology } \\
\hline Aefivitinen & $\begin{array}{l}\text { Concopplual Dosign } \\
\text { \& Systom Dofitintion }\end{array}$ & SAR Dosign & $\begin{array}{c}\text { Final Procuremont } \\
\text { Configuration } \\
\text { Denian }\end{array}$ & Construction & Testing & Operations \\
\hline $\begin{array}{l}\text { Cost Control } \\
\text { Trecting }\end{array}$ & 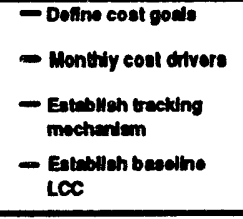 & 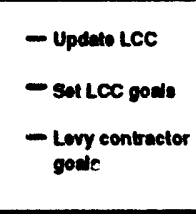 & 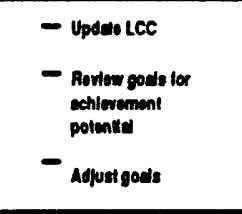 & 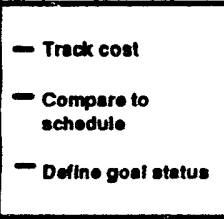 & 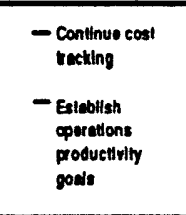 & 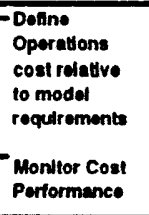 \\
\hline Evaluations & 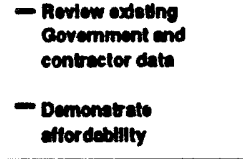 & 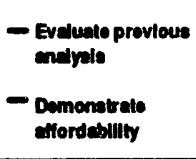 & 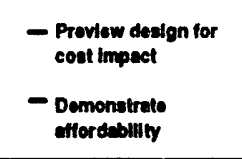 & 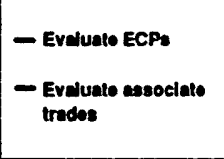 & 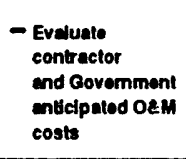 & 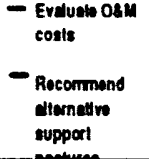 \\
\hline $\begin{array}{l}\text { Treddio } \\
\text { Studioe }\end{array}$ & 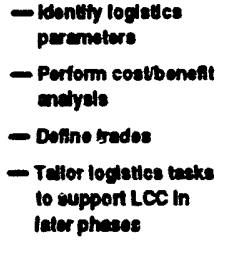 & 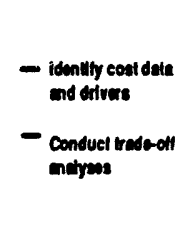 & 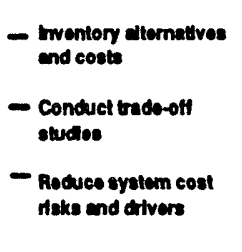 & 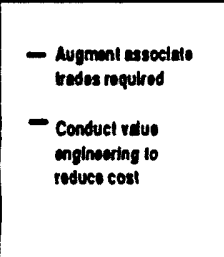 & 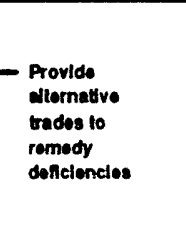 & 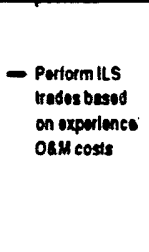 \\
\hline 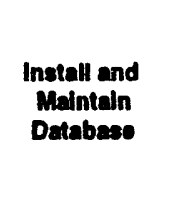 & 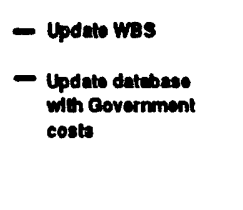 & 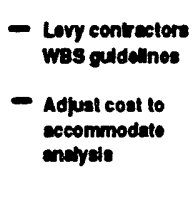 & 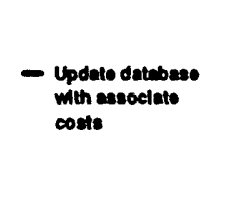 & 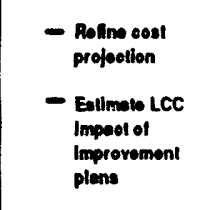 & 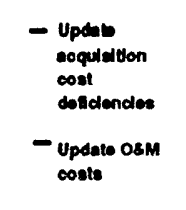 & 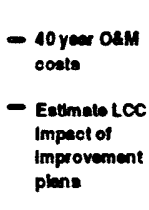 \\
\hline
\end{tabular}




\subsubsection{Logistics Engineering}

The principal objectives of the MRS Project ILS program are to ensure that the required support and readiness characteristics are designed into the MRS Project Elements and that resources necessary for project readiness are identified and available when required. To achieve these objectives, readiness and supportability requirements must be defined and included in the system and subsystem specifications, and considered in the formal review process prior to key decisions (reliability and maintenance requirements are addressed in the RAM section). The ILS chapter of the Project ESP will provide the detailed plan for how ILS will be integrated into the MRS design and LCC efforts, and will be consistent with the ILS program described in the Program ESP.

An ILS program identifies the support resources required to ensure that the MRS Project System Elements are ready to begin and maintain full operations when scheduled and ensures that these support resources are in place when needed. It identifies attainable supportability characteristics and ensures that they are integrated into the design of the MRS Project Elements. The ILS program accomplishes this throughout the design and construction phases, through design tradeoffs involving all applicable logistics disciplines. The logistics disciplines include maintenance planning, personnel, training, technical documentation, supply support, support equipment, computer resources support, facilities, packaging, handling, storage, and transportation support.

A logistics support analysis will be conducted to examine the MRS Project system elements to determine the logistics support required to keep these elements useable for their intended purpose during the system's entire design life. This analysis will include: consideration of a computeraided acquisition and logistics system to aid in electronic data transfer between project and customer functions; provisioning for full documentation of vendor and parts data; supply support with respect to spares, repair parts, support equipment, and consumables; and tecinical documentation in terms of technical manuals and drawings for operation and maintenance. Each element of the ILS process will be integrated with all the other elements, including feedback loops to system design factors, to ensure a fully integrated project level logistics support and design process.

A formal list of logistics support analysis tasks will be finalized and documented in the ILS Chapter of the MRS Project ESP. The scope of the logistics support analysis will be guided by the OCRWM SEMP, Program technical baseline documentation, and DOE Order 4700.1 .

\subsubsection{Computer-Aided Acquisition and Logistics}

The logistics support analysis process will also consider standardized collection and recording of logistic and supportability data to be maintained in automated logistics support analysis records. A computer-aided acquisition and logistics system, or its equivalent, will be employed to aid in electronic transfer of data between project and customer functions, and to provide greater flexibility in the use of data for supportability analysis and simulation modeling of performance characteristics. 


\subsubsection{Provisioning and Supply Support}

Provisioning and supply support will be critical activities in the early phases of the MRS Project having significant influence on the budgetary allocation effort and will ensure supplies are available when they are required. In addition, provisioning data are needed for maintenance concept development, technical data, and logistics support analysis.

The MRS Project provisioning effort will provide full documentation of vendor data to allow for competitive procurement of required parts and supplies; verification of parts quality to meet quality assurance program requirements; identification of alternate sources of supply to avoid sole source procurement; parts data to allow future re-procurement in the event current vendors are unavailable; database of all parts and equipment in the MRS Project system elements for certification - recertification requirements; identification of parts usage for economic ordering; and identification of parts locations for purposes of upgrading, enhancements, or modifications.

Supply support encompasses the management actions, procedures, and techniques used to determine requirements to acquire, catalog, receive, store, transfer, issue, and dispose of secondary supply items. Supply support planning encompasses the following: spares, repair parts, support equipment, and consumables.

\subsubsection{Technical Documentation (Technical Manuals/Drawings)}

The technical documentation portion of the ILS Chapter will describe how documentation requirements will be provided to system users/operators, maintenance personnel, regulators, and MRS Project management.

As with other ILS functional areas, technical data and documentation requirements will result primarily from the LSA process. Operation and Maintenance (O\&M) requirements, O\&M task analysis, O\&M task summaries, and personnel and support requirements provide the basic data necessary to prepare technical manuals and training materials. Where appropriate, commercial manuals will be used to provide operators and maintenance personnel with technical documentation. However, the unique requirements of the MRS Project will require development of special operations and maintenance technical manuals. All technical documentation to be used with the operational system will undergo specific validation and verification processes prior to release with the operational system.

\subsubsection{Reliability, Availability, and Maintainability Engineering}

The project will establish and manage a RAM program to ensure the MRS Project is designed to meet its stringent reliability requirements and its long-term maintainability and availability objectives. The Project RAM program will address the MRS facility, the Transportation and the Waste Acceptance elements, and will be described in the Project ESP. It will also be consistent with program-level RAM program established in the Program ESP. Since RAM factors will have a major impact on the project's design and requirements, it is important that they be addressed in the early project design stages as well as throughout the project life cycle. 
A number of analysis tools will be used to model, predict, and evaluate MRS RAM compliance with critical project requirements. Two specific tools that are available for use by the project include TRW's Reliability, Availability, and Maintainability Analysis (RAMA) model and Simulation Language for Alternative Modeling (SLAM). RAMA may be used to develop reliability block diagrams for the project and model inherent RAM characteristics to support the establishment of design requirements. The SLAM simulation tool may be used to model some of the dynamic features of the MRS Project and to analyze the system's operational RAM attributes.

\subsubsection{Human Factors Engineering}

The human factors engineering (HFE) portion of the Project ESP will describe how the programlevel HFE guidance described in the Program ESP will be implemented at the project level. HFE ensures that applicable requirements are incorporated into the technical baseline, and that decisions and actions affecting the waste management system do not adversely affect the health and safety of the public and workers or the quality of the environment.

HFE ensures that the technical baseline is developed with an awareness of the nature and limits of human capabilities as they relate to the chezk-out, operation, maintenance, or control of systems or equipment. Consideration of HFE reduces the potential for human error in system operation and ensures system safety, operational efficiency, ease of maintainability, and reliability. HFE activities include: identifying HFE implications of regulations and codes; deriving system design requirements and specifications that take into account human physical and cognitive capabilities and limitations; assisting in the allocation of functional requirements to humans and the development of human/human and human/machine interfaces; ensuring that HFE considerations are adequately reflected in project training programs; and participating as an integral part of technical reviews and audits. HFE will be addressed throughout the design process (starting early in the preliminary design phase). It will identify ways to optimize compatibility between system items and human performance, identify design options that achieve the objectives of system safety, operational efficiency, and RAM, and perform trade-off studies to evaluate options and optimize system performance with respect to human factors.

\subsubsection{Safeguards and Security Engineering}

In accordance with the Program SEMP, the Program ESP will describe how the Safeguards and Security (S\&S) program will be implemented by the Project. The purpose of the S\&S program is to establish and maintain adequate safeguards (including physical security) to protect nuclear materials, program facilities, and essential program records (including site characterization data, test results, licensing documentation, etc.). The Program ESP will identify S\&S issues that affect the development of the technical baseline including the need for S\&S related requirements, specifications, and conformance verification methods. The Program ESP will also identify suggested conformance verification methods.

The MRS Facility's NRC License Application provides a specific example of the type of information that will be included in the S\&S portion of the Program ESP. 10 CFR Part 72, requires that the MRS Facility License Application include four security-related documents: (1) an MRS Facility Physical Security Plan required under 10 CFR \$72.180 (1988); (2) an MRS 
Facility Safeguards Contingency Plan required under 10 CFR $\$ 72.184$ (1988); (3) the MRS Facility Design for Physical Protection required under 10 CFR \$72.182 (1988); and (4) the MRS Facility Guard Training Plan specified in 10 CFR \$72.186(a) (1988).

Additional information on Project-level compliance with Program-level requirements will be added to this section in future revision of this SEMP as this information becomes available.

\subsubsection{System Safety Engineering}

In accordance with the Program SEMP, the Program ESP will describe how the System Safety (SS) program will be implemented by the Project and integrated into engineering and verification processes. The purpose of the S\&S program is to ensure that potential hazards are systematically identified, potential consequences analyzed, and reasonable efforts to eliminate, control, or mitigate the hazards have been taken. The SS program will interface with the regulatory compliance program described in Section 5.3. This interface will ensure that all aspects of safety are addressed, particularly the provision for engineering support for the preparation of the Safety Analysis Report, which accompanies NRC license applications.

Additional information on Project-level compliance with Program-level requirements will be added to this section in future revisions of this SEMP as this information becomes available.

\subsubsection{Value Engineering}

The purpose of the Value Engineering portion of the Project ESP is to describe the process by which the MRS designs' cost effectiveness will be evaluated and improved. Value Engineering is described in the MRS Facility Conceptual Design Report. The plan will be developed early in the preliminary design phase and updated as needed.

\subsection{PROGRAMMATIC SPECIALTIES}

Systems engineering will work in coordination with project management and representatives from the various "programmatic specialties" to ensure that design impacts associated with these programmatic specialties are identified during the preliminary design phase so thit they can be effectively integrated into the design of the MRS Project. This interaction will include participation by systems engineering and programmatic specialty organizations in the development and review each others plans and procedures, participation in POICWGs, and the establishment of frequent interface.

The principal programmatic specialty planning documents are appendixes to the MRS PMP and will be prepared under the direction and control of the MRS Project Office (with one noted exception). Brief descriptions of these documents are provided below.

A. The MRS Facility Siting Plan (Volume 4 of the PMP), to be developed by the project, will include strategies and contingency plans for obtaining an MRS site and for performing site investigation activates. Since these activities will have a significant 
impact on MRS Project design and cost and schedule baselines, systems engineering will work with project management to ensure that the technical impacts of these activities are effectively managed.

B. The Regulatory Guidance Document (RGD) will be developed by the Program to identify licensing and permitting requirements associated with NRC and various Federal, State, and local environment, safety, and health regulations and provide a general strategy for obtaining these permits. The Project will develop an MRS Project Regulatory Compliance Plan (RCP), PMP Volume 10, that will describe how the general strategy outlined in the RGD will be implemented by each project element.

The RGD would document how the LA Annotated Outline (described in Section 4.8 of this SEMP) was being used to expedite the NRC approval of the MRS Facility's NRC License. This SEMP describes how this process is being integrated into the design effort.

C. The Environmental, Safety, and Health Protection Implementation Plan (ESHPIP), PMP Volume 11 , is required by DOE Order 4700.1 . It will define the specific actions that will be taken by the project to comply with existing environmental, safety, and health directives.

D. The MRS Environmental Management Plan (EMP), PMP Volume 12, will be prepared by the Project that provides a road map for the sequencing and development of environmental plans, activities, and program elements related to the MRS Facility.

E. The MRS nal Plan (PMP Volume 13) will identify groups affected by the MRS and Trans. Elements and their issues and concerns; develop communications strategies; $\mu_{n} \ldots$, and programs; and provide guidance as to how outreach will be integrated into all MRS Project efforts. Other institutional considerations will be handled by respective design organizations as directed by the MRS Project Uffice.

F. The MRS Socioeconomic Program Plan (PMP Volume 14) will provide supporting details of the methodologies and data requirements for the identified socioeconomic studies, and describe socioeconomic monitoring and mitigation activities. The plan will be developed under the direction and control of OSC during the preliminary design phase. The Director of the Office of External Relations will prepare a Socioeconomic Policy and Requirements Document; determine the need for supporting plans; and ensure those plans are consistent with the Socioeconomic Policy and Requirements Document.

G. The Transportation Plan (PMP Volume 15) will provide an overviev of the OCRWM national transportation program and its three major elements: 1) cask design and development; 2) planning for transportation operations and the development of support facilities and services; and 3 ) institutional interactions. 


\subsection{CONCURRENT ENGINEERING}

One classical technique used for designing systems is to have the various engineering disciplines (civil, structural, mechanical, electrical, etc.) complete a design and then have that design reviewed by the representatives from the various engineering specialties identified in Sections 6.1 and 6.2. As a result of this review, both major and minor modifications to the design may be required. The complexities and time constraints associated with the MRS Project make the use of such a classic technique untenable.

Recently a technique named "concurrent engineering" has been widely applied to projects with significant time constraints. Concurrent engineering calls for the continuing involvement of representatives from all design impacting specialties throughout the acquisition process, from conceptual design through operations. Classically, these "specialties" have been the engineering specialties identified in Sections 6.1 and 6.2. However, in the case of the MRS Project, its design may also be influenced by the results of the various programmatic specialty activities described in Section 6.3. As such, for the purposes of the MRS Project, the scope of the term "concurrent engineering" will broadened to include the activity of representatives from both the engineering and programmatic specialties throughout the design process.

Specialty engineering activities will be performed and integrated into the design effort as a part of the Project's systems engineering activities. Programmatic activities, on the other hand, will be performed outside systems engineering. As such, repiesentatives from these disciplines will be asked periodically to identify potential design impacts of their activities throughout the design phases (beginning early in the preliminary design phase).

By using concurrent engineering principles to include representatives from the specialty engineering and programmatic specialty disciplines throughout the design process, the number of costly design modifications that may be required late in design (or during construction and operation), as the result of a late input from one of these disciplines, can be significantly reduced. 
INTENTIONALLY LEFT BLANK 
APPENDIX A

ACRONYM LIST 


\section{ACRONYM LIST}

$\begin{array}{ll}\text { ARMS } & \text { Automated Requirements Management System } \\ \text { BMP } & \text { Baseline Management Plan } \\ \text { C\&SB } & \text { Cost and Schedule Baseline } \\ \text { CDR } & \text { Conceptual Design Report } \\ \text { CFR } & \text { Code of Federal Regulations } \\ \text { CI DS } & \text { Configuration Item Design Specification } \\ \text { CM } & \text { Configuration Management } \\ \text { CMP } & \text { Configuration Management Plan } \\ \text { CRD } & \text { CRWMS Requirements Document } \\ \text { CRWMS } & \text { Civilian Radioactive Waste Management System } \\ & \\ \text { DDR } & \text { Detailed Design Review } \\ \text { DOE } & \text { Department of Energy } \\ \text { DRD } & \text { Design Requirements Document } \\ \text { DS } & \text { Design Specification } \\ & \\ \text { EH-1 } & \text { Office of Environment, Safety, and Health } \\ \text { EM-1 } & \text { Office of Environment Restoration and Waste Management } \\ \text { EPA } & \text { Environmental Protection Agency } \\ \text { ESAAB } & \text { Energy System Acquisition Advisory Board } \\ \text { ESP } & \text { Engineering Specialty Plan } \\ \text { FICA } & \text { Facility Interface Capacity Assessment } \\ \text { FCA } & \text { Functional Configuration Audit } \\ \text { FQR } & \text { Formal Qualification Review } \\ \text { FP\&C } & \text { Final Procurement and Construction } \\ \text { FRCS } & \text { From Reactor Cask System } \\ & \\ \text { GC-1 } & \text { Office of General Counsel } \\ & \\ \text { HLW } & \text { High Level Waste } \\ \text { HFE } & \text { Human Factors Engineering } \\ \text { HR } & \text { Headquarters Review } \\ \text { ICD } & \text { Interface Control Document } \\ \text { ICWG } & \text { Interface Control Working Group } \\ \text { IFS } & \text { Interface Specification } \\ \text { IIS } & \text { Integrated Logistics Support } \\ \text { IPR } & \text { In-Process Review } \\ \text { KD } & \text { Key Decision } \\ \text { KDRR } & \text { Key Decision Readiness Review } \\ & \\ & \end{array}$




\begin{tabular}{|c|c|c|}
\hline LA & $\begin{array}{l}\text { License Application } \\
\text { Life Cvcle Cost }\end{array}$ & \\
\hline LCC & Life Cycle Cost & \\
\hline $\mathrm{M} \& \mathrm{O}$ & Management and Operating & \\
\hline MR & Milestone Review & \\
\hline MRS & Monitored Retrievable Storage & \\
\hline MSA & Major System Acquisition & \\
\hline NWPA & Nuclear Waste Policy Act & \\
\hline NWPAA & Nuclear Waste Policy Amendments Act & \\
\hline NEPA & National Environmental Policy Act & \\
\hline NRC & Nuclear Regulatory Commission & \\
\hline OCRWM & Office of Civilian Radioactive Waste Management & RW-1 \\
\hline OST & Office of Storage and Transportation & RW-40 \\
\hline & Storage Division & RW-42 \\
\hline & Facilities Development Branch & RW-421 \\
\hline & Project Management Branch & RW-422 \\
\hline & Transportation and Logistics Division & RW-43 \\
\hline & Transportation Branch & RW-431 \\
\hline & Logistics and Utility Interface Branch & RW-432 \\
\hline OS\&T & Office of Storage and Transportation (M\&O) & \\
\hline PBCCB & Program Baseline Change Control Board & \\
\hline PCA & Physical Configuration Audit & \\
\hline PDR & Preliminary Design Review & \\
\hline PLCC & Project Life Cycle Cost & \\
\hline PMP & Project Management Plan & \\
\hline PMSM & Program Management Systems Manual & \\
\hline РОВСCB & Project Office Baseline Change Control Board & \\
\hline POICWG & Project Office Interface Control Working Group & \\
\hline PR & Project Review & \\
\hline PR-1 & Office of Procurement & \\
\hline PSR & Physical System Requirements & \\
\hline QA & Quality Assurance & \\
\hline QAP & Quality Assurance Procedure & \\
\hline QARD & Quality Assurance Requirements Document & \\
\hline RAM & Reliability, Availability, and Maintainability & \\
\hline RAMA & Reliability, Availability, Maintainability Analysis & \\
\hline RFP & Request for Proposal & \\
\hline RMP & Risk Management Plan & \\
\hline SAR & Safety Analysis Report & \\
\hline SARDR & Safety Analysis Report Design Review & \\
\hline SDR & System Design Review & \\
\hline
\end{tabular}




$\begin{array}{ll}\text { SEMP } & \text { Systems Engineering Management Plan } \\ \text { SLAM } & \text { Simulation Language for Alternative Modeling } \\ \text { SOW } & \text { Statement of Work } \\ \text { SNF } & \text { Spent Nuclear Fuel } \\ \text { SRD } & \text { System Requirements Document } \\ \text { SRR } & \text { System Requirements Review } \\ \text { STPS } & \text { Summary Task Planning Sheets } \\ \text { SWDR } & \text { Software Design Review } \\ \text { SWRR } & \text { Software Requirements Review } \\ & \\ \text { T\&E } & \text { Test and Evaluation } \\ \text { T\&EP } & \text { Test and Evaluation Plan } \\ \text { TDPP } & \text { Technical Document Preparation Plan } \\ \text { TEMP } & \text { Test and Evaluation Master Plan } \\ \text { TPM } & \text { Technical Performance Measurement } \\ \text { TRR } & \text { Test Readiness Review } \\ \text { TSDD } & \text { Transportation System Description Document } \\ \text { TSLCC } & \text { Total System Life Cycle Cost } \\ & \\ \text { WA } & \text { Waste Acceptance } \\ \text { WAD } & \text { Work Authorization Directive } \\ \text { WBS } & \text { Work Breakdown Structure }\end{array}$




\section{APPENDIX B}

DOCUMENT DEVELOPMENT 
Table B1. Assignment Matrix for Technical Baseline Documentation

\begin{tabular}{|c|c|c|c|c|c|}
\hline Step ${ }^{1}$ & $\begin{array}{l}\text { Associated } \\
\text { Baseline }^{2}\end{array}$ & Document Name & $\begin{array}{l}\text { OCRWM } \\
\text { Sponsor }\end{array}$ & $\begin{array}{l}\text { M\&O } \\
\text { Responsibility }\end{array}$ & $\begin{array}{l}\text { Approval } \\
\text { Authority }\end{array}$ \\
\hline Step 1 & $\begin{array}{l}\text { Functional } \\
\text { Baseline } \\
\text { (A Spec) } \\
\text { (Program Level) }\end{array}$ & $\begin{array}{l}\text { CRWMS Requirements Document (CRD) } \\
\text { - Overall }\end{array}$ & $\begin{array}{l}\text { Office of } \\
\text { Systems and } \\
\text { Compliance }\end{array}$ & $\begin{array}{l}\text { Systems Engineering } \\
\text { Office }\end{array}$ & $\begin{array}{l}\text { PBCCB } \\
\text { Chairman }\end{array}$ \\
\hline Step 2 & $\begin{array}{l}\text { Technical } \\
\text { Requirements } \\
\text { Baseline } \\
\text { (A Specs) } \\
\text { (Program Level) }\end{array}$ & $\begin{array}{l}\text { System Requirements Documents (SRDs) } \\
\text { - Waste Acceptance } \\
\text { - Transportation } \\
\text { - MRS }\end{array}$ & $\begin{array}{l}\text { Office of } \\
\text { Systems and } \\
\text { Compliance }\end{array}$ & $\begin{array}{l}\text { Systems Engineering } \\
\text { Office }\end{array}$ & $\begin{array}{l}\text { PBCCB } \\
\text { Chairman }\end{array}$ \\
\hline & & Interface Specification (IFS) & $\begin{array}{l}\text { Office of } \\
\text { Systems and } \\
\text { Compliance }\end{array}$ & $\begin{array}{l}\text { Systems Engineering } \\
\text { Department }\end{array}$ & $\begin{array}{l}\text { PBCCB } \\
\text { Chairman }\end{array}$ \\
\hline
\end{tabular}

1 Steps in the system engineering process.

${ }^{2}$ Refer to Figure 2.3-6 in document. 
Table B1. Assignment Matrix for Technical Baseline Documentation (Continued)

\begin{tabular}{|c|c|c|c|c|c|}
\hline Step ${ }^{1}$ & $\begin{array}{l}\text { Associated } \\
\text { Baseline }^{2}\end{array}$ & Document Name & $\begin{array}{l}\text { OCRWM } \\
\text { Sponsor }\end{array}$ & $\begin{array}{l}\text { M\&O } \\
\text { Responsibility }\end{array}$ & $\begin{array}{l}\text { Approval } \\
\text { Authority }\end{array}$ \\
\hline \multirow[t]{3}{*}{ Step 3} & $\begin{array}{l}\text { Design } \\
\text { Requirements } \\
\text { Baseline } \\
\text { (Project Level) }\end{array}$ & $\begin{array}{l}\text { Design Requirements Documents (DRDs) } \\
\text { - Waste Acceptance } \\
\text { - Transportation } \\
\text { - MRS }\end{array}$ & $\begin{array}{l}\text { Office of } \\
\text { Storage and } \\
\text { Transportation } \\
\text { Division } \\
\text { Directors }\end{array}$ & OS\&T & $\begin{array}{l}\text { POBCCB } \\
\text { Chairman }\end{array}$ \\
\hline & & $\begin{array}{l}\text { Intra-Element ICDs } \\
\text { - Waste Acceptance ICDs } \\
\text { - Transportation ICDs } \\
\text { - MRS ICDs }\end{array}$ & $\begin{array}{l}\text { Office of } \\
\text { Storage and } \\
\text { Transportation } \\
\text { Division } \\
\text { Directors }\end{array}$ & OS\&T & $\begin{array}{l}\text { POBCCB } \\
\text { Chairman }\end{array}$ \\
\hline & (Program Level) & $\begin{array}{l}\text { Inter-Element Interface Control } \\
\text { Documents (ICDs) } \\
\text { - MRS - Trans } \\
\text { - WA - Trans } \\
\text { : MGDS - Trans } \\
\text { : WA - MRS } \\
\text { - MGDS - MRS } \\
\text { - WA - MGDS }\end{array}$ & $\begin{array}{l}\text { Office of } \\
\text { Systems and } \\
\text { Compliance }\end{array}$ & $\begin{array}{l}\text { Systems Engineering } \\
\text { Department }\end{array}$ & $\begin{array}{l}\text { PBCCB } \\
\text { Chairman }\end{array}$ \\
\hline
\end{tabular}

\footnotetext{
${ }^{1}$ Steps in the system engineering process.

2 Refer to Figure 2.3-6 in document.
} 
Table B1. Assignment Matrix for Technical Baseline Documentation (Continued)

\begin{tabular}{|c|c|c|c|c|c|}
\hline Step ${ }^{1}$ & $\begin{array}{l}\text { Associated } \\
\text { Baseline }^{2}\end{array}$ & Document Name & $\begin{array}{l}\text { OCRWM } \\
\text { Sponsor }\end{array}$ & $\begin{array}{l}\text { M\&O } \\
\text { Responsibility }\end{array}$ & $\begin{array}{l}\text { Approval } \\
\text { Authority }\end{array}$ \\
\hline Step 4 & $\begin{array}{l}\text { Design } \\
\text { Configuration } \\
\text { Baseline } \\
\text { (Project Level) }\end{array}$ & $\begin{array}{l}\text { CI Design Specifications } \\
\text { (CI DSs) W } \\
\text { - Waste Acceptance CIs } \\
\text { - Transportation CIs } \\
\text { MRS Cls }\end{array}$ & $\begin{array}{l}\text { Office of } \\
\text { Storage and } \\
\text { Transportation } \\
\text { Division } \\
\text { Directors }\end{array}$ & OS\&T & $\begin{array}{l}\text { POBCCB } \\
\text { Chairman }\end{array}$ \\
\hline Step 5 & $\begin{array}{l}\text { As-Built } \\
\text { Baseline } \\
\text { (Project Level)) }\end{array}$ & $\begin{array}{l}\text { AB Ci DSs } \\
\text { - Waste Acceptance CIs } \\
\text { - Transportation CIs } \\
\text { - MRS CIs }\end{array}$ & $\begin{array}{l}\text { Office of } \\
\text { Storage and } \\
\text { Transportation } \\
\text { Division } \\
\text { Directors }\end{array}$ & OS\&T & $\begin{array}{l}\text { POBCCB } \\
\text { Chairman }\end{array}$ \\
\hline Source: & \multicolumn{5}{|c|}{ Program Management Systerns Manual (PMSM) Rev. 5, Preliminary Draft, Assignment matrix, and other information. } \\
\hline
\end{tabular}

'Steps in the system engineering process.

2 Refer to Figure 2.3-6 in document. 
Table B2. Assignment Matrix for Selected PMP- Related Documentation

\begin{tabular}{|c|c|c|c|c|}
\hline Vol \# & Document Name & $\begin{array}{l}\text { OCRWM } \\
\text { Sponsor }\end{array}$ & $\begin{array}{l}\text { M\&O } \\
\text { Responsibility }\end{array}$ & $\begin{array}{l}\text { Approval } \\
\text { Authority }\end{array}$ \\
\hline 1 & $\begin{array}{l}\text { MRS Project } \\
\text { Management Plan }\end{array}$ & $\begin{array}{l}\text { MRS } \\
\text { Project Office }\end{array}$ & OS\&T & $\begin{array}{l}\text { OCRWM } \\
\text { Director }\end{array}$ \\
\hline 2 & $\begin{array}{l}\text { MRS Project WBS/ } \\
\text { WBS Dictionary }\end{array}$ & $\begin{array}{l}\text { MRS } \\
\text { Project Office }\end{array}$ & OS\&T & $\begin{array}{l}\text { MRS MSA } \\
\text { Project Office }\end{array}$ \\
\hline 3 & $\begin{array}{l}\text { MRS Project Cost \& } \\
\text { Schedule Baseline Document }\end{array}$ & $\begin{array}{l}\text { MRS } \\
\text { Project Offic }\end{array}$ & OS\&T & РОВСCВ \\
\hline 4 & $\begin{array}{l}\text { MRS Facility } \\
\text { Siting Plan }\end{array}$ & $\begin{array}{l}\text { MRS } \\
\text { Project Office }\end{array}$ & OS\&T & $\begin{array}{l}\text { MRS MSA } \\
\text { Project Office }\end{array}$ \\
\hline
\end{tabular}


Table B2. Assignment Matrix for Selected PMP- Related Documentation (Continued)

\begin{tabular}{|c|c|c|c|c|}
\hline Vol.\# & Document Name & $\begin{array}{l}\text { OCRWM } \\
\text { Sponsor }\end{array}$ & $\begin{array}{l}\text { M\&O } \\
\text { Responsibility }\end{array}$ & $\begin{array}{l}\text { Approval } \\
\text { Authority } \\
\end{array}$ \\
\hline 7 & $\begin{array}{l}\text { MRS Project Test } \\
\text { \& Evaluation Plan } \\
\text { (MRS, WA, \& } \\
\text { Transportation) }\end{array}$ & $\begin{array}{l}\text { MRS } \\
\text { Project Office }\end{array}$ & $\begin{array}{l}\text { OS\&T, Systems } \\
\text { Engineering Office }\end{array}$ & $\begin{array}{l}\text { POBCCB } \\
\text { Chairman }\end{array}$ \\
\hline 8 & $\begin{array}{l}\text { MRS Project } \\
\text { Information Resource } \\
\text { Management Plan }\end{array}$ & $\begin{array}{l}\text { MRS } \\
\text { Project Office }\end{array}$ & OS\&T & $\begin{array}{l}\text { POBCCB } \\
\text { Chairman }\end{array}$ \\
\hline 9 & $\begin{array}{l}\text { MRS Project Advanced } \\
\text { Acquisition Plan }\end{array}$ & $\begin{array}{l}\text { MRS } \\
\text { Project Office }\end{array}$ & OS\&T & $\begin{array}{l}\text { POBCCB } \\
\text { Chairman }\end{array}$ \\
\hline 10 & $\begin{array}{l}\text { MRS Project Regulatory } \\
\text { Compliance Plans } \\
\text { (NRC, non-NRC) }\end{array}$ & $\begin{array}{l}\text { MRS } \\
\text { Project Office }\end{array}$ & OR\&L & $\begin{array}{l}\text { POBCCB } \\
\text { Chairman }\end{array}$ \\
\hline 11 & $\begin{array}{l}\text { MRS Environmental, } \\
\text { Safety, and Health } \\
\text { Protection Implementation } \\
\text { Plan }\end{array}$ & $\begin{array}{l}\text { MRS } \\
\text { Project Office } \\
\text { (OST) }\end{array}$ & OR\&L & $\begin{array}{l}\text { POBCCB } \\
\text { Chairman }\end{array}$ \\
\hline
\end{tabular}


Table B2. Assignment Matrix for Selected PMP- Related Documentation (Continued)

\begin{tabular}{|c|c|c|c|c|}
\hline Vol \# & Document Name & $\begin{array}{l}\text { OCRWM } \\
\text { Sponsor }\end{array}$ & $\begin{array}{l}\text { M\&O } \\
\text { Responsibility }\end{array}$ & $\begin{array}{l}\text { Approval } \\
\text { Authority }\end{array}$ \\
\hline \multirow[t]{4}{*}{5} & $\begin{array}{l}\text { MRS Project Systems } \\
\text { Engineering Management } \\
\text { Plan }\end{array}$ & $\begin{array}{l}\text { MRS } \\
\text { Project Office }\end{array}$ & OS\&T & $\begin{array}{l}\text { POBCCB } \\
\text { Chairman }\end{array}$ \\
\hline & $\begin{array}{l}\text { MRS Project Risk } \\
\text { Management Plan }\end{array}$ & $\begin{array}{l}\text { MRS } \\
\text { Project Office }\end{array}$ & OS\&T & $\begin{array}{l}\text { POBCCB } \\
\text { Chairman }\end{array}$ \\
\hline & $\begin{array}{l}\text { MRS Project Life Cycle } \\
\text { Cost Plan }\end{array}$ & $\begin{array}{l}\text { MRS } \\
\text { Project Office }\end{array}$ & OS\&T & $\begin{array}{l}\text { POBCCB } \\
\text { Chairman }\end{array}$ \\
\hline & $\begin{array}{l}\text { MRS Project Engineering } \\
\text { Specialties Plan }\end{array}$ & $\begin{array}{l}\text { MRS } \\
\text { Project Office }\end{array}$ & OS\&T & $\begin{array}{l}\text { POBCCB } \\
\text { Chairman }\end{array}$ \\
\hline 6 & $\begin{array}{l}\text { MRS Project Configuration } \\
\text { Management Plan }\end{array}$ & $\begin{array}{l}\text { MRS } \\
\text { Project Office }\end{array}$ & OS\&T & $\begin{array}{l}\text { POBCCB } \\
\text { Chairman }\end{array}$ \\
\hline
\end{tabular}


Table B2. Assignment Matrix for Selected PMP- Related Documentation (Continued)

\begin{tabular}{|c|c|c|c|c|}
\hline Vol.\# & Document Name & $\begin{array}{l}\text { OCRWM } \\
\text { Sponsor }\end{array}$ & $\begin{array}{l}\text { M\&O } \\
\text { Responsibility }\end{array}$ & $\begin{array}{l}\text { Approval } \\
\text { Authority }\end{array}$ \\
\hline 12 & $\begin{array}{l}\text { MRS Environmental } \\
\text { Management Plan }\end{array}$ & $\begin{array}{l}\text { MRS } \\
\text { Project Office }\end{array}$ & OS\&T & $\begin{array}{l}\text { POBCCB } \\
\text { Chairman }\end{array}$ \\
\hline 13 & MRS Institutional Plan & $\begin{array}{l}\text { MRS } \\
\text { Project Office }\end{array}$ & $\begin{array}{l}\text { Outreach Support } \\
\text { Office }\end{array}$ & $\begin{array}{l}\text { POBCCB } \\
\text { Chairman }\end{array}$ \\
\hline 14 & $\begin{array}{l}\text { MRS Socioeconomic } \\
\text { Program Plan }\end{array}$ & $\begin{array}{l}\text { MRS } \\
\text { Project Office }\end{array}$ & OR\&L & $\begin{array}{l}\text { POBCCB } \\
\text { Chairman }\end{array}$ \\
\hline 15 & Transportation Plan & $\begin{array}{l}\text { MRS } \\
\text { Project Office }\end{array}$ & OS\&T & $\begin{array}{l}\text { POBCCB } \\
\text { Chairman }\end{array}$ \\
\hline
\end{tabular}




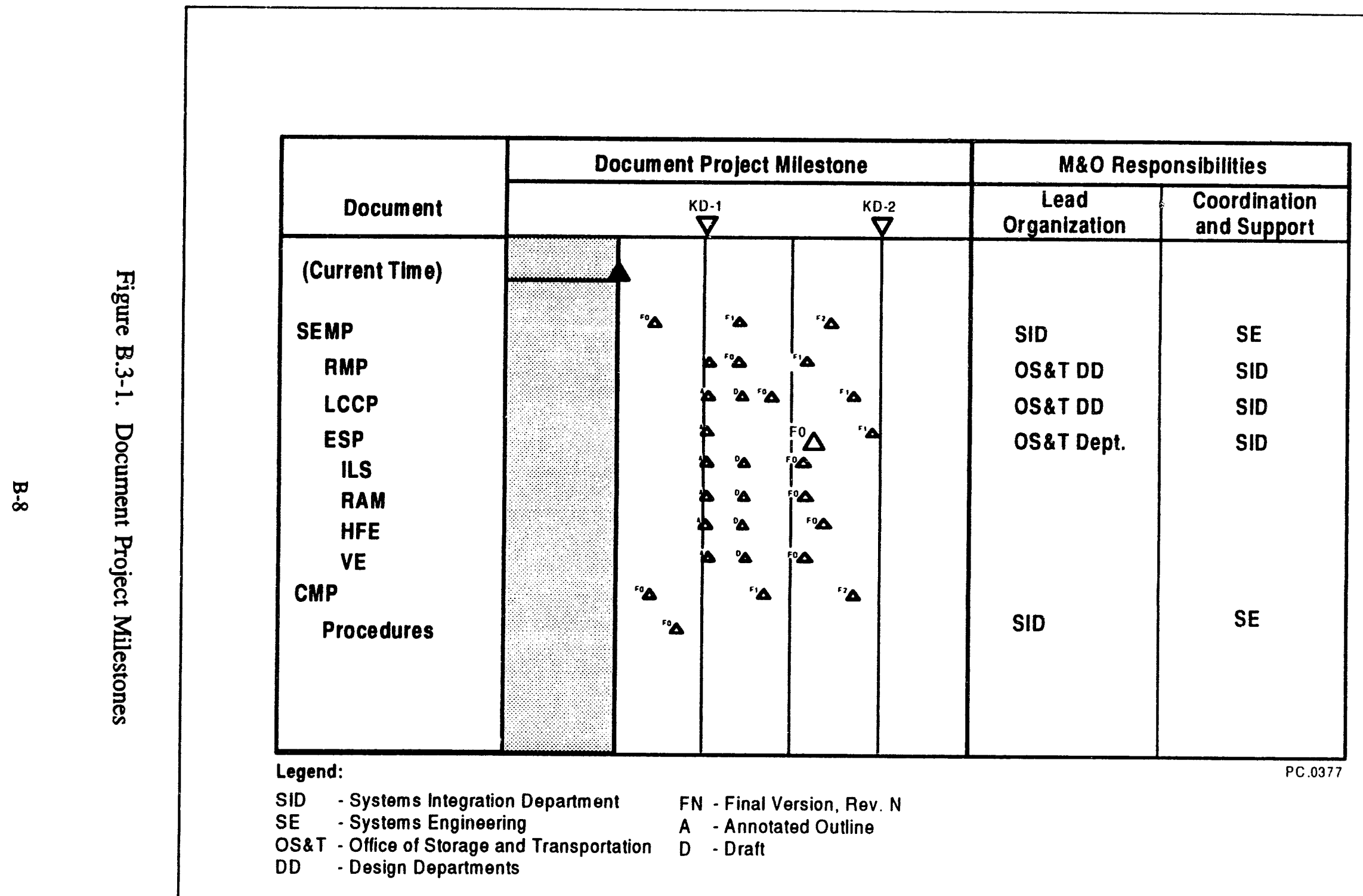



INTENTIONALLY LEFT BLANK

B-10 
APPENDIX B.4

\section{DOCUMENT SUMMARIES}

This appendix will summarize the documents described in this SEMP, providing information on the scope, applicability, and purpose of each. 
INTENTIONALLY LEFT BLANK

B-12 


\section{APPENDIX C \\ MODELS AND TRADE STUDIES}

This appendix will discuss the models developed in support of the MRS Project. This discussion will include information on how the models were developed, what they simulate, and their key functions.

This appendix will also describe how trade studies support the project and will include a list of past and planned studies. 
INTENTIONALLY LEFT BLANK 


\section{APPENDIX D}

\section{RISK MANAGEMENT PLAN}

This appendix will include discussion of how Project-specific risks are identified, assessed, prioritized, reduced, and managed. It will also address the process by which issues are identified and resolved to support critical decisions for the project. 
INTENTIONALLY LEFT BLANK

D-2 


\section{APPENDIX E \\ LIFE CYCLE COST PLAN}

This appendix will identify and describe the MRS Project's Life Cycle Cost (LCC) program's: tasks, milestones, deliverables, and responsibilities; policies, procedures, and structures for maintaining LCC visibility and control; recommended goals and allocation procedures; methods for determining and identifying LCC cost drivers and issues subject to trade-off analyses; planned LCC models, analyses methods, and modeling techniques to be employed; data sources and output descriptions; the management approach for integrating LCC efforts into project and technical management activities, including description of WBS or cost element structure; relationship of LCC to RAM and logistics support analysis; planned feedback mechanism for tracking and supporting cost-related design goals and status; and subcontractor relationships. 
INTENTIONALLY LEFT BLANK 


\section{APPENDIX F}

\section{ENGINEERING SPECIALTY PLAN}

This appendix will describe how guidance provided in the Program Engineering Specialties Plan will be implemented by the MRS Project. This plan will contain one chapter devoted to each of the following: integrated logistics support; reliability, availability and maintainability; human factors engineering; system safety engineering; system safeguards and security engineering; personnel and training; value engineering; and constructability/producibility analysis. Each chapter will describe how that specialty will be integrated into the design effort. 


\section{INTENTIONALLY LEFT BLANK}

F-2 
APPENDIX G

REFERENCE AND RELEVANT DOCUMENTS 


\section{APPENDIX G.1 REFERENCED DOCUMENTS}

A. DOE Documents:

DOE 4700.1 Project Management System, Change 1, June 2, 1992.

B. OCRWM Documents:

DOE/ RW-0043 OCRWM Program Management System Manual (PMSM), rev.5, December 23, 1992.

OCRWM Systems Engineering Management Plan (SEMP), rev.2, December, 1992.

OCRWM Baseline Management Plan (BMP), rev.0, November, 1992.

Program Technical Baselines:

- Civilian Radioactive Waste Management System (CRWMS) Requirements Document (CRD), rev.0, 23 December, 1992.

- Waste Acceptance (WA) System Requirements Document (SRD), 23 December, 1992.

- Transportation System (TS) System Requirements Document (SRD), draft.

- Monitored Retrievable Storage (MRS) System Requirements Document (SRD), draft.

- Monitored Retrievable Storage (MRS) Facility Conceptual Design Report (CDR), draft.

DOE/ RW-0333P Quality Assurance Requirements and Description (QARD), rev. 0, December 18, 1992. 
C. M\&O Quality Administrative Procedures (QAPs):

- 3-5 - Development of Baseline Technical Documents, rev.1, 1 April, 1992.

D. Monitored Retrievable Storage (MRS) Project Documents:

MRS Project Cost and Schedule Baseline (CSB), to be produced

MRS Project Management Plan (PMP), rev.0, draft, October 1992.

MRS Project Management Plan Volumes:

MRS Project Work Breakdown Structure (WBS) and WBS Dictionary.

MRS Facility Siting Plan, to be produced.

MRS Project Configuration Management Plan (CMP), draft, February 26, 1993.

MRS Project Office Baseline Change Control Board Charter, draft.

MRS Project Baseline Change Control Procedures, draft.

MRS Systems Engineering Management Plan Appendices:

MRS Project Risk Management Plan, to be produced.

MRS Project Life Cycle Cost Plan, to be produced.

MRS Project Engineering Specialty Plan, to be produced.

MRS Project Test and Evaluation Plan (T\&EP), to be produced.

MRS Project Test and Evaluation Master Plan (T\&EMP), to be produced.

MRS Project Technical Performance Measurement Plan, to be produced.

MRS Project Performance Assessment Plan, to be produced.

MRS Project System Operational Test and Evaluation Plan, to be produced.

MRS Project Information Resource Management Plan (IRPM), to be produced. 
MRS Project Advanced Acquisition Plan (AAP), to be produced.

MRS Project Construction Management Plan, to be produced.

MRS Project Regulatcry Compliance Plan (RCP), to be produced.

MRS Project Environmental, Safety, and Health Protection Implementation Plan (ESHPIP), to be produced.

MRS Facility Environmental Management Plan (EMP), to be produced.

MRS Project Institutional Plan, to be produced.

MRS Project Socioeconomic Plan, to be produced.

MRS Project Transportation Plan, to be produced.

MRS Facility License Application (LA), annotated outline.

MRS Facility Safety Analysis Report (SAR), annotated outline.

\section{E. Federal Laws and Documents:}

Code of Federal Regulations and Executive Orders:

- 10 CFR 72, Licensing Requirements for the Independent Storage of Spent Nuclear Fuel and High-Level Radioactive Waste, January 1, 1992.

\section{F. NRC Regulations:}

NRC Reg. Guide 3.48

Standard Format and Content for the Safety Analysis Report for an Independent Spent Fuel Storage Installation or Monitored Retrievable Storage Installation (Dry Storage), Rev 1, August 1989. 


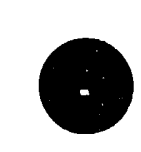

INTENTIONALLY LEFT BLANK 


\section{APPENDIX G.2 RELEVANT DOCUMENTS}

\section{A. DOE Documents:}

DOE N 4700.5 Project Control System Guidelines, August 21, 1992.

DOE 6430.1A General Design Criteria, April 6, 1989.

\section{B. OCRWM Documents:}

DOE/ RW-0005 Mission Plan for the Civilian Radioactive Waste Management Program, Volumes 1 - 3, June 1, 1985.

DOE/ RW-0253 OCRWM Program Cost and Schedule Baseline, Rev 3, September 10, 1992.

Program Work Breakdown Structure (WBS) Dictionary, February, 1992.

MRS Project Plan, draft, June 1992.

BMP- related OCRWM Baseline Management Procedures:

- DOE/ RW-0223 OCRWM Program Change Control Procedure, rev. 4, March 31, 1992.

- OCRWM Program Baseline Change Control Board Charter, rev.0, 23 March, 1992.

- Configuration Verification, rev.0, draft. 
B. OCRWM Documents (continued):

- CIS Data Entry, rev.0, draft.

- CIS Maintenance and Operations, rev.0, draft.

- Configuration Item (CI) and CI Identifiers, rev.0, draft.

- Document Identifiers, rev.0, draft.

Associated OCRWM Quality Assurance Administrative Procedures (QAAPs):

- 2.10 - HOLD Points, rev.0, 10 April, 1992.

- 16.1 - Corrective Action, rev.4, 11 November, 1991.

- 16.9 - Corrective Action Process, rev.0, 17 October, 1990.

- 17.1 - QA Records Management, rev.2, 9 December, 1991.

C. M\&O Quality Administrative Procedures (QAPs):

- 2-1 - Indoctrination and Training, rev.1, 21 November, 1991.

- 3-4 - Baseline Control, rev.0, 26 March, 1992.

- 3-7 - Interface Control, rev.0, 20 March 1992.

- 19-1 - Computer Software Verification and Validation, rev.1, 1 June, 1992.

- 19-2 - Software Configuration Management, rev.1, 1 June , 1992.

\section{Monitored Retrievable Storage (MRS) Project Documents:}

MRS Facility Contingency Siting Plan, to be produced.

Individual Test and Evaluation Plans, to be produced. 


\section{E. Federal Laws and Documents:}

Laws, Statutes, U.S. Codes, and Treaties:

- Energy Reorganization Act of 1974

- Nuclear Waste Policy Act of 1982 and Nuclear Waste Policy Amendments Act of 1987.

Code of Federal Regulations and Executive Orders:

- 10 CFR 71, Packaging and Transportation of Radioactive Material, January 1, 1992.

- 10 CFR 73, Physical Protection of Plants and Materials, January 1, 1992.

F. NRC Regulations:

NRC NUREG 0800

Standard Review Plan for the Review of Safety Analysis Reports for Nuclear Power Plants, June 1, 1987.

NRC Reg. Guide 3.50

Standard Format and Content for a License Application to Store Spent Fuel and High-Level Radioactive Waste, rev.1, September 1989.

NRC Reg. Guide 3.60 Design of an Independent Spent Fuel Storage Installation (Dry Storage), March 1987.

G. Standards:

Index and Directory of Industry Standards:

American National Standards Institute (ANSI):

- 57.9 Design Criteria for an Independent Spent Fuel Storage Installation (Dry Storage Type), 1984.

- Y14.1 Drawing Sheet Size and Format, 1980 (rev. 1987).

American Society of Mechanical Engineering (ASME):

- NQA-1 Quality Assurance Program Requirements for Nuclear Facilities.

- NQA-2A Quality Assurance Requirements for Nuclear Facility Applications, 1989 (1990 Addenda to ASME NQA-2). 
H. DoD Documents:

MIL-STD-490A Military Standard Specification Practices.

MIL-S-83490 Specifications, Types and Forms.

DI-CMAN-80008A System/Segment Specification.

DoD-HDBK-763 Human Engineering Procedures Guide.

DoD-STD-1795A Lightning Protection of Aerospace Vehicles and Hardware.

MIL-STD-129L Marking for Shipment and Storage.

MIL-STD-470B Maintainability Program Requirements (for Systems and equipments).

MIL-STD-794E Procedures for Packaging and Packing Parts and Equipment (Note: inactive standard - designers should use MIL-STD2073/1B).

MIL-STD-882B System Safety Program Requirements.

MIL,-STD-1367A Packaging, Handling, Storage, and Transportability Program Requirements for Systems and Equipments.

MIL-STD-1388/1A Logistic Support Analysis.

MIL-STD-2073/1B DoD Material Procedures for Development and Application of Packaging Requirements. 

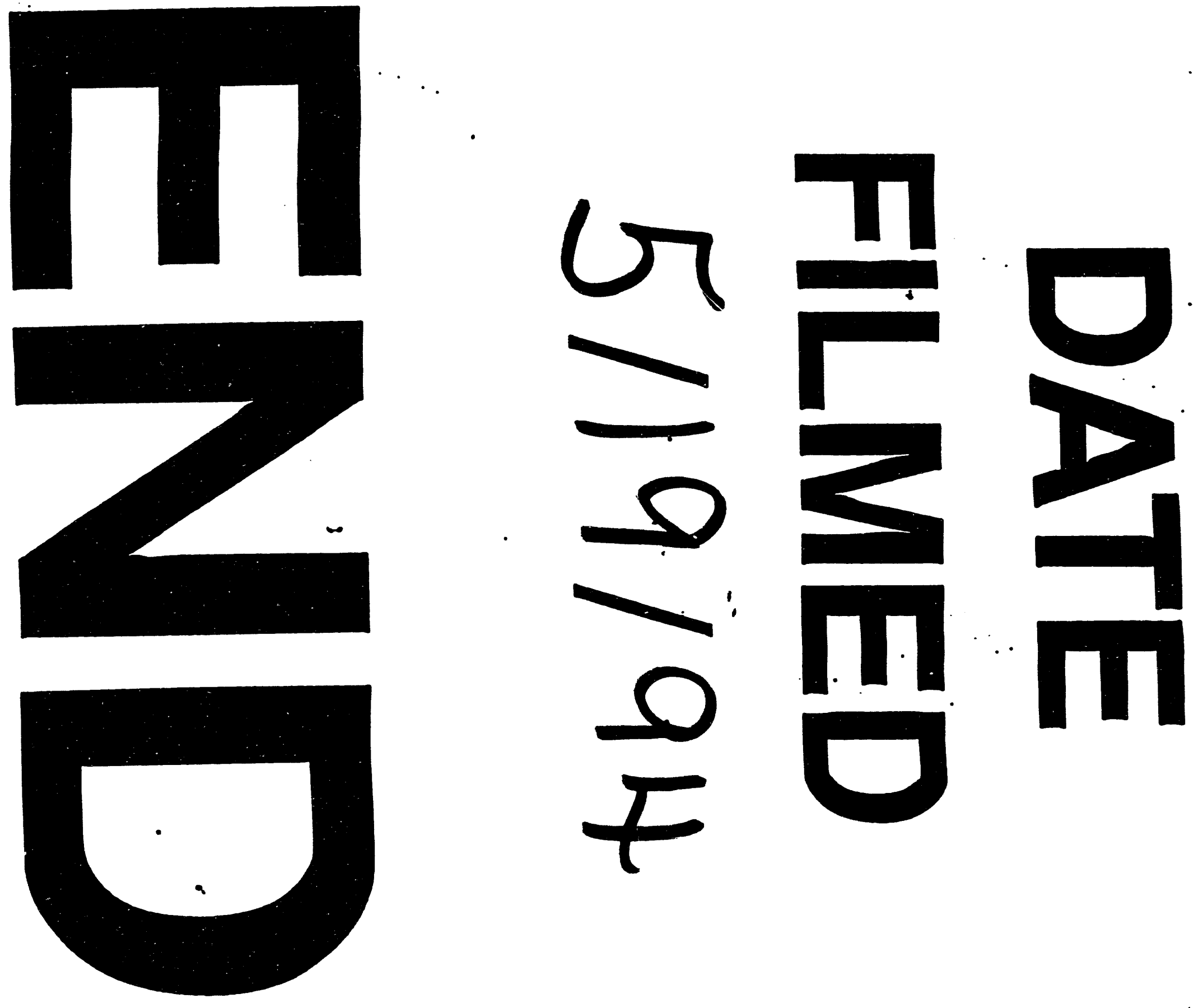
